Aus dem Institut für Pathologie

(Prof. Dr. med. H.-J. Radzun, Prof. Dr. med. P. Ströbel)

der Medizinischen Fakultät der Universität Göttingen

\title{
Prognostische Relevanz der Autophagie in histologischen Subtypen des papillären Nierenzellkarzinoms
}

\author{
INAUGURAL - DISSERTATION \\ zur Erlangung des Doktorgrades \\ der Medizinischen Fakultät der \\ Georg-August-Universität zu Göttingen
}

vorgelegt von

Christina Schlegel

aus

Bonn

Göttingen 2018 
Dekan:

Prof. Dr. rer. nat. H. K. Kroemer

Referent:

Prof. Dr. med. H.-J. Radzun

Ko-Referent:

PD Dr. med. R. Vasko

Datum der mündlichen Prüfung: 22.08.2018 
Hiermit erkläre ich, die Dissertation mit dem Titel „Prognostische Relevanz der Autophagie in histologischen Subtypen des papillären Nierenzellkarzinoms" eigenständig angefertigt und keine anderen als die von mir angegebenen Quellen und Hilfsmittel verwendet zu haben.

Göttingen, den 03.03.2018

(Unterschrift) 


\section{Inhaltsverzeichnis}

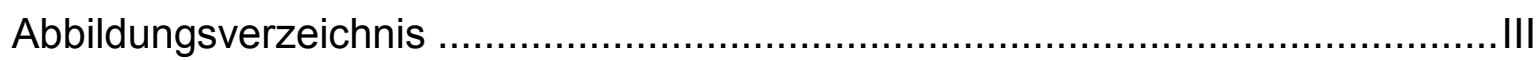

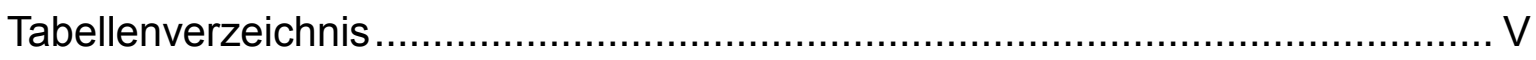

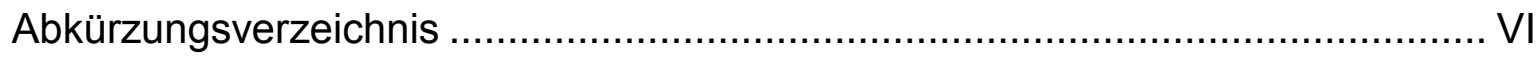

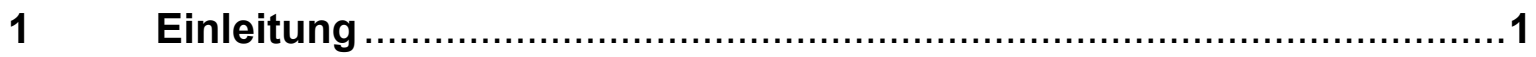

$1.1 \quad$ Nierenzellkarzinom - Epidemiologie und Ätiologie ...............................

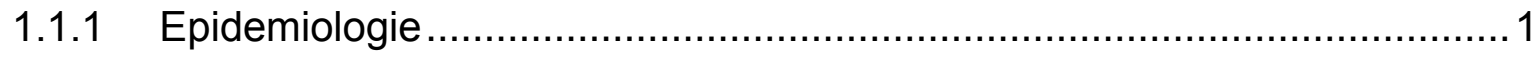

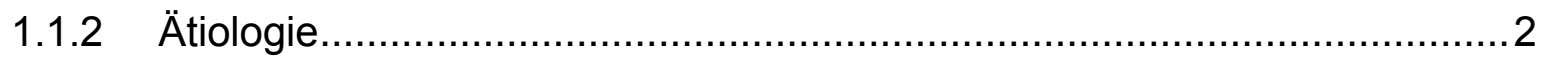

$1.2 \quad$ Klinik, Diagnostik und Therapie ...............................................

1.3 Histologische Subtypen und Klassifizierung ...................................4

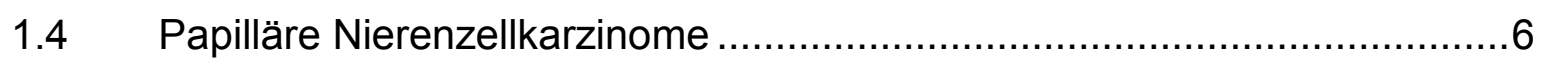

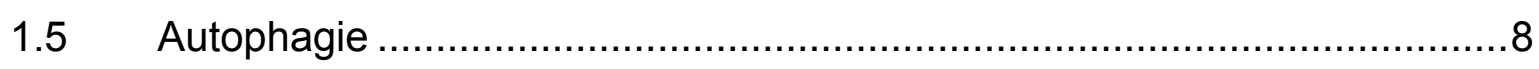

1.5.1 Molekularer Mechanismus der Makroautophagie ................................ 9

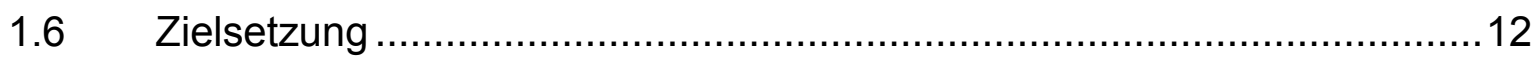

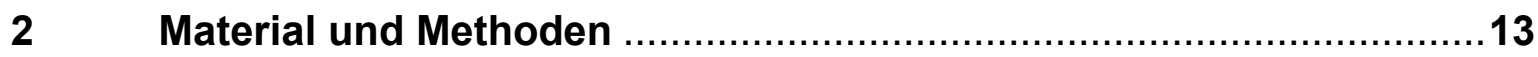

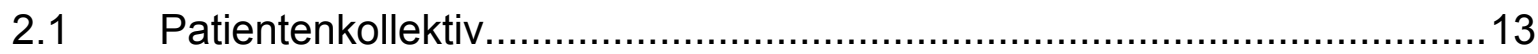

$2.2 \quad$ Untersuchungsmaterial.......................................................... 13

2.3 Untersuchung am Tumorgewebe ............................................... 15

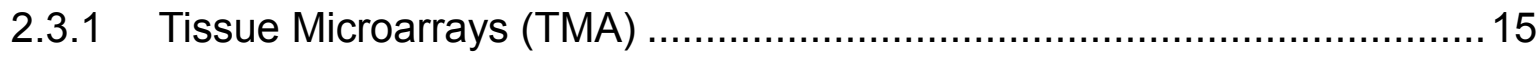

2.3.2 Präparation der Paraffinschnittpräparate .................................... 15

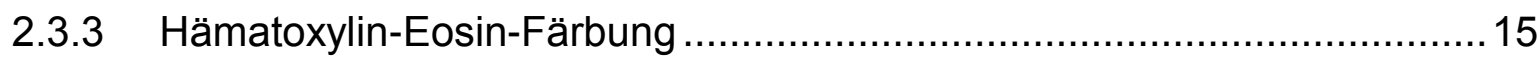

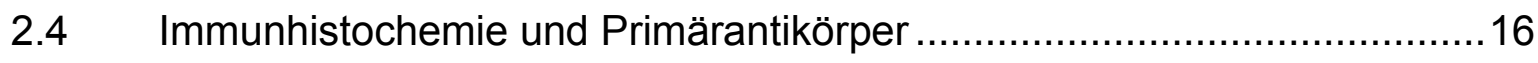

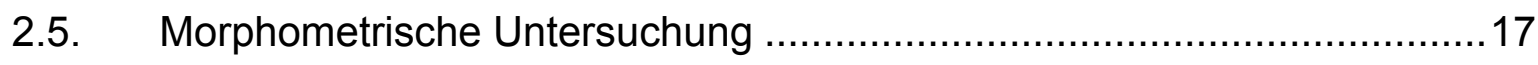

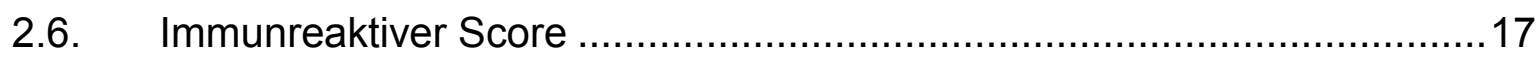

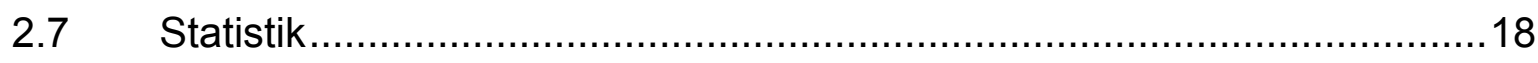

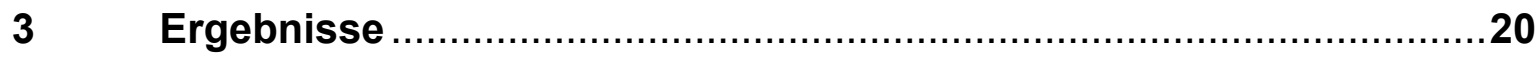

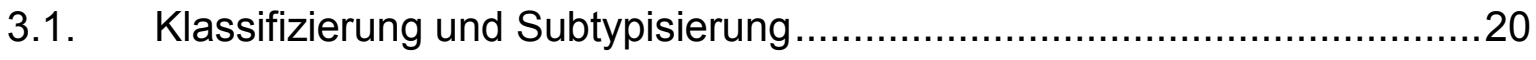




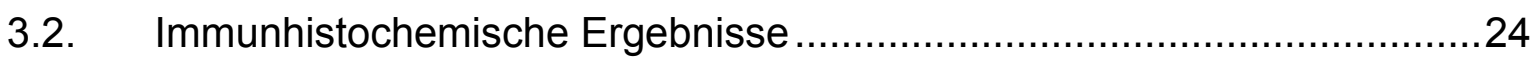

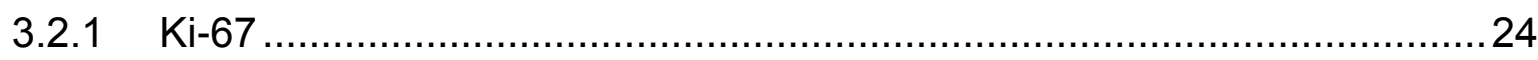

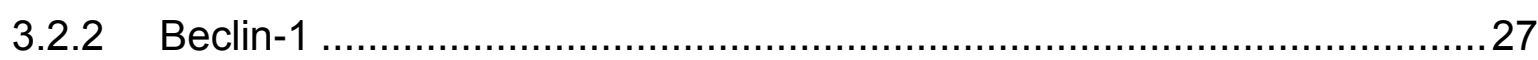

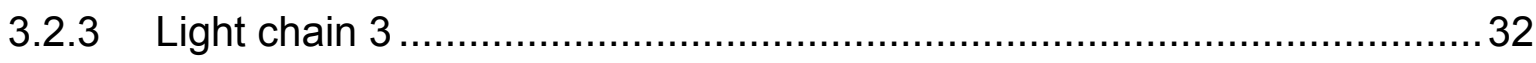

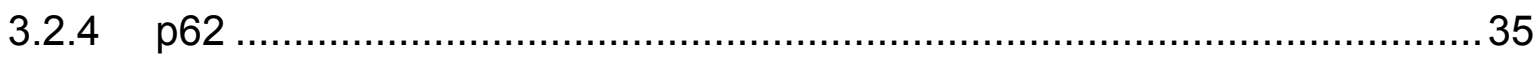

3.3 Gesamtüberleben und remissionsfreies Überleben vom papillären

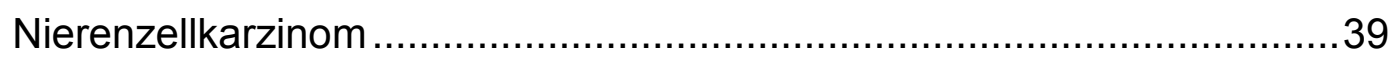

3.4 Gesamtüberleben und remissionsfreies Überleben in Subtypen des papillären Nierenzellkarzinoms...............................................................46

3.5 Gesamtüberleben und remissionsfreies Überleben in Bezug zur Expression der Autophagie-Proteine .................................................. 48

3.5.1 Expression der Autophagie-Proteine und Gesamtüberleben .................... 49

3.5.2 Expression der Autophagie-Proteine und remissionsfreies Überleben ......51

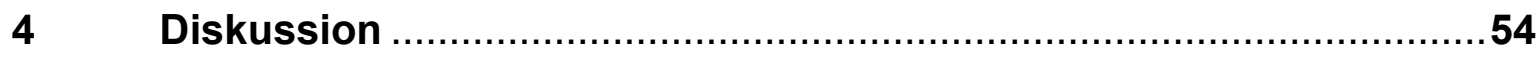

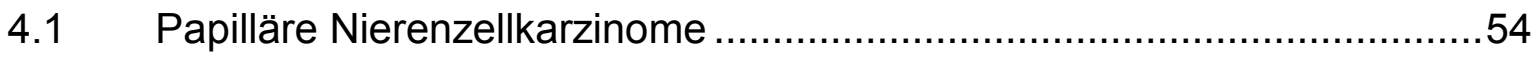

4.2 Autophagie in papillären Nierenzellkarzinomen.....................................55

4.3 Autophagie und Überleben in papillären Nierenzellkarzinomen ................63

4.4 Autophagie und Therapie in papillären Nierenzellkarzinomen ...................65

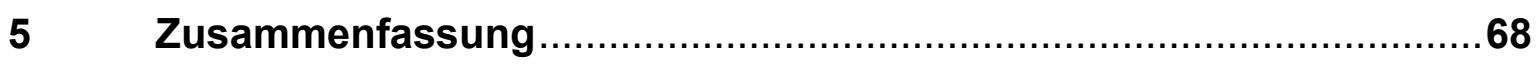

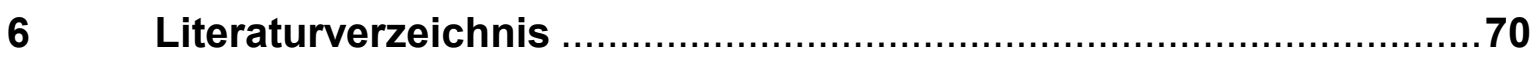




\section{Abbildungsverzeichnis}

Abbildung 1: Entstehung des Autophagosoms 10

Abbildung 2: Ausschnitt aus einem Schnittpräparat: HE-Färbung, papilläres Nierenzellkarzinom Typ 1

Abbildung 3: Ausschnitt aus einem Schnittpräparat: HE-Färbung, papilläres Nierenzellkarzinom Typ 2.

Abbildung 4: Histogramme: a) T-Stadium b) N-Stadium, jeweils gruppiert nach papillärem Nierenzellkarzinom Typ 1 und 2 in Abhängigkeit von den beobachteten Fällen. .23

Abbildung 5: 1) Histogramm für Ki-67-Expression in papillären Nierenzellkarzinomen Typ 1 und 2. 2) Ausschnitte aus den Schnittpräparaten: Ki-67-Antikörper-Färbung in Typ 1 und 2. 25

Abbildung 6: 1) Balkendiagramm: Beclin-1 zytoplasmatisch und nukleär in papillären Nierenzellkarzinomen. 2) Ausschnitte aus den Schnittpräparaten: Beclin-1, zytoplasmatische sowie nukleäre Anfärbung in Typ 1 und 2. 27

Abbildung 7: 1) Balkendiagramm: niedrige und hohe nukleäre Beclin-1-Expression 2) Balkendiagramm: Beclin-1 nukleär nach dem IRS, jeweils in papillären Nierenzellkarzinomen Typ 1 und 2. 30

Abbildung 8: Korrelationsanalyse der nukleären Beclin-1-Expression nach dem IRS und des T-Stadiums in papillären Nierenzellkarzinomen 31

Abbildung 9: Korrelationsanalyse der nukleären Beclin-1-Expression nach dem IRS und dem Grading 31

Abbildung 10: 1) Balkendiagramm: LC3 nach dem IRS in papillären Nierenzellkarzinomen. 2) Ausschnitte aus den Schnittpräparaten: LC3Anfärbung in Typ 1 und 2

Abbildung 11: Balkendiagramm: p62-Expression nach dem IRS in papillären Nierenzellkarzinomen. .35

Abbildung 12: 1) Balkendiagramm: niedrige und hohe zytoplasmatische (a) und nukleäre (b) p62-Expression nach dem IRS in papillären Nierenzellkarzinomen Typ 1 und 2. 2) Ausschnitte aus den Schnittpräparaten: p62-Färbung in Typ 1 und 2. 36 
Abbildung 13: Scatterplot: Korrelationsanalyse der zytoplasmatischen und nukleären p62-Expression und Grading in papillären Nierenzellkarzinomen 38

Abbildung 14: Kaplan-Meier-Kurve für das OS und DFS in papillären Nierenzellkarzinomen (a), in Bezug auf das T-Stadium (b), auf Lymphknotenmetastasen (c), auf Metastasen (d) und auf das Grading (e).

Abbildung 15: Kaplan-Meier-Kurve: kumulierte Überlebensanteile in Abhängigkeit von der Zeit in Jahren, aufgeteilt in OS und DFS für Typ 1 und 2 ...47 Abbildung 16: Kaplan-Meier-Kurve für das Gesamtüberleben: Kumulierte Überlebensanteile in Abhängigkeit von der Zeit in Jahren in Bezug auf die kodierten Autophagie-Proteine 49

Abbildung 17: Kaplan-Meier-Kurve für das rezidivfreie Überleben: Kumulierte Überlebensanteile in Abhängigkeit von der Zeit in Jahren in Bezug auf die kodierten Autophagie-Proteine .51

Abbildung 18: Histogramm: Autophagiemarker nach dem IRS papillären Nierenzellkarzinomen. .56 


\section{Tabellenverzeichnis}

Tabelle 1: WHO-Klassifikation der histologischen Typen und Subtypen des Nierenzellkarzinoms

Tabelle 2: TNM-Stadien nach UICC

Tabelle 3: Pathologische Kenndaten des untersuchten Tumorgewebes (papilläres Nierenzellkarzinom Typ 1 und 2, T-Stadien und Grading) 14

Tabelle 4: Antikörper und Färbeprotokoll. 17

Tabelle 5: Immunreaktiver Score: Intensität der Zellsignale 18

Tabelle 6: Pathologische Kenndaten: Häufigkeitsverteilung der TNM-Stadien in Abhängigkeit von den Subtypen (Typ 1 und 2)

Tabelle 7: Übersichtstabelle der Kendalls Tau-Korrelationen zwischen AutophagieMarker und pTNM-Stadium und Grading

Tabelle 8: Anzahl und Prozentanteil der vollständigen und zensierten Überlebenszeiten in Bezug auf das TNM-Stadium und Grading im OS und DFS ...39

Tabelle 9: OS in Abhängigkeit von T-Stadium und Grading 40

Tabelle 10: DFS in Abhängigkeit von T-Stadium und Grading .40

Tabelle 11: Log-Rank-Test: Auswirkungen der Expression der Autophagie-Marker auf das OS und DFS 


\section{Abkürzungsverzeichnis}

$\begin{array}{ll}\text { ATG } & \text { Autophagy-related gene } \\ \text { Bcl-2 } & \text { B-Zell Lymphom } 2 \\ \text { DFS } & \text { Disease-free survival } \\ \text { G } & \text { Grading } \\ \text { IRS } & \text { Immunreaktiver Score nach Allred } \\ \text { ISUP } & \text { International Society of Uropathology } \\ \text { Ki-67 } & \text { Kiel 67 Prolifertationsprotein } \\ \text { LC3 } & \text { Light chain 3 } \\ \mathrm{n} & \text { Anzahl } \\ \text { OS } & \text { Overall survival } \\ \text { p62 } & \text { Rezeptorprotein 62 } \\ \text { pTNM } & \text { pathologische Beurteilung des TNM Stadiums } \\ \text { TMA } & \text { Tissue Microarrays } \\ \text { TNM } & \text { Tumorausdehnung, Nodus, Metastasen } \\ \text { UICC } & \text { Union internationale contre le cancer }\end{array}$




\section{$1 \quad$ Einleitung}

\section{$1.1 \quad$ Nierenzellkarzinom - Epidemiologie und Ätiologie}

\subsubsection{Epidemiologie}

Maligne Erkrankungen der Niere machen insgesamt 10-15 \% aller Krebsneuerkrankungen in Europa aus. Im Jahr 2008 wurden europaweit 88.400 neue Fälle von Nierenzellkarzinomen angegeben, von denen ungefähr 39.300 Fälle im gleichen Jahr nicht überlebt haben (Ferlay et al. 2010). Nierentumoren sind die sechsthäufigsten Tumoren des Mannes und die zehnthäufigsten der Frau (Kaatsch et al. 2015).

Die vom Robert Koch-Institut berechneten altersstandardisierten durchschnittlichen Erkrankungsraten in Deutschland aus dem Jahr 2012 betrugen 16,9 männliche und 8,0 weibliche Fälle auf 100.000 Einwohner. Die Inzidenz des Nierenzellkarzinoms ist in den letzten Jahrzenten um 2-4 \% stetig angestiegen, wobei die Ursache unbekannt ist (Murai und Oya 2004; Cairns 2010). Je nach histologischem Subtyp variieren die Häufigkeit und das mittlere Erkrankungsalter. Das klarzellige Nierenzellkarzinom ist mit einer Häufigkeit von 75-80\% das häufigste Karzinom, wohingegen das papilläre Nierenzellkarzinom (10-15\%) und das chromophobe Nierenzellkarzinom (5\%) seltener zu beobachten sind (Mejean et al. 2003; Cairns 2010). Das mittlere Erkrankungsalter des Nierenzellkarzinoms liegt bei 72 Jahren für Frauen und 68 Jahren für Männer (Kaatsch et al. 2015). Beim papillären Nierenzellkarzinom liegt das Erkrankungsalter zwischen 52 und 66 Jahren und das Geschlechterverhältnis (M:F) erstreckt sich von 2:1 bis 3:1 (Delahunt und Eble 1997; Ross et al. 2012).

Die Inzidenz des Nierenzellkarzinoms unterliegt weltweit einer hohen Variation. Während sie in Europa und Nord-Amerika hoch ist, wird sie in Asien und Afrika niedrig beziffert. Deutschland liegt weltweit bei Männern auf Platz fünf und bei Frauen auf Platz neun (Kaatsch et al. 2015).

Das Nierenzellkarzinom wird in Deutschland bei Erstdiagnose mit einer Häufigkeit von $74-77$ \% vor allem in den frühen Stadien (pT1 und 2) erkannt (Kaatsch et al. 2015). Etwa ein Drittel aller Patienten mit Nierenzellkarzinomen weisen bei der Erstvorstellung ein lokal fortgeschrittenes Karzinom (pT3 und 4) oder Metastasen auf (Cairns 2010; Kaatsch et al. 2015). 
Der wichtigste Faktor zur Einschätzung der Prognose ist das TNM-Stadium (Ljungberg et al. 1999; Delahunt et al. 2007). Abhängig vom Stadium bei Erstdiagnose und vom histologischen Subtyp liegt die 5-Jahres-Überlebensrate in Deutschland bei etwa 76-78 \% (Kaatsch et al. 2015). Es ist anzumerken, dass die 5-Jahres-Überlebensrate mit circa $90 \%$ bei dem sporadischen, lokal begrenzten papillären Nierenzellkarzinom günstiger ist als bei dem klarzelligen Nierenzellkarzinom (circa 70 \%) (Cheville et al. 2003; Cohen und McGovern 2005; Delahunt et al. 2007). Metastasierte oder fortgeschrittene Nierenzellkarzinome von papillärem und klarzelligem Typ dagegen weisen beide nur eine circa $10 \%$ ige Überlebensrate über 5 Jahre und ein mittleres Überleben von 13 Monaten auf (Patard et al. 2005; Delahunt et al. 2007; Cairns 2010). Das chromophobe Nierenzellkarzinom hat von allen Typen die beste Prognose mit einer 5-JahresÜberlebensrate von $80-100 \%$ (Amin et al. 2002; Cheville et al. 2003). Zudem ist festzuhalten, dass die Mortalität aufgrund der stetig verbesserten diagnostischen Bildgebung sinkt, da die Diagnose in früheren Stadien gestellt werden kann (Chow et al. 2010).

\subsection{2 Ätiologie}

Die wichtigsten Ursachen für das Entstehen eines Nierenzellkarzinoms sind der Nikotinkonsum, der Bluthochdruck und das Übergewicht.

Es besteht eine Dosis-Wirkung-Beziehung zwischen vermehrtem Zigarettenkonsum und erhöhtem Risiko für ein Nierenzellkarzinom (Hunt et al. 2005; McGuire und Fitzpatrick 2011). Bei männlichen Rauchern erhöht sich das Risiko um $50 \%$, bei weiblichen Rauchern um $20 \%$, im Laufe des Lebens, an einem Nierenzellkarzinom zu erkranken. Einige Studien beobachteten bei steigendem Blutdruck eine Risikoerhöhung für das Auftreten des Nierenzellkarzinoms. Wahrscheinlichste Ursache der Risikoerhöhung seien chronische Hypoxie der Niere sowie Fett-Peroxidation mit Entstehung von freien Radikalen (Chow et al. 2010).

In mehreren prospektiven und retrospektive Studien mit unterschiedlichen Populationen wurde ein positiver Zusammenhang zwischen dem Body Mass Index und dem Risiko für Nierentumoren beschrieben (Eble et al. 2004; Murai und Oya 
2004; Chow et al. 2010; McGuire und Fitzpatrick 2011). Adipöse Patienten erkrankten doppelt so häufig wie normalgewichtige Patienten (Eble et al. 2004). Es wird geschätzt, dass in Europa etwa ein Drittel der Nierentumoren beider Geschlechter durch unter anderem extremes Übergewicht bedingt ist (Chow et al. 2010; McGuire und Fitzpatrick 2011).

Neben diesen Hauptursachen tragen auch unterschiedliche Vorerkrankungen der Niere, wie die erworbene Zystenniere, chronische Niereninsuffizienz im Endstadium mit Hämodialyse oder Nierentransplantation sowie die langjährige Exposition mit karzinogenen Stoffen wie Arsen, Cadmium, Pestizide und Pilzgifte zu einer erhöhten Inzidenz des Nierenzellkarzinoms bei (Eble et al. 2004).

Schließlich sind hereditäre Nierenzellkarzinome bekannt, von denen das klarzellige Nierenzellkarzinom bei Von-Hippel-Lindau-Syndrom, mit einer Penetranz von über $90 \%$ ab dem 65. Lebensjahr, die häufigste Form darstellt (Lonser et al. 2003; Sudarshan et al. 2007). Daneben werden das Birt-Hogg-Dubé und die tuberöse Sklerose mit chromophobem Nierenzellkarzinom, das hereditäre papilläre Nierenzellkarzinom vom Typ 1 und das hereditäre papilläre Nierenzellkarzinom vom Typ 2 mit Leiomyomatose beschrieben (Schmidt et al. 1997; Zbar et al. 2002; Toro et al. 2003; Hartmann et al. 2010; Behnes et al. 2013).

\subsection{Klinik, Diagnostik und Therapie}

$50 \%$ der Patienten mit Nierenzellkarzinomen sind bei der Erstdiagnose symptomfrei und werden im Rahmen anderer Untersuchungen zufällig entdeckt. Die Symptome treten meist erst spät auf und schließen Flankenschmerz, schmerzlose Makrohämaturie, tastbaren abdominellen Tumor oder paraneoplastische Symptome mit ein. Typische B-Symptomatik wie Gewichts-verlust, unklares Fieber, Nachtschweiß, Anämie und Abgeschlagenheit können auftreten. Metastasen-bedingte Symptome entsprechen den Prädilektionsstellen, wie beispielsweise tastbare Knoten am Hals bei zervikalem Lymphknotenbefall, Knochenschmerzen bei Skelettmetastasen und neurologische Ausfälle bei zentralnervöser Beteiligung. 
Da das Nierenzellkarzinom in früheren Stadien mit kleinerer Masse im Ultraschall oft Isoechogenität im Vergleich mit normalem Nierengewebe aufweist, wird der Tumor leicht übersehen. Mittels Computertomografie des Abdomens mit intravenöser Kontrastmittelgabe können in der Regel Nierenzellkarzinome mit einer charakteristischen Kontrastmittelanreicherung näher charakterisiert und ihre Ausbreitung in das umliegende Gewebe sowie in lokale Lymphknoten beschrieben werden.

Die Therapie des Nierenzellkarzinoms besteht nach aktuellen Leitlinien aus dem Jahre 2015 bei lokalen Stadien (pT1-2, $<7 \mathrm{~cm}$ Tumorausdehnung) aus einer partiellen Nephrektomie mit dem Ziel der R0-Resektion.

In fortgeschrittenen Stadien stellt die operative Totalresektion der Niere mit gegebenenfalls Resektion der Nebenniere und der regionalen Lymphknoten die Therapie der Wahl dar. Neoadjuvante oder adjuvante Therapien werden in nichtmetastasierten Stadien aufgrund der erhöhten Komplikationsrate nicht durchgeführt. Der Beginn einer Systemtherapie ist vom Risikoprofil des Patienten abhängig. In fortgeschrittenen Stadien mit oder ohne Metastasierung und geringem oder intermediärem Risiko werden als Erstlinientherapie vaskuläre endotheliale Wachstumsfaktor-Inhibitoren wie beispielsweise Sunitinib empfohlen, welche die Vaskularisierung und damit die Nährstoffzufuhr zum Tumor unterdrücken. Bei ungünstigem Risikoprofil wird beispielsweise Temsirolismus eingesetzt, welches über Hemmung des mTOR-Proteins (mammalian target of rapamycin) die Proliferation und das Wachstum der Zelle reduziert (Laplante und Sabatini 2012). Beim multipel metastasierten Nierenzellkarzinom kann Interleukin2 gegeben werden. Eine adjuvante Strahlentherapie wird aufgrund fehlenden Einflusses auf das Gesamtüberleben nicht durchgeführt (Leitlinie Nierenzellkarzinom 2017).

\subsection{Histologische Subtypen und Klassifizierung}

Die Karzinome der Niere werden in histologische Subtypen eingeteilt und entstehen aus den verschiedenen epithelialen Zelltypen, die entlang der Nephrone lokalisiert sind. Das klarzellige und das papilläre Nierenzellkarzinom entstehen aus den Epithelzellen des proximalen Tubulus, wohingegen sich das chromophobe 
Nierenzellkarzinom, das Onkozytom und das Karzinom des Sammelgangs aus dem distalen Tubulus entwickeln (Mejean et al. 2003; Cairns 2010). Selten können sich einzelne Subtypen gleichzeitig in einer Niere bilden. Tabelle 1 zeigt die Häufigkeiten der einzelnen Subtypen.

Das Nierenzellkarzinom tritt typischerweise unifokal und unilateral auf. In 10-15 \% der Fälle entwickelt es sich multifokal in einer Niere oder auch bilateral, was beim papillären Nierenzellkarzinom häufiger als beim klarzelligen Nierenzellkarzinom zu beobachten ist (Mejean et al. 2003; Cairns 2010).

Die Klassifikation der Nierenzellkarzinome erfolgt nach UICC (Union internationale contre le cancer) anhand der Größe und Ausbreitung des Tumors. In Tabelle 2 sind die einzelnen Stadien der Klassifikation nach UICC aufgeführt.

Eine internationale Einteilung ist auch das Gradingsystem nach ISUP (International Society of Uropathology, G1-4), welches Kerngröße, Kernmorphologie, mitotische Aktivität sowie Ähnlichkeit zum Ursprungsgewebe berücksichtigt (Srigley et al. 2013).

Tabelle 1: WHO-Klassifikation der histologischen Typen und Subtypen des Nierenzellkarzinoms (Lopez-Beltran et al. 2006)

\begin{tabular}{ll}
\hline Tumortyp & Häufigkeit \\
\hline Klarzelliges Nierenzellkarzinom & $75 \%$ \\
Papilläres Nierenzellkarzinom & $10 \%$ \\
Typ 1 & ca. $60 \%$ \\
Typ 2 & ca. $35 \%$ \\
Chromophobes Nierenzellkarzinom & $5 \%$ \\
Sammelgang-Karzinom (Ductus-Bellini-Karzinom) & $1 \%$ \\
Multilokulär-zystisches Nierenzellkarzinom & $<1 \%$ \\
Neuroblastom-assoziierte Nierenzellkarzinome & $<1 \%$ \\
Muzinös-tubuläres und spindelzelliges Nierenzellkarzinom & $<1 \%$ \\
Undifferenzierte Karzinome & $4-6 \%$ \\
\hline
\end{tabular}




\section{Tx Primärtumor kann nicht beurteilt werden}

T0 Kein Anhalt für Primärtumor

T1 Tumor $<=7 \mathrm{~cm}$ in größter Ausdehnung, begrenzt auf die Niere

T1a Tumor $4 \mathrm{~cm}$ oder weniger in größter Ausdehnung

T1b Tumor $>4 \mathrm{~cm}$, aber $<7 \mathrm{~cm}$ in größter Ausdehnung

T2 Tumor $>7 \mathrm{~cm}$ in größter Ausdehnung, begrenzt auf die Niere

T2a Tumor $>7 \mathrm{~cm}-10 \mathrm{~cm}$, begrenzt auf die Niere

T2b Tumor $>10 \mathrm{~cm}$, begrenzt auf die Niere

T3 Tumor infiltriert größere Venen, Nebenniere oder perirenale Invasion

T3a Tumor infiltriert Nierenvene oder perirenale Fettkapsel, aber nicht Gerota'sche Faszie

T3b Tumorausbreitung in Hohlvene unterhalb des Zwerchfells

T3c Tumorausdehnung in Hohlvene oberhalb des Zwerchfells

T4 Tumorausdehnung über Gerota'sche Faszie hinaus oder ipsilaterale Nebenniere

NX Benachbarte (regionäre) Lymphknoten sind nicht beurteilbar

No Kein Anhalt für Metastasen in benachbarten Lymphknoten

N1 Metastase in einem benachbarten Lymphknoten

N2 Metastasen in mehr als einem benachbarten Lymphknoten

MX Vorliegen von Fernmetastasen kann nicht beurteilt werden

M0 Kein Anhalt für Fernmetastasen

M1 Fernmetastasen in Lunge, Skelett, Lymphknoten, Gehirn und Leber

\subsection{Papilläre Nierenzellkarzinome}

Das im Fokus dieser Untersuchung stehende papilläre Nierenzellkarzinom stellt die zweithäufigste Variante unter den Nierenzellkarzinomen dar.

Makroskopisch wird das papilläre Nierenzellkarzinom zumeist als hämorrhagisch, nekrotisch oder zystisch beschrieben. Bei lokalen gut abgrenzbaren Stadien kann es von einer bindegewebigen Pseudokapsel umgeben sein (Delahunt und Eble 1997). 
Mikroskopisch unterteilt sich das papilläre Nierenzellkarzinom anhand morphologischer Kriterien in zwei Subtypen, die sich auch hinsichtlich Malignität und Prognose unterscheiden.

Papilläre Nierenzellkarzinome vom Typ 1 haben eine Inzidenz von 52-70\% (Waldert et al. 2008). Morphologisch präsentieren sie sich streng einreihig, haben einen basophilen, dünnen Zytoplasmasaum und weisen keine Nukleolen oder atypische Mitosen auf. Die Papillen sind häufig infiltriert von Makrophagen, der Malignitätsgrad ist eher niedrig und die Prognose besser als bei Typ 2.

Papilläre Nierenzellkarzinome vom Typ 2 weisen eine Inzidenz von 30-38 \% auf. Charakteristisch sind große eosinophile Tumorzellen mit scheinbarer Mehrreihigkeit (Pseudostratifikation). Es finden sich atypische Mitosefiguren sowie Zellen mit unterschiedlicher Kerngröße, deutlichen Nukleolen und teilweise Nekrosen. Makrophagen sind selten zu beobachten (Delahunt und Eble 1997; Waldert et al. 2008; Behnes et al. 2012; Ross et al. 2012).

Eine eindeutige Subtypisierung der papillären Nierenzellkarzinome kann anhand der beschriebenen morphologischen Kriterien nicht immer festgelegt werden. Es werden einige immunhistochemische Marker wie Cytokeratin 7, membranöses Mukoglykoprotein 1 und $\mathrm{N}$-Cadherin herangezogen, um die Subtypisierung zu ermöglichen (Delahunt und Eble 1997; Perret et al. 2008; Bonsip und Bhalodia 2010; Behnes et al. 2012; Ross et al. 2012).

Zytogenetisch werden in lokal begrenzten papillären Nierenzellkarzinomen hauptsächlich kombinierte Trisomien von Chromosom 7 und 17 und eine Deletion von Chromosom $\mathrm{Y}$ beobachtet. In fortgeschrittenen Stadien der Erkrankung kommen gehäuft komplexere Mutationen vor (Kovacs 1993; Delahunt et al. 2001). Das papilläre Nierenzellkarzinom kann bilateral, solitär und multifokal vorkommen (Lopez-Beltran et al. 2006). Delahunt und Eble berichten, dass in $40 \%$ der papillären Nierenzellkarzinome Typ 1 und in 10,5\% der Typ 2 eine Multifokalität nachzuweisen ist, diese jedoch keine Auswirkung auf das Überleben haben soll (Dimarco et al. 2004). 


\subsection{Autophagie}

Autophagie beschreibt ein System von verschiedenen Mechanismen, die zu einem Abbau und einer Wiederverwertung von zelleigenen veralteten Proteinen führt. Autophagie ist ein Bestandteil der physiologischen Zellhomöostase, an der Proteasomen und Lysosomen beteiligt sind. Neben dem Abbau von degenerierten Proteinen im Ubiquitin Proteasom-System, werden durch das lysosomale System Makromoleküle und Proteinaggregate zur erneuten Energiebereitstellung abgebaut (Baba et al. 1994; Dunn 1994; Klionsky und Ohsumi 1999; Mehrpour et al. 2010).

Der Mechanismus der Autophagie kommt ubiquitär physiologisch in eukaryoten und prokaryoten Zellen vor und wird darüber hinaus auch als Antwort auf zellschädigende oder -belastende Ereignisse verstanden (Tsukada und Ohsumi 1993; Ohsumi 2001; Klionsky 2007). Durch die physiologisch vorkommende Autophagie wird eine ständige Qualitätskontrolle der intrazellulären Bestandteile gewährleistet (Mizushima und Levine 2010). Neueste Studien vermuten, dass durch Autophagie Adenosintriphosphat gewonnen werden kann (Loos et al. 2013). Physiologisch spielt die Autophagie eine Rolle beim programmierten Zelltod Typ II, welcher aufgrund intrinsischer Aktivierung von mehrerer Faktoren und Enzymen entsteht und die Zelle von innen heraus abbaut. Anders als beim programmierten Zelltod Typ I, bei dem äußere Faktoren die Apoptose einleiten. Zum anderen ist die Autophagie bei der Differenzierung und Lebensverlängerung von Zellen beteiligt (Yue et al. 2003; Levine und Klionsky 2004; Yu et al. 2004; Boya et al. 2005; Reggiori und Klionsky 2005; Dalby et al. 2010). Aus diesem Grund kann man die Autophagie in eine zytoreduktiv-apoptotische sowie in eine zytoprotektive Autophagie einteilen.

Unter pathologischen Bedingungen übt die Autophagie verschiedene Funktionen aus. Man vermutet, dass die Autophagie einen Mechanismus zur Abwehr von pathogenen Keimen und Tumoren, aber auch einen Mechanismus der Überlebensstrategie von Tumoren darstellt (Levine und Klionsky 2004; Shintani und Klionsky 2004; Levine 2005; Reggiori und Klionsky 2005; Dalby et al. 2010). Darüber hinaus wird eine Interaktion zwischen Autophagie und Invasion von Viren und Mikroorganismen diskutiert, wie beispielsweise des Mykobakterium tuberkulosis (Liang et al. 1998; Gutierrez et al. 2004; Tallóczy et al. 2006). 
Es wird zwischen Mikroautophagie, Chaperon-vermittelte Autophagie und Makroautophagie unterschieden. Die verschiedenen Formen unterscheiden sich hinsichtlich des Weges, auf dem die abzubauenden Proteine in das Lysosomen transportiert werden.

Mikroautophagie beschreibt einen Prozess, bei dem Zellorganellen direkt durch Einstülpung der lysosomalen Membran eingeschlossen werden (Mortimore et al. 1988; Klionsky und Ohsumi 1999; Levine und Klionsky 2004). Dagegen werden bei der Chaperon-vermittelten Autophagie Zellbestandteile durch Stimulierung von Chaperonen in Lysosomen zur anschließenden Proteolyse eingeschleust (Dice 2014). Die Makroautophagie implementiert eine Aufnahme von beschädigten Zellorganellen aus dem Zytoplasma in das Autophagosom und den anschließenden Transport in das Lysosom (Baba et al. 1994; Ohsumi 2001; Reggiori und Klionsky 2002). In der vorliegenden Dissertation wurde das Augenmerk auf die Makroautophagie gelegt, da ihr in zahlreichen Studien ein Einfluss auf Tumoren zugesprochen wird.

\subsubsection{Molekularer Mechanismus der Makroautophagie}

Das autophagale System wurde erstmals durch Christian de Duve im Jahre 1955 beschrieben. Die experimentelle Erforschung des molekularen Mechanismus begann an Hefezellen in den 1990er Jahren (Baba et al. 1994; Thumm et al. 1994; Tsukada und Ohsumi 1993; de Duve et al. 1955).

Molekularbiologisch ist bekannt, dass das Autophagosom durch eine Absonderung der sogenannten Phagophore oder aus einer isolierten Doppelmembran entsteht, die einen Teil des Zytoplasmas sowie beschädigte Zellorganellen umgibt und verschließt. Die äußere Membran verschmilzt am Ende mit Lysosomen, die die benötigten Enzyme für den Abbau liefern (Abbildung 1) (Ohsumi 2001; Sugawara et al. 2004; Reggiori und Klionsky 2005; Klionsky 2007).

Die neu entstandenen Moleküle werden durch die Membran über Kanäle freigesetzt und von der Zelle erneut verwendet. Durch Fusion des Autophagosoms und eines Endosoms entsteht ein Amphisom, welches einen heterophagischen Prozess darstellt, da es zelleigene und zellfremde Bestandteile mit einschließt (Klionsky und Ohsumi 1999; Klionsky 2007). 
Bisherige Studien an der Hefe Saccharomyces cerevisiae konnten mehr als 30 an der Autophagie beteiligte Gene (ATG, autophagy-related gene) aufdecken, von denen 20 Gene ebenfalls eine Rolle in der Entstehung der Autophagie beim Menschen spielen (Tsukada und Ohsumi 1993; Thumm et al. 1994; Loos et al. 2013; Choi et al. 2014).

Abbildung 1: Entstehung des Autophagosoms (modifiziert nach Reggiori und Klionsky 2005). Die Verwendung erfolgt mit freundlicher Genehmigung des Elsevier-Verlags.

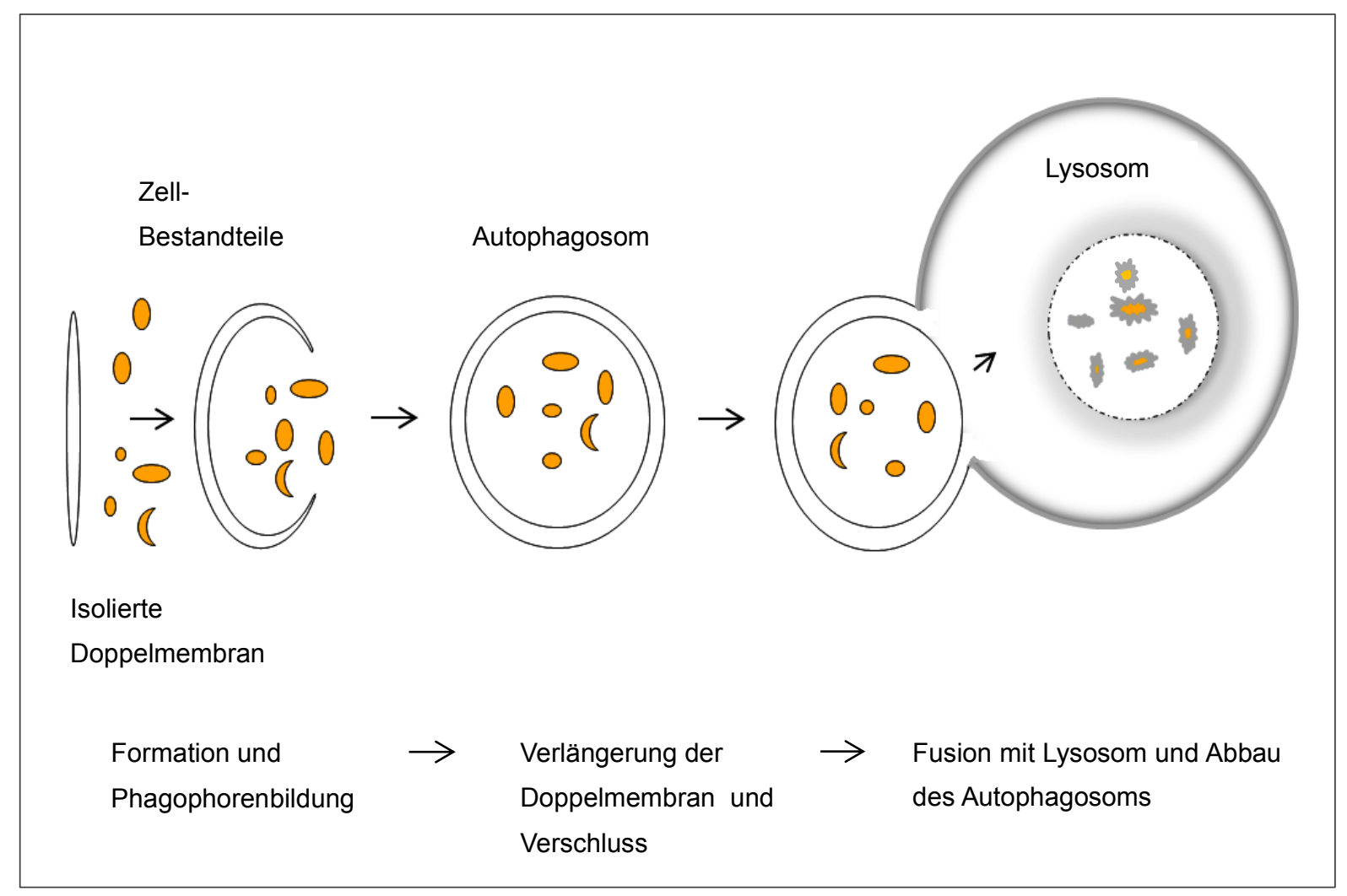

Die in unserer Studienarbeit relevanten Proteine, das Beclin-1, die light chain 3 (LC3) und das Rezeptorprotein p62, haben in den letzten Jahren im Zusammenhang mit der Autophagie vermehrt Aufmerksamkeit in der heutigen Forschung erhalten, auf die nachfolgend eingegangen wird.

Beclin-1 stammt aus dem Tumorsuppressorgen ATG6, das sowohl für die Apoptose als auch für die Autophagie in der Zelle verantwortlich ist. Es ist zu Beginn der Autophagie an der Formation einer isolierten Doppelmembran und an der Phagosombildung beteiligt (Pattingre et al. 2005; Miracco et al. 2007; Axe et al. 2008). Der Ursprung der Doppelmembran ist noch ungeklärt. Diskutiert werden Ursprungsorte wie endoplasmatisches Retikulum, Plasmamembran, Golgi-Apparat und Mitochondrium (Eskelinen 2008). Nach Mutation im Beclin-1- 
Tumorsuppressorgen kommt es zu einer verminderten Expression des physiologisch vorkommenden Beclin-1 oder zu einer Expression von verändertem Beclin-1 und damit zu einer gestörten Autophagie, die einst zytoreduktiv oder zytoprotektiv wirkte (Yue et al. 2003; Pattingre et al. 2005). Im Falle eines verminderten Nachweises von Beclin-1 in fortgeschrittenen Tumorzellen wird die Funktion von Beclin-1 häufig als zytoreduktiv interpretiert (Shintani und Klionsky 2004; Hao et al. 2014).

Das Mikrotubuli-assoziierte Protein LC3 kommt bei ausreichender Nährstofflage zytoplasmatisch vor (LC3-I) (Kabeya et al. 2000). Unter mangelnder Versorgung wird LC3 mithilfe von anderen autophagalen Proteinen an die innere und äußere Membran im Autophagosom gebunden (LC3-II). LC3 verbindet und verlängert in Zusammenarbeit mit einem an der Autophagie beteiligten Protein-Komplex kleinere Vesikel an die durch Beclin-1 entstandene Doppelmembran, die die Zellbestandteile umgibt, bis eine bläschenartige Phagophore entsteht (Ichimura et al. 2000; Kirisako et al. 2000; Ohsumi 2001; Kabeya et al. 2004; Sugawara et al. 2004; Deng et al. 2013). LC3-II ist das erste Protein, das in der Membran des Autophagosoms in Säugetieren gefunden wurde. Das membranständige Protein LC3-II entspricht in unserer Studienarbeit LC3. Es korreliert mit der Menge an Autophagosomen und spiegelt somit dessen Aktivität wider (Ichimura et al. 2000; Kabeya et al. 2000; Kabeya et al. 2004).

p62 ist ein Autophagie-assoziiertes Rezeptorprotein, welches zytoplasmatisch sowie nukleär vorkommt, und sorgt für eine Aggregation der abzubauenden Zellbestandteile (Mathew et al. 2009; Choi et al. 2013; Gutierrez et al. 2014). Durch die Bindung von LC3 an p62 können der selektive Transport und der Einschluss der abzubauenden Proteine aus dem Zellkern und aus dem Zytoplasma in das Autophagosom erfolgen. Nach Kopplung von p62 und LC3 im Zytoplasma kann die äußere Membran des Autophagosom mit dem Lysosom verschmelzen (Kim et al. 2014). Anschließend werden mithilfe der lysosomalen Enzyme die innere Membran des Autophagosoms aufgelöst und die Proteine abgebaut (Abbildung 1) (Klionsky 2007).

Im Falle einer Unterversorgung der Zelle, wie in Tumorzellen, kommt es zu einer Anhäufung von beschädigten Proteinen, welche mithilfe von p62 abgebaut und wieder verwertet werden können (Mathew et al. 2009). 


\subsection{Zielsetzung}

Ziel dieser Doktorarbeit war es, die Rolle der Autophagie in papillären Nierenzellkarzinomen darzustellen.

Folgende Aspekte sollten charakterisiert werden:

1. Morphologische, pathologische und prognostische Unterschiede zwischen papillärem Nierenzellkarzinom Typ 1 und 2.

2. Expression von Beclin-1, LC3 und p62 in papillären Nierenzellkarzinomen unter Berücksichtigung der morphologischen Subtypen.

3. Beziehung zwischen klinischen/pathologischen Parametern (Typ 1 und 2, TNM-Stadien, Grading) und Expression der oben genannten Autophagie-assoziierten Proteine.

4. Einfluss der Autophagieaktivität auf das absolute und remissionsfreie Überleben in papillären Nierenzellkarzinomen. 


\section{Material und Methoden}

\subsection{Patientenkollektiv}

Für diese retrospektive Studie wurden 38 Patienten herangezogen, die in dem Zeitraum von Jahr 2003 bis Jahr 2015 in der urologischen Abteilung der Universitätsklinik Göttingen an einem papillären Nierenzellkarzinom operiert wurden.

Es liegen schriftliche Einverständniserklärungen der Patienten vor, die zum Zeitpunkt der Studie noch gelebt haben, zur Nutzung der Präparate sowie der Patienteninformationen.

\subsection{Untersuchungsmaterial}

Die Tumorpräparate wurden in der Abteilung Pathologie der Universitätsmedizin Göttingen anhand von Paraffinblöcken und Schnittpräparaten in Typ und Subtyp des Nierenzellkarzinoms eingeteilt und nach TNM-Stadien und Grading klassifiziert. Einige ältere Tumoren mussten an die neue Klassifizierung nach UICC angepasst werden. In Tabelle 3 findet sich eine Aufstellung der hier untersuchten Tumoren. Es wurden alle Patientenakten durchgesehen und hinsichtlich nachfolgender Kriterien analysiert. Neben Alter bei Erstdiagnose und Geschlecht des Patienten wurden pTNM-Stadium, Typisierung und Grading des papillären Nierenzellkarzinoms, vorhandene Metastasen, gesamte Überlebenszeit und remissionsfreies Überleben dokumentiert. Darüber hinaus wurden der letzte Patientenkontakt und die Anzahl der verstorbenen Patienten bis zum Studienende festgehalten. 
Tabelle 3: Pathologische Kenndaten des untersuchten Tumorgewebes (papilläres Nierenzellkarzinom Typ 1 und 2, T-Stadien und Grading)

\begin{tabular}{|c|c|c|c|}
\hline Fall & Typ & T-Stadium & Grading \\
\hline 1 & 2 & $3 b$ & 3 \\
\hline 2 & 1 & $2 a$ & 2 \\
\hline 3 & 2 & 4 & 2 \\
\hline 4 & 1 & $1 a$ & 1 \\
\hline 5 & 2 & $3 b$ & 3 \\
\hline 6 & 2 & $3 a$ & 2 \\
\hline 7 & 2 & $3 b$ & 3 \\
\hline 8 & 1 & $1 b$ & 2 \\
\hline 9 & 1 & $2 a$ & 2 \\
\hline 10 & 1 & $1 b$ & 2 \\
\hline 11 & 2 & $1 \mathrm{a}$ & 2 \\
\hline 12 & 1 & $1 a$ & 1 \\
\hline 13 & 1 & $1 b$ & 2 \\
\hline 14 & 2 & $1 b$ & 2 \\
\hline 15 & 1 & $1 \mathrm{a}$ & 2 \\
\hline 16 & 1 & $1 b$ & 1 \\
\hline 17 & 1 & $1 b$ & 1 \\
\hline 18 & 1 & $1 b$ & 2 \\
\hline 19 & 1 & $1 a$ & 2 \\
\hline 20 & 1 & $1 b$ & 1 \\
\hline 21 & 1 & $1 a$ & 1 \\
\hline 22 & 1 & $2 a$ & 2 \\
\hline 23 & 2 & $3 a$ & 2 \\
\hline 24 & 1 & $3 a$ & 2 \\
\hline 25 & 1 & $1 a$ & 2 \\
\hline 26 & 1 & $1 a$ & 2 \\
\hline 27 & 2 & $3 b$ & 3 \\
\hline 28 & 1 & $1 b$ & 2 \\
\hline 29 & 1 & $1 b$ & 1 \\
\hline 30 & 1 & $1 a$ & 1 \\
\hline 31 & 1 & $1 \mathrm{a}$ & 1 \\
\hline 32 & 2 & $1 b$ & 2 \\
\hline 33 & 1 & $1 a$ & 2 \\
\hline 34 & 1 & $1 b$ & 2 \\
\hline 35 & 1 & $1 \mathrm{a}$ & 2 \\
\hline 36 & 1 & $1 \mathrm{a}$ & 2 \\
\hline 37 & 1 & $1 b$ & 2 \\
\hline 38 & 1 & $1 \mathrm{a}$ & 2 \\
\hline
\end{tabular}




\subsection{Untersuchung am Tumorgewebe}

\subsubsection{Tissue Microarrays (TMA)}

Es wurden jeweils zwei $2 \mathrm{~mm}$ dicke Stanzen (Biopsie-Stanze, pfmmedical ag, 50996 Köln) aus den Gewebeproben entnommen, welche dann in den auf $37^{\circ} \mathrm{C}$ aufgewärmten Empfängerblock (Tissue-Tek Prisma, Staufen, Germany) überführt wurden. So konnten mehrere Proben auf einem Block in einer vorher festgelegten Reihenfolge angebracht werden. Anschließend wurde der TMA-Block bei $50^{\circ} \mathrm{C}$ für circa 2 Stunden in einer Ausgießform im Wärmeofen (Memmert) erwärmt, sodass die Gewebestanzen sich mit dem Paraffin des Empfängerblockes verbanden. Darauf erfolgte das standardisierte Ausgießen des Paraffins in eine Gewebekapsel.

\subsubsection{Präparation der Paraffinschnittpräparate}

Schnittpräparate von $2 \mu \mathrm{m}$ Gewebedicke wurden mit einem Schlittenmikrotom (Mikrom HM 430, Firma Thermo Fisher Scientific, 64292 Darmstadt, Deutschland) angefertigt, in einem ca. $20^{\circ} \mathrm{C}$ kalten Wasserbad aufgefangen und gestreckt. Die Schnitte wurden auf einen beschichteten Objektträger glatt aufgezogen und abschließend bei $45{ }^{\circ} \mathrm{C}$ auf einem Strecktisch getrocknet (Strecktisch, Vogel ST 893, Vogel GmbH \& Co., 35463 Fernwald).

\subsubsection{Hämatoxylin-Eosin-Färbung}

Alle Schnittpräparate wurden zur Darstellung der Tumormorphologie und zur Einteilung des Malignitätsgrades standardisiert und automatisiert (Tissue-Tek Prisma, Staufen, Germany) mittels der Hämatoxylin-Eosin-Färbungsmethode gefärbt. Zur Kerndarstellung wurden die histologischen Präparate mit Mayers Hämalaun und zur Zytoplasmadarstellung mit Eosin gefärbt. Nach Dehydratation in alkoholischen Lösungen in aufsteigender Konzentration wurden die Schnittpräparate mittels Cytoseal ${ }^{\mathrm{TM}} \mathrm{XYL}$ Mounting Medium (Richard-Allan Scientific ${ }_{\circledast}$, Kalamazoo) mit Xylol eingedeckt. 


\subsection{Immunhistochemie und Primärantikörper}

Alle Inkubationsschritte wurden in einer feuchten Kammer und, wenn nicht anders angegeben, bei Raumtemperatur durchgeführt. Die verwendeten Antikörper, deren Verdünnungen und Inkubationszeiten sowie Vorbehandlung der Schnittpräparate werden in der Tabelle 4 erläutert.

Die Demaskierung der durch Formalinfixation maskierten Antigene erfolgte in einem Dampfgarer (B. Braun, Melsungen) mit Citrat-Puffer ( $\mathrm{pH}$-Wert 6,0) über 15 min bei 700 Watt. Nach 20-minütiger Abkühlung wurde die endogene Peroxidaseaktivität mit dreiprozentigem Wasserstoffperoxid (Merck, Darmstadt) blockiert. Unspezifische Antikörperbindungen und unspezifische Färbungen wurden durch Applikation einer Puffersubstanz namens Tris $\left(\right.$ TBST $\left.^{\circledR}\right)$ mit einem pH-Wert von 7,4 und 0,5-prozentigen fötalem Kälberserum geblockt. Die Detektion der Primärantikörper erfolgte mit EnVision-Peroxidase ${ }^{\text {TM }}$ (Dako, Hamburg) und rotem Substrat Kit (Fast-red, Dako Cytomation, Hamburg) beziehungsweise einem blau-violetten Peroxidase-Substrat Kit namens Vector ${ }^{\circledR}$ VIP (Vector Laboratories, Burlingame). Nach Abschluss der Färbereaktion mit entionisiertem Wasser wurde das Gewebe mit Mayers Hämalaun gegengefärbt und nach Dehydrierung mit Cytoseal $^{\mathrm{TM}}$ XYL Mounting Medium (Richard-Allan Scientific ${ }_{\circledast}$, Kalamazoo) mit Xylol eingedeckt. 
Tabelle 4: Antikörper und Färbeprotokoll (RT = Raumtemperatur).

\begin{tabular}{|c|c|c|c|c|c|}
\hline $\begin{array}{l}\text { Anti- } \\
\text { körper }\end{array}$ & Klon & Quelle & $\begin{array}{l}\text { Vorbe- } \\
\text { handlung }\end{array}$ & $\begin{array}{l}\text { Ver- } \\
\text { dünnung }\end{array}$ & Inkubation \\
\hline Ki-67 & K-2 (Maus) & $\begin{array}{l}\text { Zytomed } \\
\text { Systems, } \\
\text { Berlin, } \\
\text { Deutschland }\end{array}$ & $\begin{array}{l}\text { Zitratpuffer } \\
\mathrm{pH} 6.0\end{array}$ & $1: 200$ & $30 \min \mathrm{RT}$ \\
\hline Beclin-1 & $\begin{array}{l}\text { EPR17334 } \\
\text { (Kaninchen) }\end{array}$ & $\begin{array}{l}\text { Abcam, } \\
\text { Cambridge, } \\
\text { Großbritannien }\end{array}$ & $\begin{array}{l}\text { Zitratpuffer } \\
\mathrm{pH} 6.0\end{array}$ & $1: 100$ & $30 \min \mathrm{RT}$ \\
\hline p62 & $\begin{array}{l}\text { SQSTM1 } \\
\text { (Maus) }\end{array}$ & $\begin{array}{l}\text { Abcam, } \\
\text { Cambridge, } \\
\text { Großbritannien }\end{array}$ & $\begin{array}{l}\text { Zitratpuffer } \\
\mathrm{pH} 6.0\end{array}$ & $1: 100$ & $30 \min \mathrm{RT}$ \\
\hline LC3 & $\begin{array}{l}\text { polyclonal } \\
\text { (Kaninchen) }\end{array}$ & $\begin{array}{l}\text { Abcam, } \\
\text { Cambridge, } \\
\text { Großbritannien }\end{array}$ & $\begin{array}{l}\text { Zitratpuffer } \\
\mathrm{pH} 6.0\end{array}$ & $1: 50$ & $30 \min \mathrm{RT}$ \\
\hline
\end{tabular}

\subsection{Morphometrische Untersuchung}

Die Untersuchungen der gefärbten Schnittpräparate wurden unter Anleitung und Kontrolle durch einen erfahrenen Pathologen hinsichtlich des ImmunreaktivenScores nach Allred (IRS) und des Expressionsmusters an einem Diagnostiklichtmikroskop (BX 41, Olympus, Hamburg) durchgeführt.

\subsection{Immunreaktiver Score}

Bei der semiquantitativen Beurteilung der immunhistochemischen Präparate, angefärbt mit den Antikörpern Ki-67, Beclin-1, p62 und LC3, wurde der IRS herangezogen. Dieser ist die Summe aus dem prozentualen Anteil positiver Zellen und der Farbintensität und reicht von 0 bis 8 (Tabelle 5). 
Tabelle 5: Immunreaktiver Score: Intensität der Zellsignale

\begin{tabular}{lll}
\hline Punkte & Anteil positiver Zellen (\%) & Intensität der Anfärbung \\
\hline $\mathbf{0}$ & 0 & keine \\
$\mathbf{1}$ & $<1$ & schwach \\
$\mathbf{2}$ & $1-10$ & mäßig \\
$\mathbf{3}$ & $11-33$ & stark \\
$\mathbf{4}$ & $34-66$ & \\
$\mathbf{5}$ & $67-100$ & \\
\hline
\end{tabular}

\subsection{Statistik}

Die Daten wurden mit Excel 2010 und Statistica Version 13 für Windows (StatSoft, Inc. 19847-2011, Tulsa, OK 74104, USA) dokumentiert, statistisch berechnet und analysiert. Für die Entscheidung über die statistische Auswertung der erhobenen Daten wurde die medizinisch-statistische Beratung der Universität Göttingen in Anspruch genommen. Die Berechnung und Deutung der Daten erfolgten selbständig.

Das T-Stadium musste zur Vereinfachung der Berechnung durch eine Nummerierung von 1-4 und durch eine Kodierung, gekennzeichnet durch $\mathrm{pT}^{*}$, angepasst werden ( $\left.T^{*}: \mathrm{pT} 1(a, b)=1, \mathrm{pT} 2(a, b)=2, p T 3(a, b, c)=3, p T 4=4\right)$.

Bei den statistischen Tests wurde der $p$-Wert ermittelt, wobei eine Signifikanz bei $p$ $<0.05$ erreicht war.

Für jede immunhistochemische Beurteilung wurde der Median des IRS gebildet. Dieser diente als Trenn- bzw. Schwellenwert für die Unterteilung in hohe und niedrige Expression (2 Gruppen: $0<$ Median, 1 =/> Median). Diese Unterteilung wurde ebenfalls bei Ki-67, Beclin-1, LC3 sowie p62 angewendet und wurde mit folgenden Symbolen gekennzeichnet: Ki-67*, Beclin-1*, LC3*, p62*.

Zum Vergleich der Daten (TNM, Grading und Protein-Expression) mit papillärem Nierenzellkarzinom Typ 1 und 2 (in Tabellen und Graphiken mit Typ 1 und 2 gekennzeichnet) wurde der Mann-Whitney-U-Test verwendet. Die Korrelation zwischen der Protein-Expression und den klinisch-pathologischen Parametern wurde durch den Kendalls Tau-Test bei einem Signifikanzniveau $p=0,05$ ermittelt. Das Gesamtüberleben (overall survival = OS) wurde als die Zeit von Erstdiagnose bis zum Versterben oder letzter Patientenkontakt definiert. Das remissionsfreie 
Überleben (disease-free survival = DFS) dagegen stellt die Zeit zwischen Erstdiagnose und Rezidiv dar. Unzensiert waren die vollständig erfassten Überlebenszeiten, bei denen in der OS-Gruppe das Versterben und bei der DFSGruppe ein Rezidiv auftrat. Zensierte Überlebenszeiträume endeten mit dem zuletzt erfassten Patientenkontakt. Ein Tod oder ein Rezidiv wurden in dieser Gruppe nicht festgestellt oder waren nicht bekannt. Das OS und DFS wurden durch die Kaplan-Meier-Kurve graphisch dargestellt und mittels des Log-RankTests konnte ein Vergleich zwischen zwei Gruppen berechnet werden. 


\section{Ergebnisse}

\subsection{Klassifizierung und Subtypisierung}

Die Klassifizierung und Subtypisierung der Tumorgewebe unserer Patienten ergab keine Fehlanalyse der bereits dokumentierten pathologischen Auswertung. Bei einigen älteren Tumoren musste die Einteilung an die neue UICC-Klassifikation angepasst werden. In Abbildung 2 und 3 sieht man einen Ausschnitt aus einem Schnittpräparat der HE-Färbung der einzelnen Subtypen des papillären Nierenzellkarzinoms mit der typischen Morphologie. Tabellen 3 und 6 führen unsere Ergebnisse auf. Von allen getesteten Personen waren bei Erstdiagnose der jüngste Patient 31 und der Älteste 86 Jahre alt gewesen. Das mediane Erkrankungsalter der für die Studie herangezogenen Patienten mit papillärem Nierenzellkarzinom lag bei 65 Lebensjahren. 9 Fälle aus dem gesamten Patientenkollektiv wiesen bei Erstdiagnose Metastasen auf. Davon lagen bei 6 Patienten mehrere Lymphknoten- und bei 2 Patienten Organmetastasen vor.

Es konnte ein signifikant höheres T-Stadium in Typ-2- als in den Typ-1-Tumoren festgestellt werden (Mann-Whitney-U-Test: $p=0,000232$, Abbildung 4a).

Bei der Unterscheidung zwischen Typ 1 und 2 zeigten sich bei Typ $2 \mathrm{mehr}$ Lymphknotenmetastasen als bei Typ 1 (Mann-Whitney-U-Test: $p=0,000714$, Abbildung 4b). Darüber hinaus beobachteten wir in Typ-2-Tumoren mehr Organmetastasen als bei Typ 1 (Mann-Whitney-U-Test: $p=0,018462$ ), und es konnte bei Typ 2 ein signifikant höheres Grading nachgewiesen werden (MannWhitney-U-Test: $p=0,001092$ ). 
Abbildung 2: Ausschnitt aus einem Schnittpräparat: HE-Färbung, 20fache Vergrößerung, papilläres Nierenzellkarzinom Typ 1

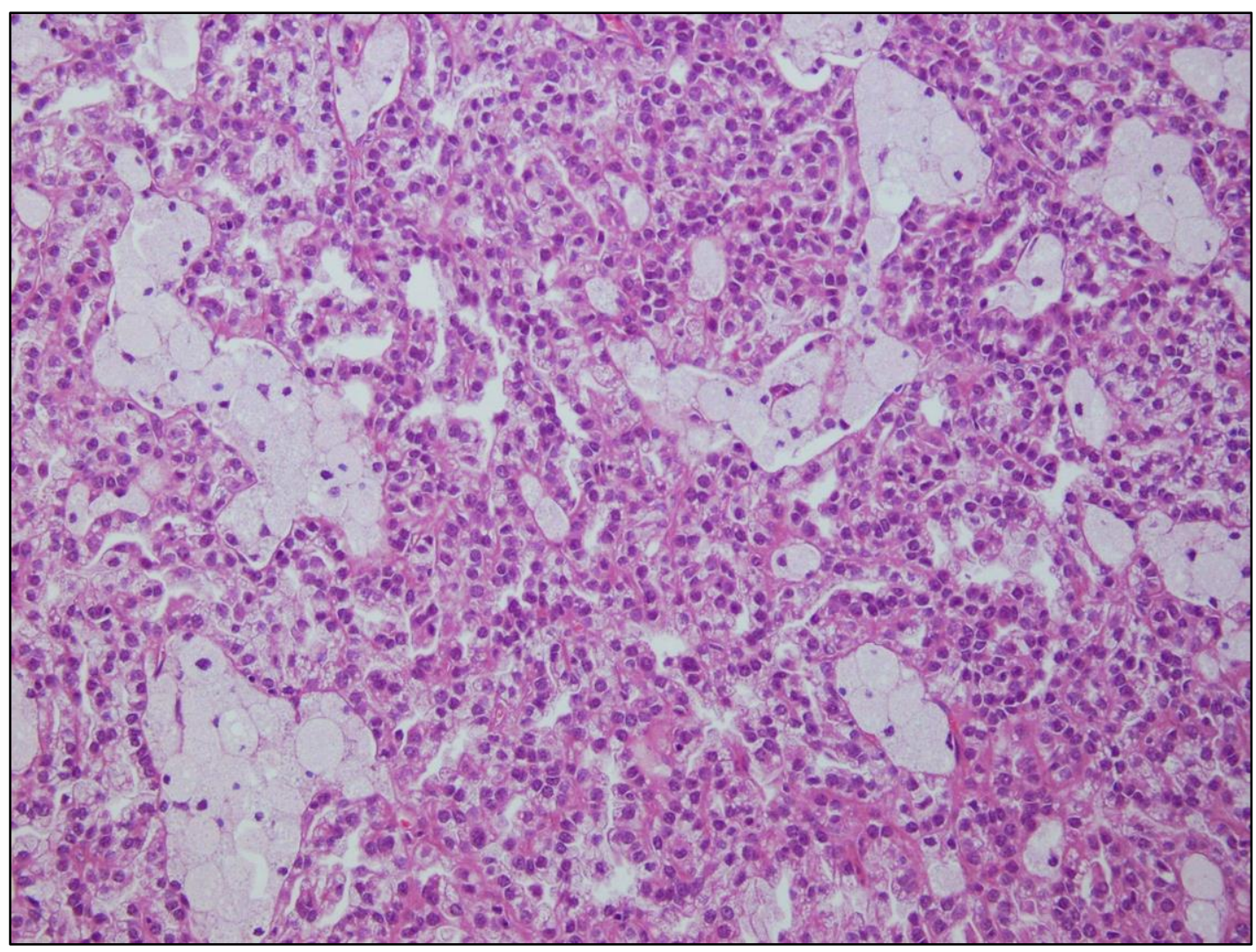

Abbildung 3: Ausschnitt aus einem Schnittpräparat: HE-Färbung, 20fache Vergrößerung, papilläres Nierenzellkarzinom Typ 2

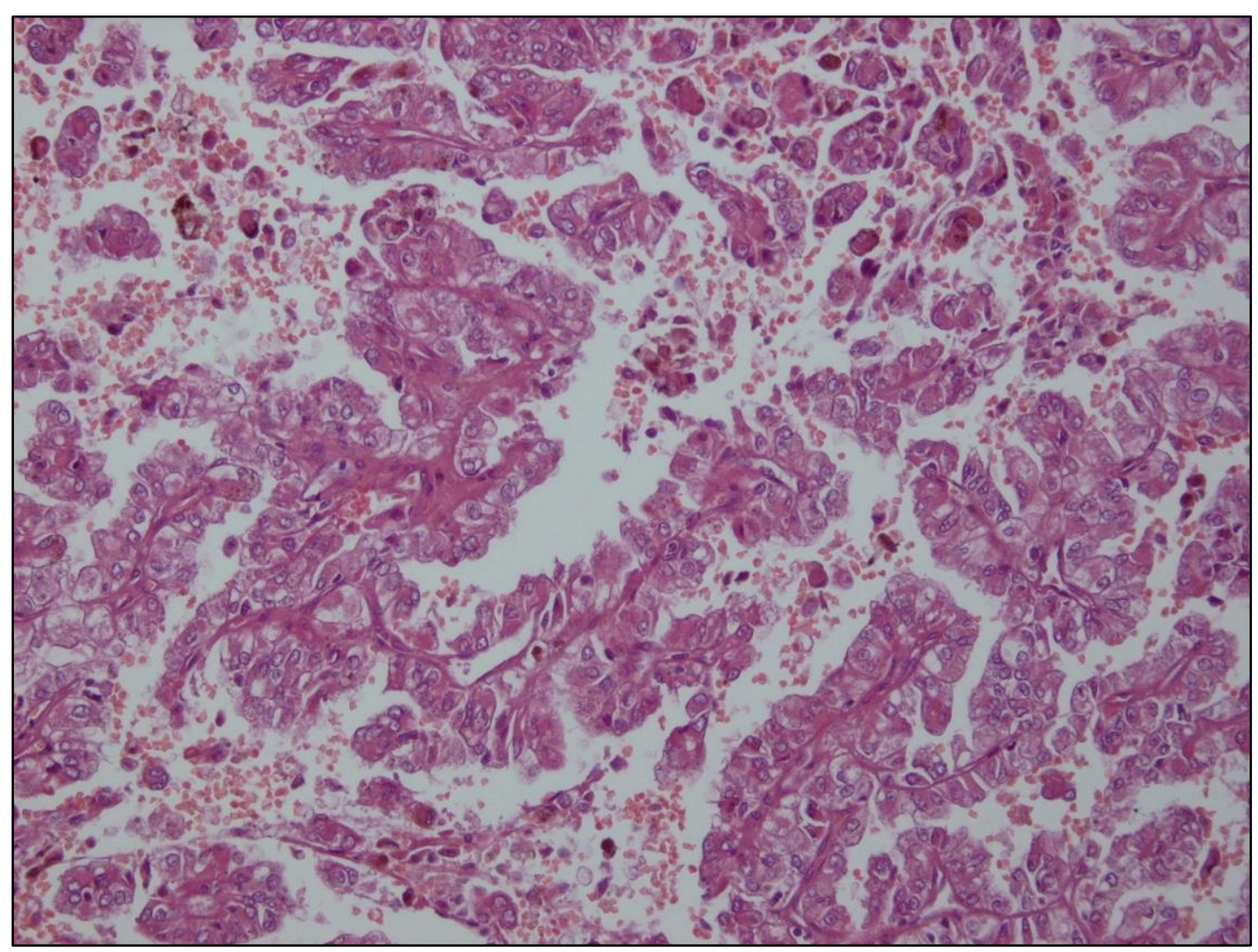


Tabelle 6: Pathologische Kenndaten: Häufigkeitsverteilung der TNM-Stadien in Abhängigkeit von den Subtypen (Typ 1 und 2). Abkürzungen: $n=$ Anzahl

\begin{tabular}{llll}
\hline & Typ 1 & Typ 2 & Gesamt \\
\hline n (Männer/Frauen) & $28(22 / 6)$ & $10(8 / 2)$ & $38(30 / 8)$ \\
$\begin{array}{l}\text { Durchschnittsalter } \\
\text { (Jahre) }\end{array}$ & 62,7 & 63,2 & 62,8 \\
n T1 (a/b) & $24(15 / 9)$ & $3(1 / 2)$ & $27(16 / 11)$ \\
n T2 (a/b) & $3(3 / 0)$ & 0 & $3(3 / 0)$ \\
n T3 (a/b/c) & $1(1 / 0)$ & $6(2 / 4 / 0)$ & $7(3 / 4 / 0)$ \\
n T4 & 0 & 1 & 1 \\
n Nx & 27 & 5 & 32 \\
n N1 & 1 & 0 & 1 \\
n N2 & 0 & 5 & 5 \\
n Mx & 28 & 8 & 36 \\
n M1 & 0 & 2 & 2 \\
n G1 & 0 & 0 & 9 \\
n G2 & 19 & 6 & 25 \\
n G3 & 0 & 0 & 4 \\
N G4 & 0 & 0 & 0 \\
\hline
\end{tabular}


Abbildung 4: Histogramme: a) T-Stadium (1-4= $p T^{*}$ gruppiert nach papillären Nierenzellkarzinom Typ 1 und 2 in Abhängigkeit von den beobachteten Fällen. Mann-Whitney-U-Test: $p=0,002320$; b) $N$-Stadium ( $p N$ : $0=$ $p N x, 1=p N 1,2=p N 2)$ gruppiert nach papillärem Nierenzellkarzinom Typ 1 und 2 in Abhängigkeit von den beobachteten Fällen. Mann-Whitney-U-Test: $p=0,023491$.

a)

Histogramm

Variable: $\mathrm{pT}^{*}$, Gruppen: Typ 1 und 2

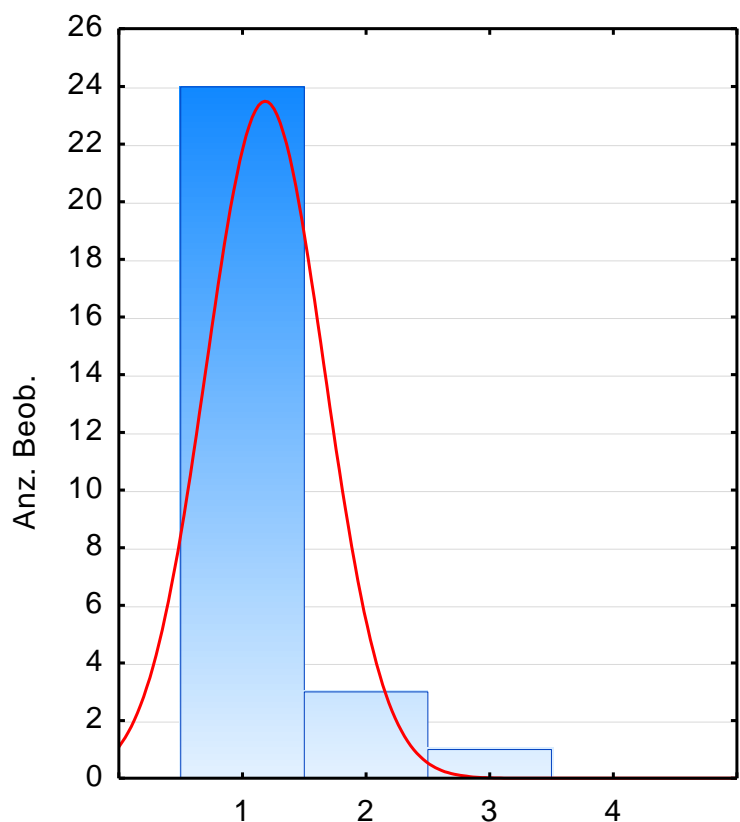

Typ: 1

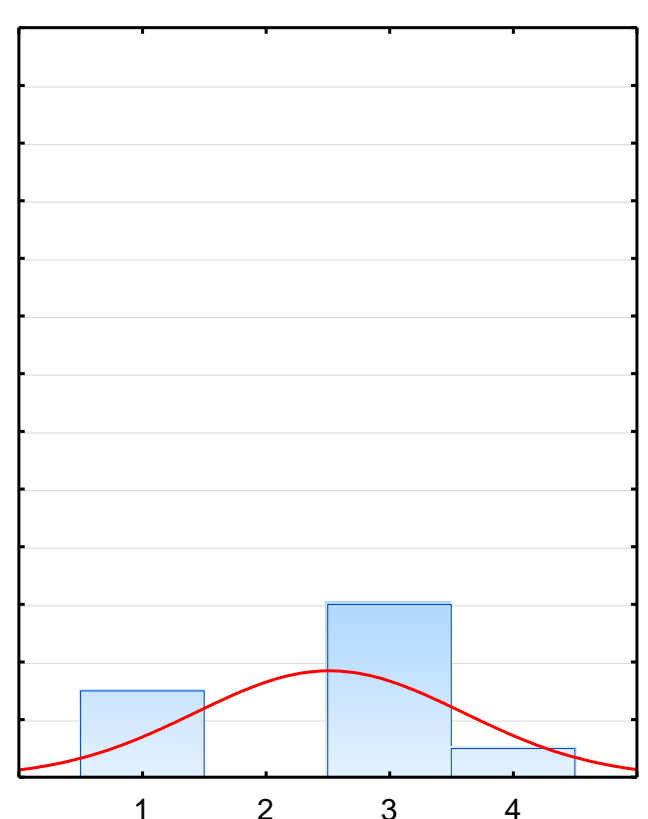

Typ: 2

b)

Histogramm

Variable: pN, Gruppen: Typ 1 und 2

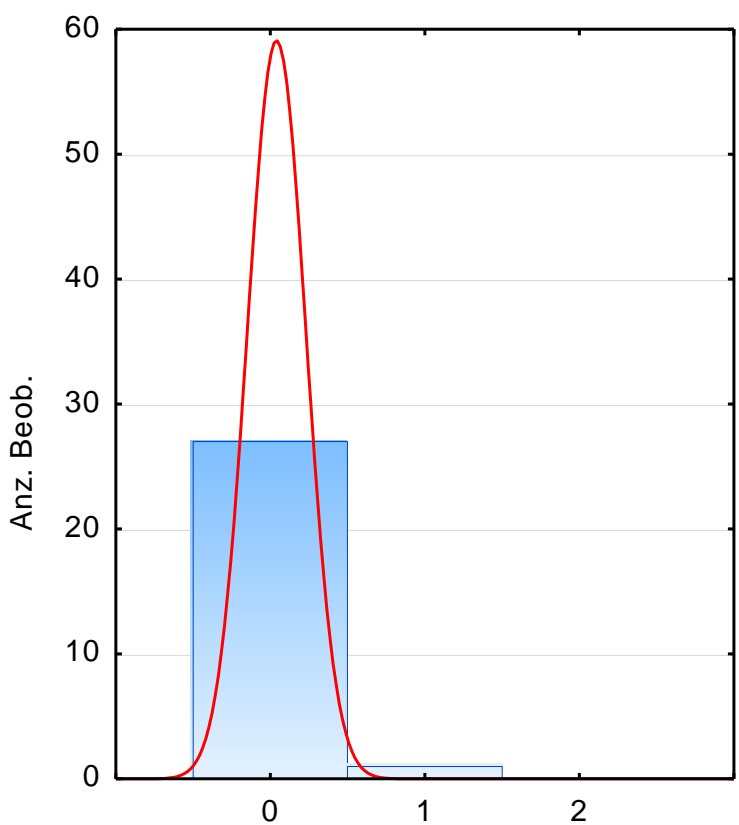

Typ: 1

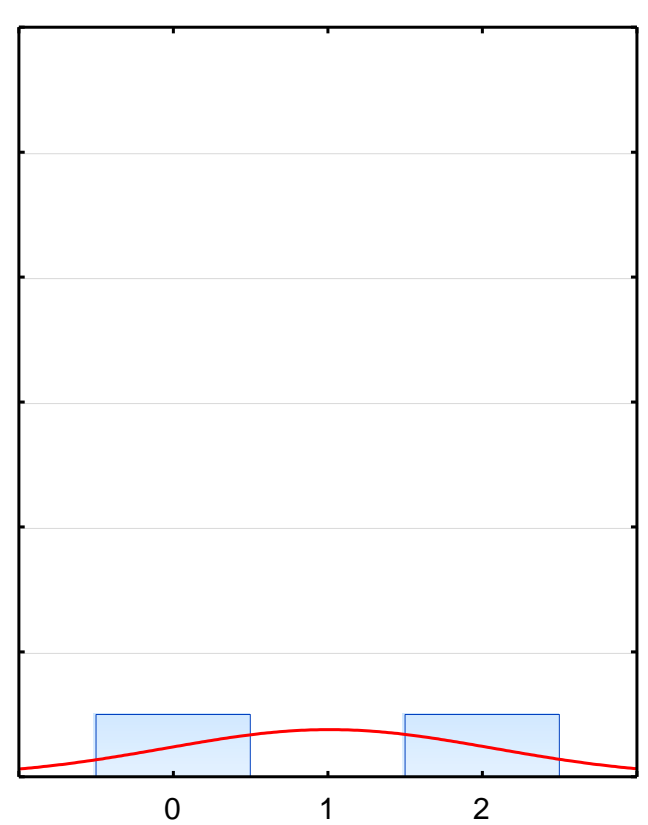

Typ: 2 


\subsection{Immunhistochemische Ergebnisse}

Tabelle 7: Übersichtstabelle der Kendalls Tau-Korrelationen zwischen Autophagie-Marker und pTNM-Stadium und Grading. Signifikante Korrelationen $(p<0,05)$ sind rot markiert.

\begin{tabular}{|c|c|c|c|c|}
\hline \multirow{2}{*}{ Variablenpaar } & \multicolumn{4}{|c|}{$\begin{array}{l}\text { Kendalls Tau-Korrelation } \\
\text { Markierte Korrelation signifikant ab } p<0,05\end{array}$} \\
\hline & $\underset{N}{\text { Gültige }}$ & $\begin{array}{l}\text { Kendalls } \\
\text { Tau }\end{array}$ & Z & $p$-Wert \\
\hline $\mathrm{Ki}-67^{*} \& p T^{*}$ & 38 & 0,323378 & 2,85803 & 0,004263 \\
\hline $\mathrm{Ki}-67^{*} \& \mathrm{pN}$ & 38 & 0,574806 & 5,08017 & 0,000000 \\
\hline $\mathrm{Ki}-67^{*} \& \mathrm{pM}$ & 38 & 0,126773 & 1,12043 & 0,262532 \\
\hline $\mathrm{Ki}-67^{*} \& \mathrm{G}$ & 38 & 0,430911 & 3,80842 & 0,000140 \\
\hline Beclin-1 zytoplasmatisch* \& $\mathrm{pT}^{*}$ & 38 & $-0,087304$ & $-0,77160$ & 0,440354 \\
\hline Beclin-1 zytoplasmatisch* \& pN & 38 & $-0,033795$ & $-0,29869$ & 0,765180 \\
\hline Beclin-1 zytoplasmatisch* \& pM & 38 & $-0,248452$ & $-2,19583$ & 0,028104 \\
\hline Beclin-1 zytoplasmatisch* \& G & 38 & 0,061026 & 0,53935 & 0,589642 \\
\hline Beclin-1 nukleär* \& $\mathrm{pT}^{*}$ & 38 & $-0,425098$ & $-3,75704$ & 0,000172 \\
\hline Beclin-1 nukleär* \& pN & 38 & $-0,253164$ & $-2,23747$ & 0,025255 \\
\hline Beclin-1 nukleär* \& pM & 38 & $-0,291865$ & $-2,57952$ & 0,009894 \\
\hline Beclin-1 nukleär* \& G & 38 & $-0,266357$ & $-2,35408$ & 0,018569 \\
\hline $\mathrm{LC}^{*} \& \mathrm{pT} T^{*}$ & 38 & $-0,086506$ & $-0,76455$ & 0,444540 \\
\hline $\mathrm{LC}^{*} \& \mathrm{pN}$ & 38 & 0,111623 & 0,98653 & 0,323875 \\
\hline $\mathrm{LC3}^{*} \& \mathrm{pM}$ & 38 & $-0,109415$ & $-0,96701$ & 0,333538 \\
\hline $\mathrm{LC3}^{*} \& \mathrm{G}$ & 38 & 0,158808 & 1,40355 & 0,160453 \\
\hline p62 zytoplasmatisch ${ }^{*} \& T^{*}$ & 38 & 0,197889 & 1,74895 & 0,080300 \\
\hline p62 zytoplasmatisch* \& pN & 38 & 0,405545 & 3,58423 & 0,000338 \\
\hline p62 zytoplasmatisch* \& pM & 38 & 0,223607 & 1,97625 & 0,048127 \\
\hline p62 zytoplasmatisch* \& G & 38 & 0,504855 & 4,46193 & 0,000008 \\
\hline p62 nukleär* \& pT* & 38 & $-0,331354$ & $-2,92852$ & 0,003406 \\
\hline p62 nukleär* \& pN & 38 & $-0,314618$ & $-2,78061$ & 0,005426 \\
\hline p62 nukleär* \& pM & 38 & $-0,346944$ & $-3,06631$ & 0,002167 \\
\hline p62 nukleär \& G $^{*}$ & 38 & $-0,336703$ & $-2,97580$ & 0,002922 \\
\hline
\end{tabular}

\subsubsection{Ki-67}

Das Ki-67-Protein wird von Zellen exprimiert, die sich in der in der G1-, S-, G2oder in der M-Phase eines Zellzyklus befinden. Ki-67 ist ein Kernprotein und wird in der G0-Phase exprimiert. Es kann mittels eines Ki-67-Antikörpers angefärbt werden und zeigt somit die Proliferationsaktivität eines Tumors an. Diese wurde in Prozentwerten gemessen. Darüber hinaus lässt es Rückschlüsse auf das biologische Verhalten zu und wird meist in den prognostisch ungünstigen Tumoren vermehrt exprimiert.

Bei der Ki-67-Expression lag der mediane Prozentsatz bei 5\%. In der vorliegenden Arbeit zeigte sich eine signifikant höhere Ki-67-Expression im papillären 
Nierenzellkarzinom Typ 2 als in Typ 1 ( $p=0,000338)$. In Abbildung 5 ist der Vergleich der Ki-67-Antikörper-Färbung zwischen papillärem Nierenzellkarzinom Typ 1 und 2 als braune Anfärbung der Zellkerne zu sehen.

Eine signifikant positive Korrelation wurde zwischen dem Anteil Ki-67exprimierender Tumorzellen und der Tumorgröße nach dem T-Stadium beobachtet $(p=0,004263$, Kendalls Tau=0,323378). Ferner zeigte sich eine signifikant höhere Ki-67-Expression bei Tumoren, die Lymphknoten aufwiesen ( $p=0,000000$, Kendalls Tau= 0,574806). Bei Auftreten von Fernmetastasen war eine nicht signifikante positive Korrelation festzustellen $(p=0,262532$, Kendalls Tau= 0,126773).

Darüber hinaus ergab sich ein positiver Zusammenhang zwischen dem Anteil Ki67-exprimierender Tumorzellen und Grading eines Tumors ( $p=0,000140$, Kendalls $\mathrm{Tau}=0,430911)$.

Abbildung 5: 1) Histogramm für niedrige (=0) und hohe (= 1) Ki-67-Expression in papillären Nierenzellkarzinomen Typ 1 und 2. 2) Ausschnitte aus den Schnittpräparaten: Ki-67-Antikörper-Färbung in brauner Farbe, 20fache Vergrößerung, papilläres Nierenzellkarzinom Typ 1 und 2.

1)

Histogramm in Kategorien

Variable: niedrige $(=0)$ und hohe $(=1)$ Expression von Ki-67. Gruppen: Typ 1 und 2

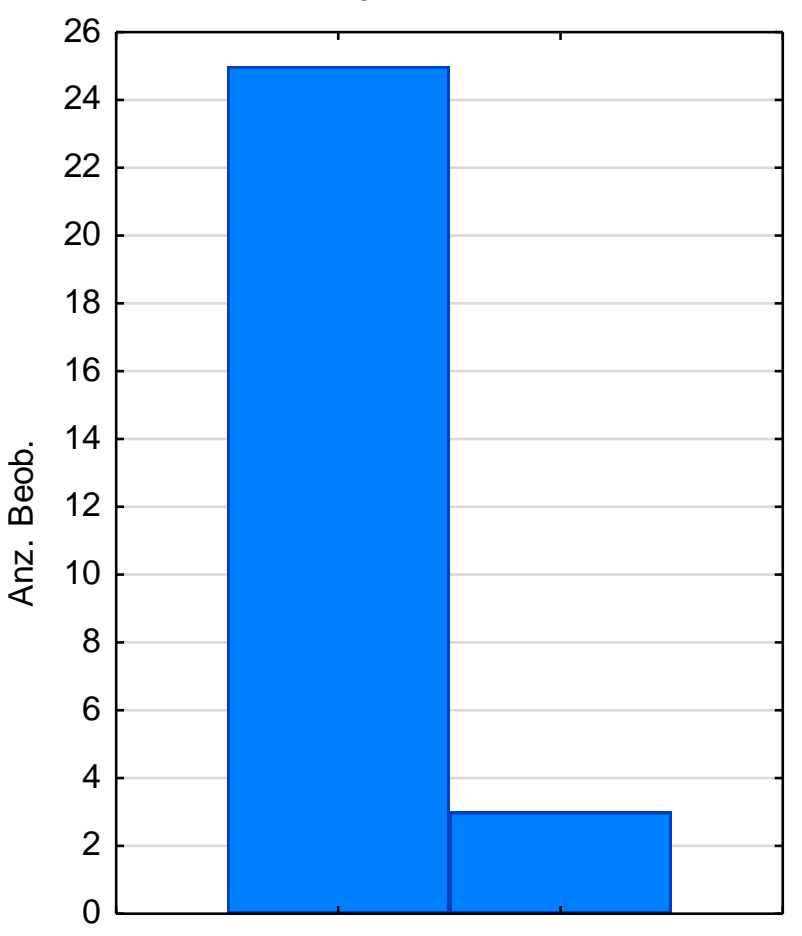

0

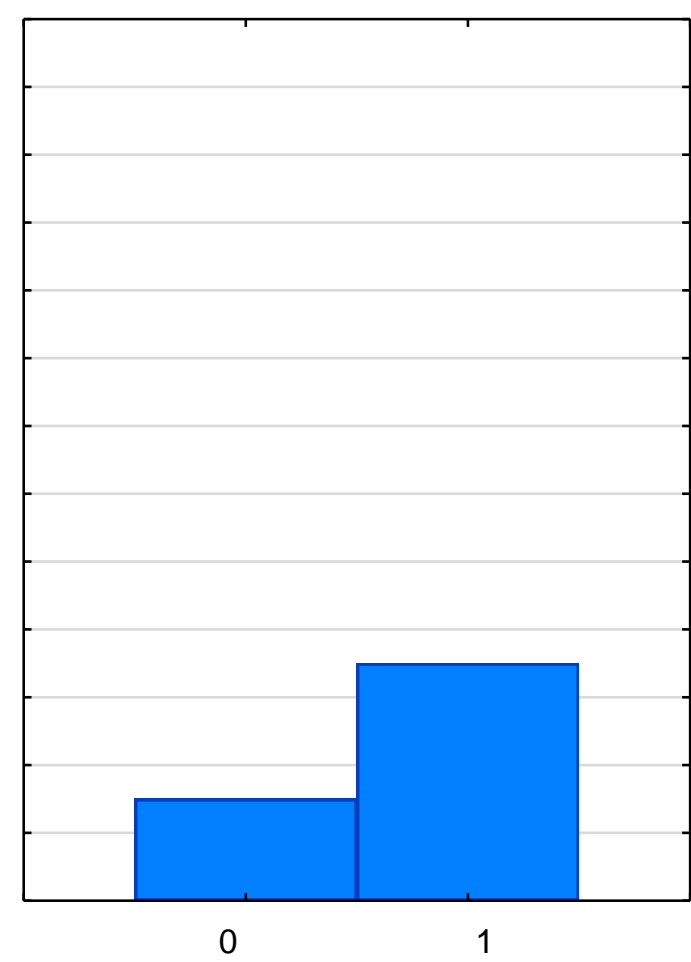

Typ: 2 


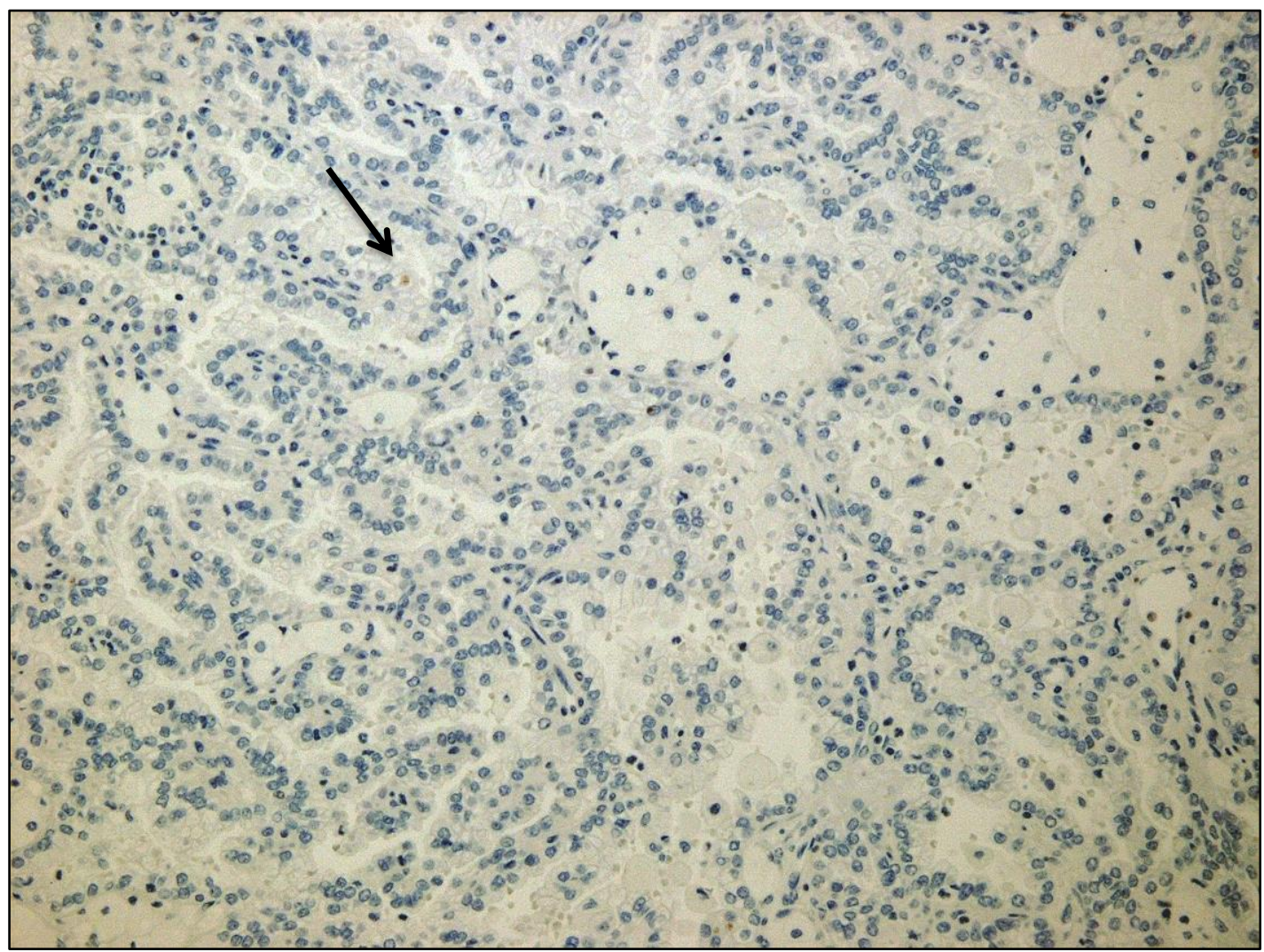

Typ 2

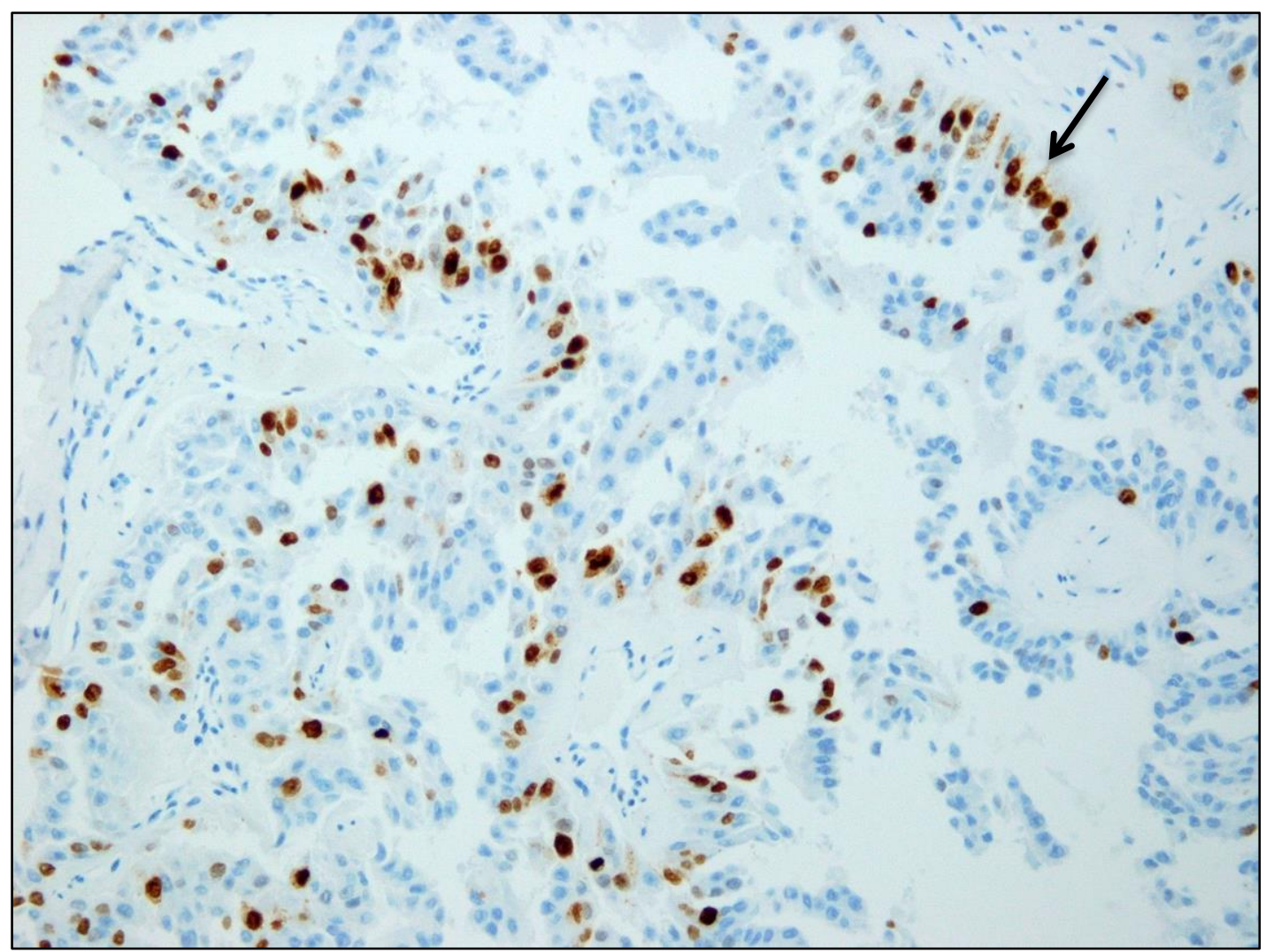




\subsubsection{Beclin-1}

Beclin-1 ist ein am Prozess der Autophagie beteiligtes Protein, welches für die Phagosombildung, insbesondere für die Bildung von isolierten Doppelmembranen in der Zelle, verantwortlich ist. Beclin-1 ist zum einen an der Apoptose und zum anderen an der Regulation der Autophagie beteiligt und kommt zytoplasmatisch sowie nukleär vor. Obwohl die Rolle von Beclin-1 als Bestandteil der Autophagie noch nicht bewiesen ist, vermutet man unter pathologischen Bedingungen eine zytoreduktive Wirkung, da es molekulargenetisch einem Tumorsuppressorgen entspricht.

Es konnte in allen papillären Nierenzellkarzinomen für die zytoplasmatische Beclin-1-Expression ein Median von 7 und für die nukleäre Expression ein Median von 6 festgestellt werden, sodass man insgesamt von einer Hochregulation von Beclin-1 sprechen kann (Abbildung 6).

Abbildung 6: 1) Balkendiagramm: Beclin-1 zytoplasmatisch und nukleär in papillären Nierenzellkarzinomen. Dargestellt ist die Proteinexpression nach dem IRS in Abhängigkeit von den beobachteten Fällen. 2) Ausschnitte aus den Schnittpräparaten: Beclin-1, zytoplasmatische sowie nukleäre Anfärbung, 20fache Vergrößerung, papilläres Nierenzellkarzinom Typ 1 und 2.

1)

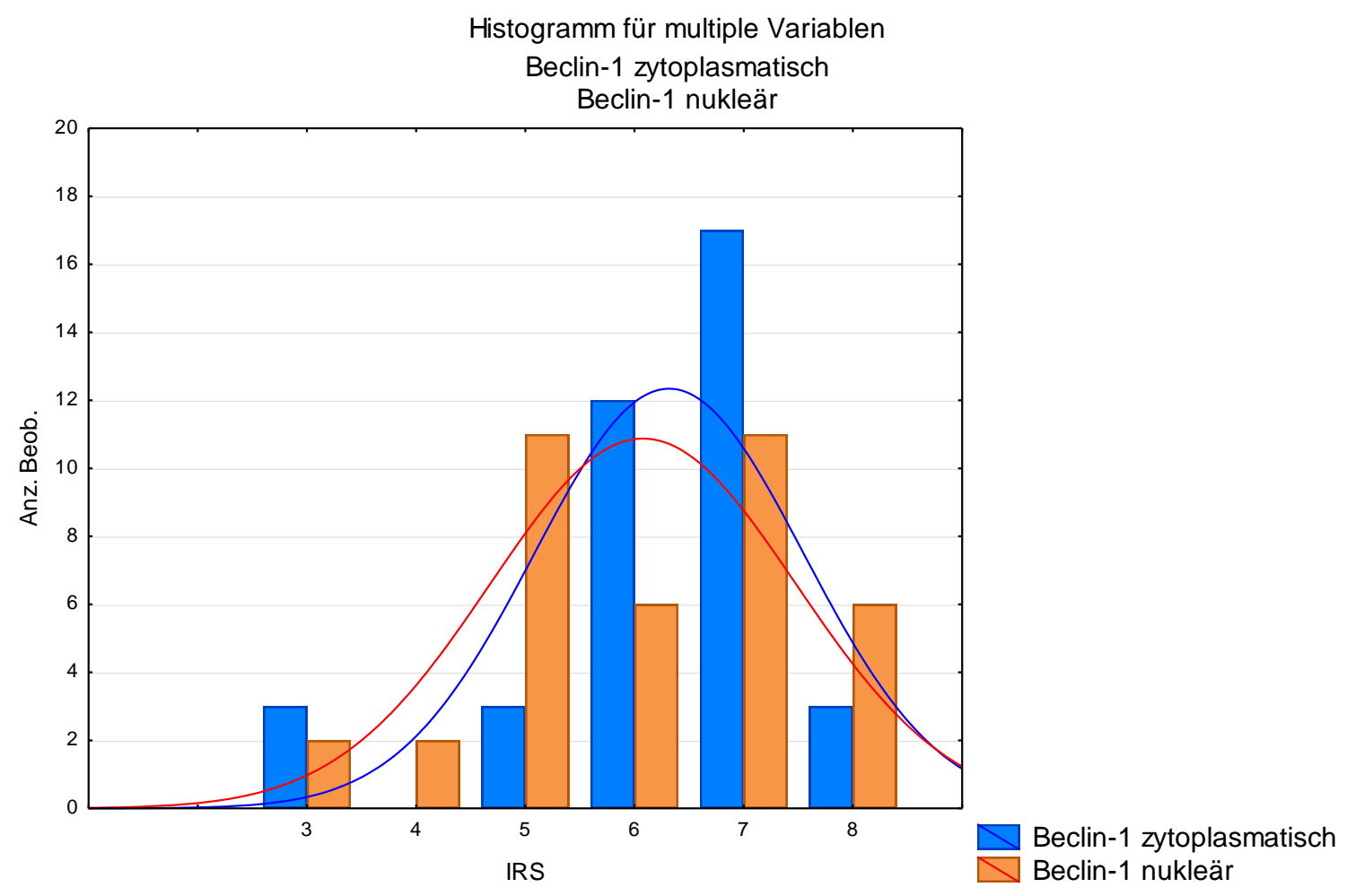


2) Legende:

: zytoplasmatisch e Anfärbung

$\longrightarrow \quad$ : nukleäre Anfärbung

Typ 1

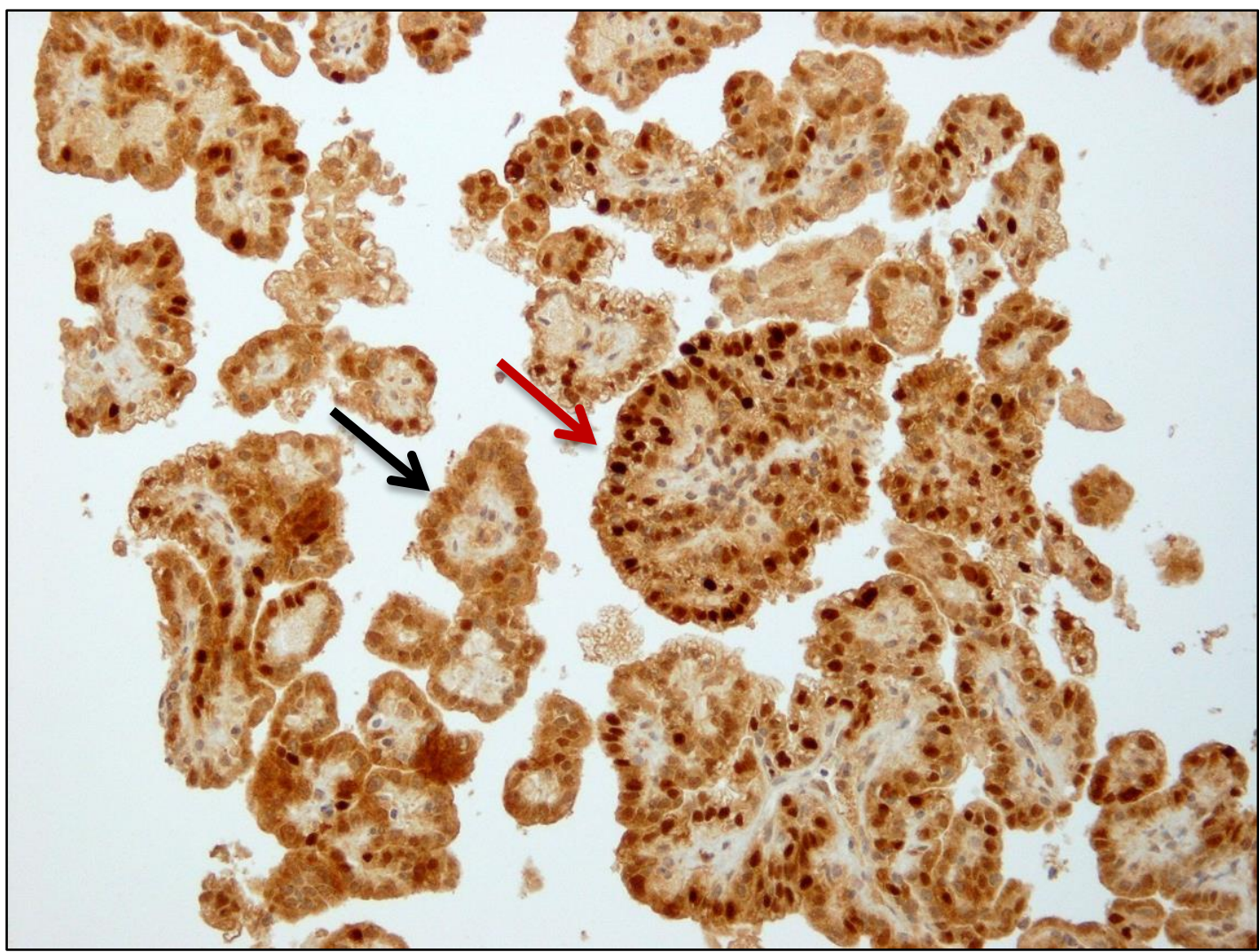

Typ 2

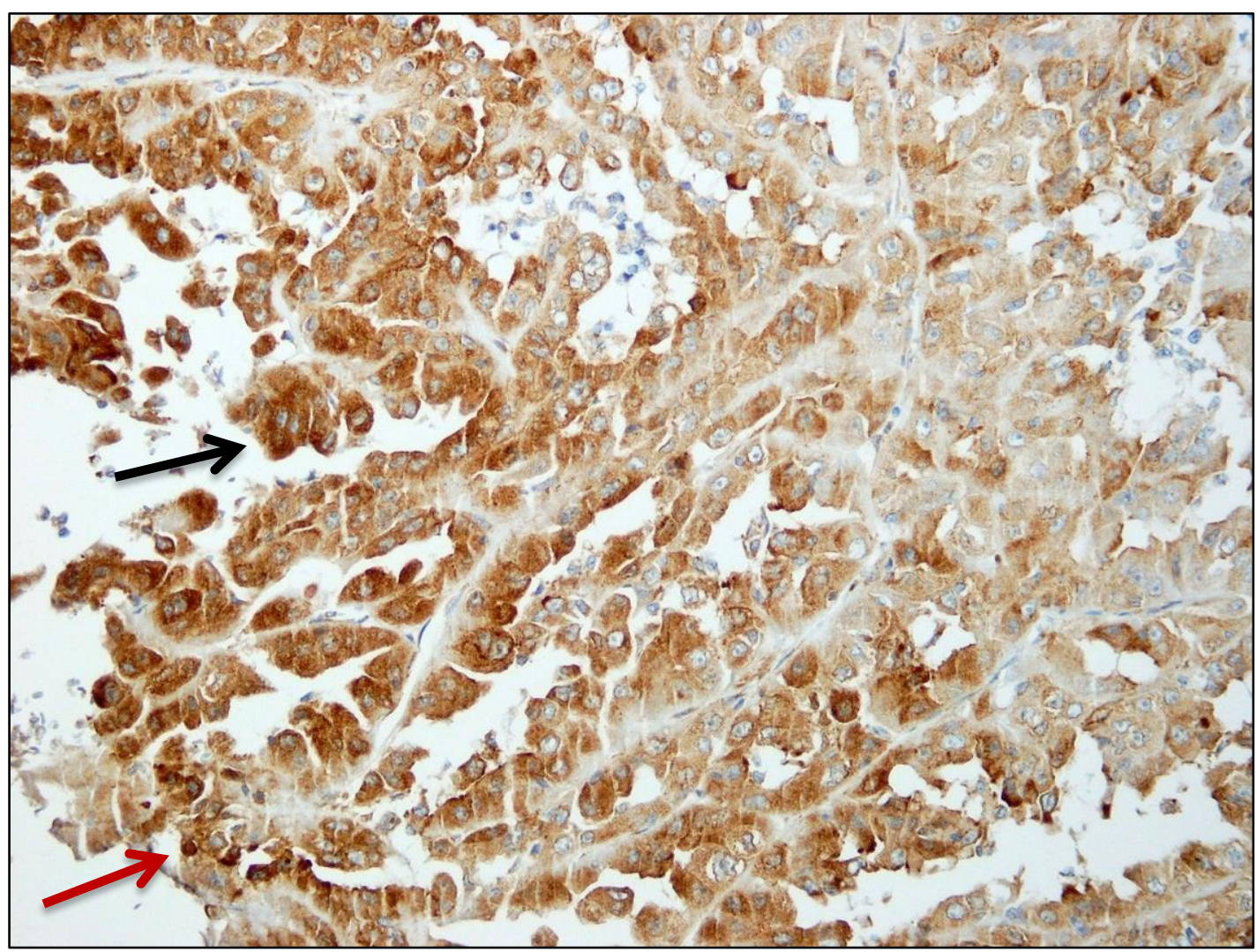


In Typ 1 zeigte sich für Beclin-1 zytoplasmatisch ein Median von 7, in Typ 2 ein Median von 6. Es ließ sich kein signifikanter Unterschied aufzeigen ( $p=0,367872$ ). Bei der nukleären Beclin-1-Expression wurde ein Median von 7 in der Typ-1Gruppe und ein Median von 5 in der Typ-2-Gruppe errechnet. Statistisch zeigte sich hier eine signifikant geringere Expression in Typ 2- als in Typ 1-Tumoren $(p=$ 0,024408, Abbildung 7).

Es konnte eine signifikant negative Korrelation zwischen nukleäre Beclin-1Expression und T-Stadium beobachtet werden $(p=0,001738$, Kendalls Tau= 0,354344, Abbildung 8). Bei niedriger nukleärer Beclin-1-Expression waren eher höhere T-Stadien und bei höherer nukleärer Beclin-1-Expression eher niedrigere T-Stadien zu beobachten. Der Zusammenhang zwischen zytoplasmatischer Beclin-1- Expression und Tumorgröße zeigte ebenfalls eine negative Korrelation, jedoch konnte keine ausreichende Evidenz festgestellt werden ( $p=0,209827$, Kendalls Tau= $-0,141891)$. Bei Auftreten von Lymphknotenmetastasen war nicht signifikant weniger zytoplasmatisches Beclin-1 nachweisbar, jedoch signifikant weniger nukleäres Beclin-1 (zytoplasmatisch: $p=0,765180$, Kendalls Tau= 0,033795, nukleär: $p=0,025255$, Kendalls Tau= -0,253163). Zusätzlich stellten wir eine signifikant negative Korrelation zwischen nukleärem und zytoplasmatischem Beclin-1 und pM-Stadium fest (zytoplasmatisch: $p=0,028104$, Kendalls Tau= 0,248452, nukleär: $p=0,009894$, Kendalls Tau= -0,291865). Somit kann ein Lymphknoten- und Metastasennachweis mit geringerer Beclin-1-Expression in Zusammenhang gebracht werden. Außerdem konnte für die nukleäre Expression eine negative Korrelation zum Grading eines Tumors oberhalb des Signifikanzniveaus aufgezeigt werden $(p=0,001738$, Kendalls Tau= -0,354344, Abbildung 9). Die zytoplasmatische Expression zeigte keinen signifikanten Zusammenhang zum Grading ( $p=0,248743$, Kendalls Tau= 0,130505). 
Abbildung 7: 1) Balkendiagramm: niedrige (=0) und hohe $(=1)$ nukleäre Beclin-1-Expression in papillären Nierenzellkarzinomen Typ 1 und 2. 2) Balkendiagramm: Beclin-1 nukleär in papillären Nierenzellkarzinomen Typ 1 und 2. Dargestellt ist die Proteinexpression nach dem IRS in Abhängigkeit von den beobachteten Fällen. $p=0,004868$.

1)

Histogramm

Variable: niedrige $(=0)$ und hohe $(=1)$ nukleäre Beclin-1 Expression, Gruppen: Typ 1 und 2

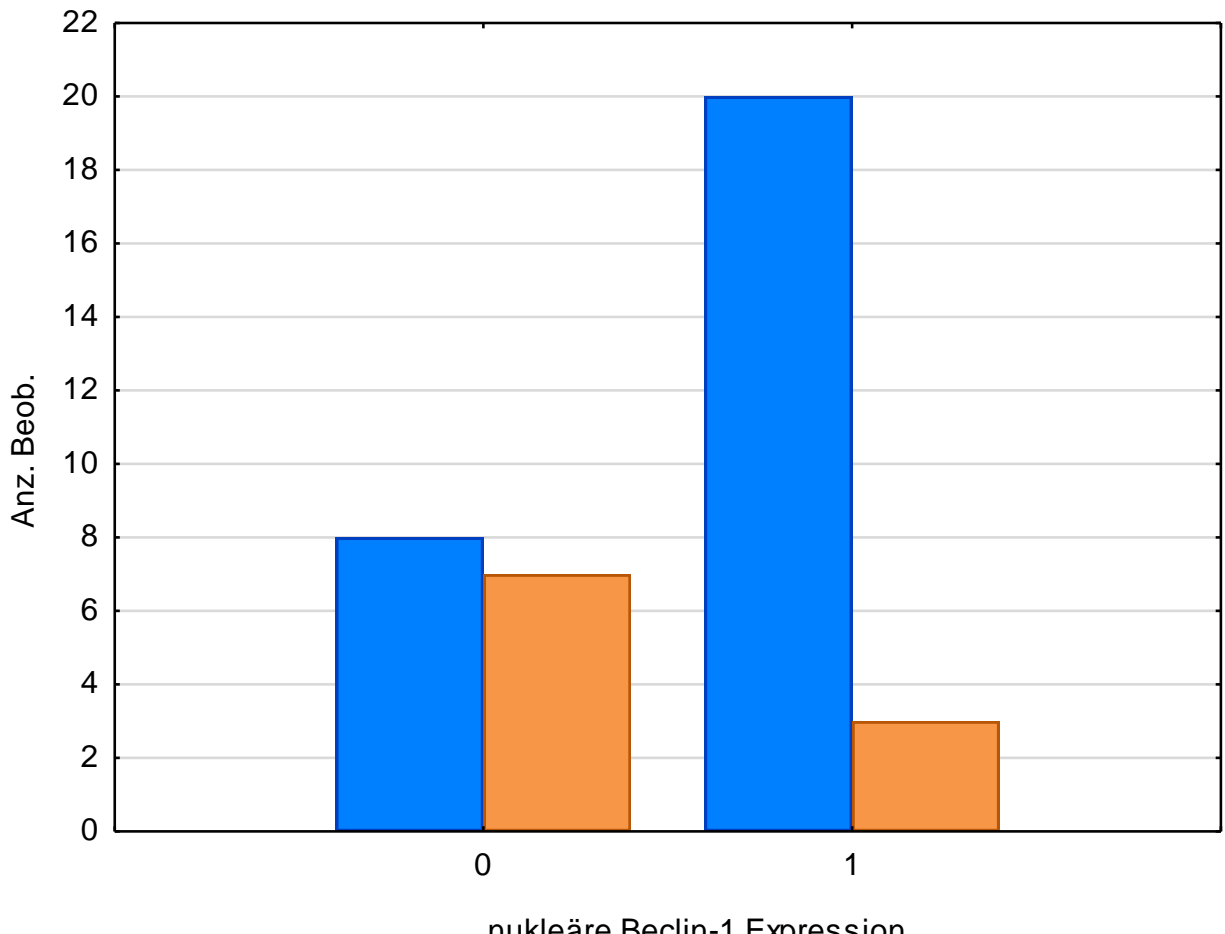

Typ: 1

nukleäre Beclin-1 Expression

Typ: 2

2)

Histogramm

Variable: Beclin-1 nukleär nach dem IRS

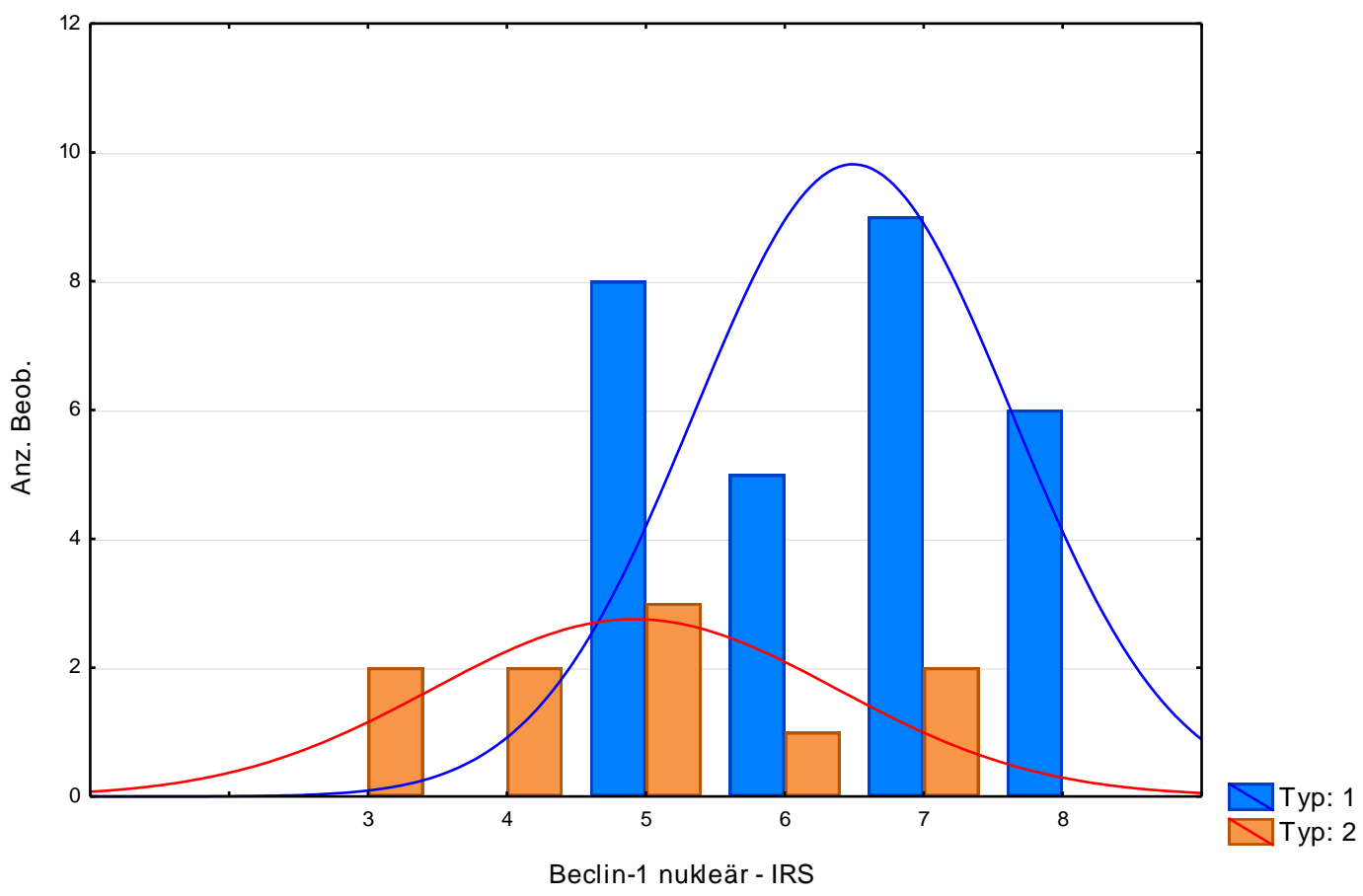


Abbildung 8: Korrelationsanalyse (Histogramm und Bubble-Plot) der nukleären Beclin-1-Expression nach dem IRS und dem T-Stadium $\left(1-4=p T^{*}\right)$ in papillären Nierenzellkarzinomen. $p=0,001738$, Kendalls Tau= 0,354344 .

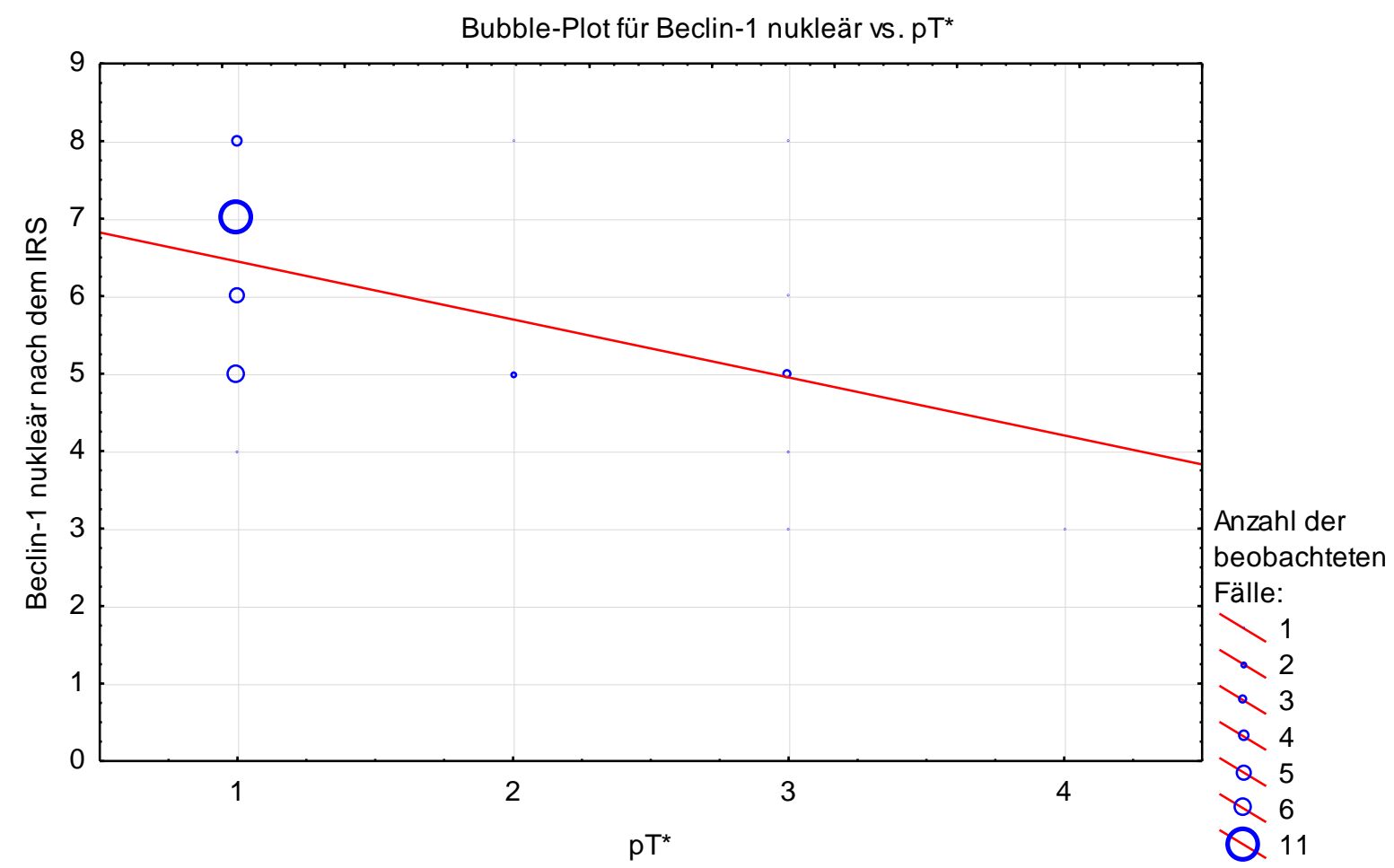

Abbildung 9: Korrelationsanalyse (Histogramm und Bubble-Plot) der nukleären Beclin-1-Expression nach dem IRS und dem Grading (1-3). $P=0,002321$, Kendalls Tau= -0,322293.

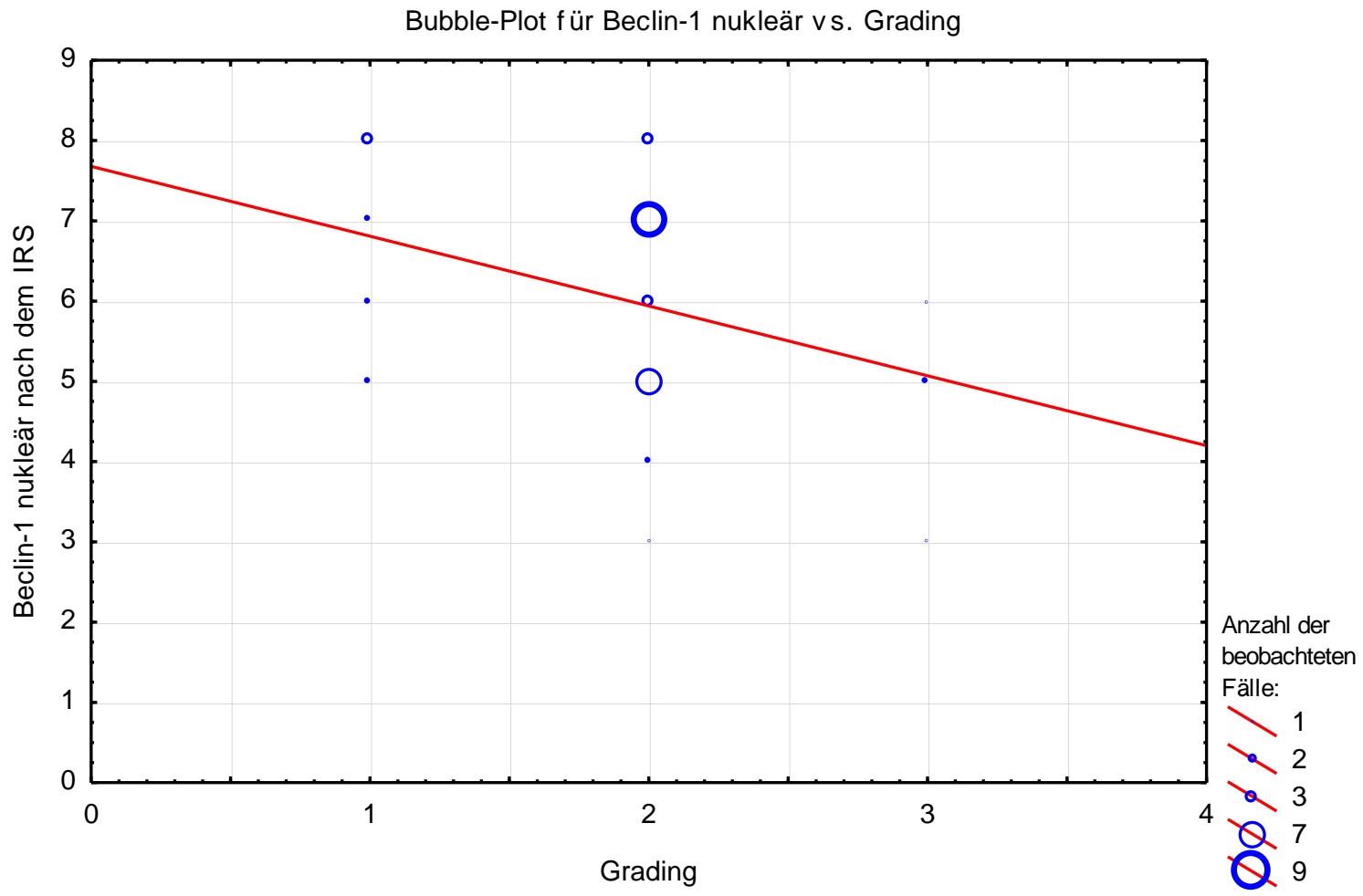




\subsubsection{Light chain 3}

Light chain 3 (LC3) oder auch Mikrotubuli-assoziiertes Protein ist ein Marker für eine anhaltende Autophagie. Es ist für die Erweiterung und für den Zusammenschluss der Doppelmembran zum Autophagosom verantwortlich und befindet sich unter mangelnder Nährstoffversorgung jeweils an der inneren und äußeren Membran. Bei aktiven Umbauprozessen im Inneren des Autophagosoms ist LC3 der inneren Membran als Marker vermehrt nachweisbar. Unter pathologischen Bedingungen wie bei der Tumorentstehung wird eine zytoprotektive Wirkung von LC3 vermutet.

Nach immunhistochemischer Anfärbung sowie mikroskopischer Begutachtung mittels IRS konnte eine erhöhte Expression von LC3 in papillären Nierenzellkarzinomen Typ 1 sowie Typ 2 aufgezeigt werden (Abbildung 10). Der mediane IRS betrug 8. Bei der Unterteilung in Typ 1 und 2 zeigte sich kein signifikanter Unterschied der Expression ( $p=0,486381)$.

Ebenfalls ergaben unsere Berechnungen keine ausreichende Evidenz für eine negative Korrelation zwischen LC3 und Höhe des T-Stadiums ( $p=0,425967$, Kendalls Tau $=-0,090078)$. Im Zusammenhang mit einem Lymphknotenbefall stellte sich eine nicht signifikante positive Korrelation $(p=0,323875$, Kendalls Tau= 0,111623), mit Auftreten von Metastasen eine nicht signifikante negative Korrelation $(p=0,333538$, Kendalls Tau= -0,109415) und mit dem Grading eine nicht signifikante positive Korrelation heraus $(p=0,228707$, Kendalls Tau= 0,136195). 
Abbildung 10: 1) Balkendiagramm: LC3 in papillären Nierenzellkarzinomen. Dargestellt ist die Proteinexpression nach dem IRS in Abhängigkeit von der beobachteten Anzahl. 2) Ausschnitte aus den Schnittpräparaten: LC3-Anfärbung, 20fache Vergrößerung, papilläres Nierenzellkarzinom Typ 1 und 2

1)

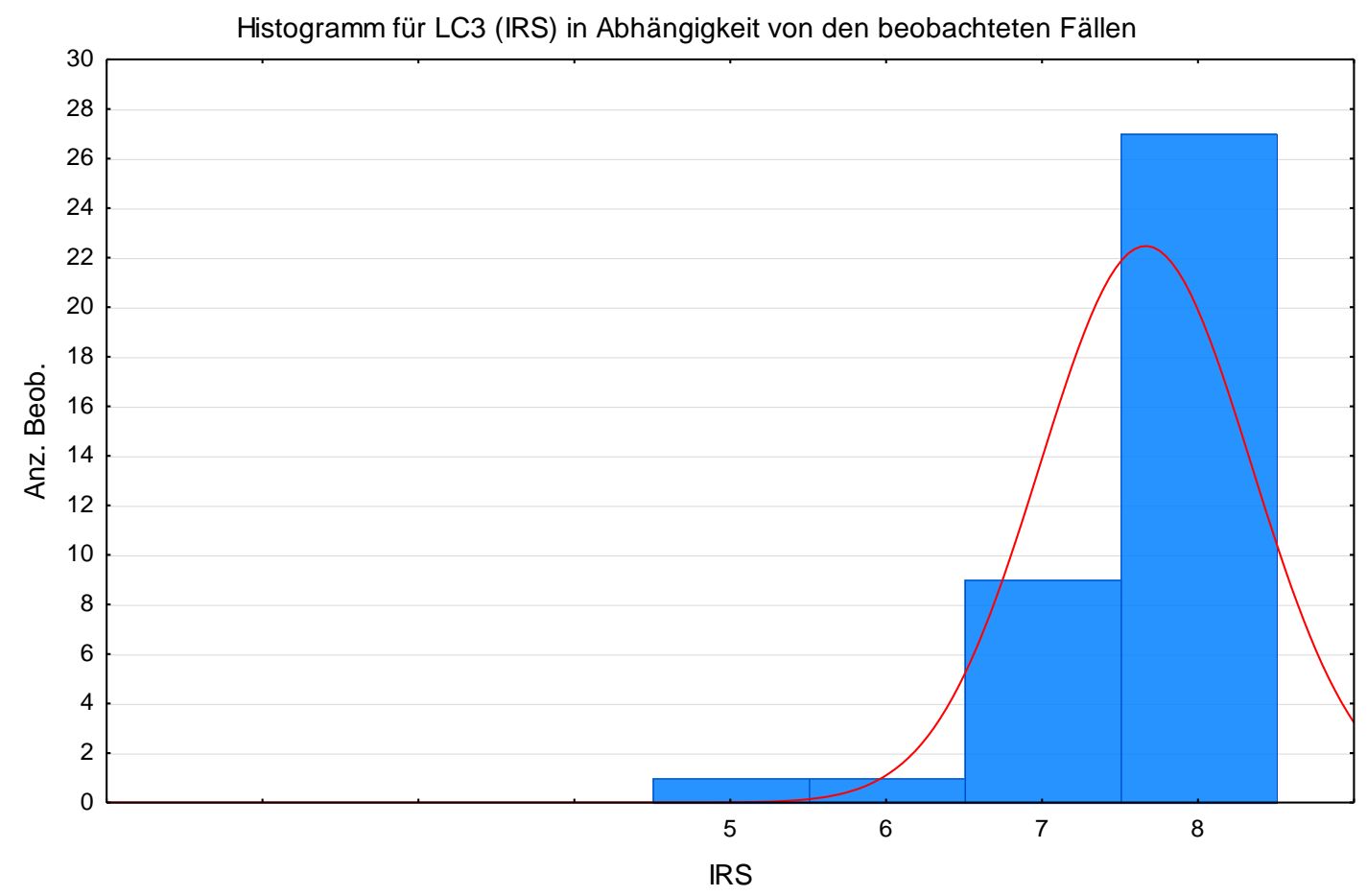


2)

Typ 1

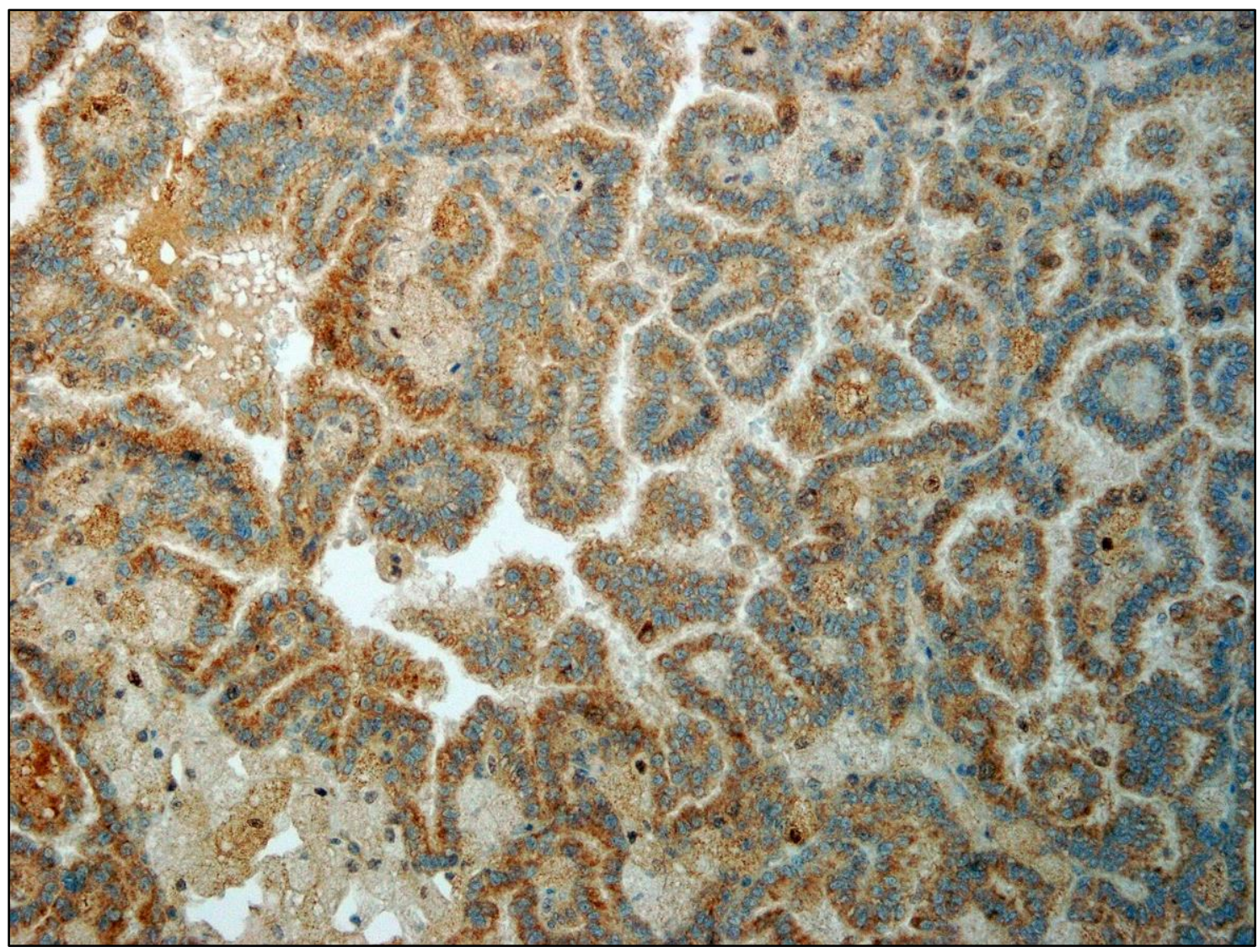

Typ 2

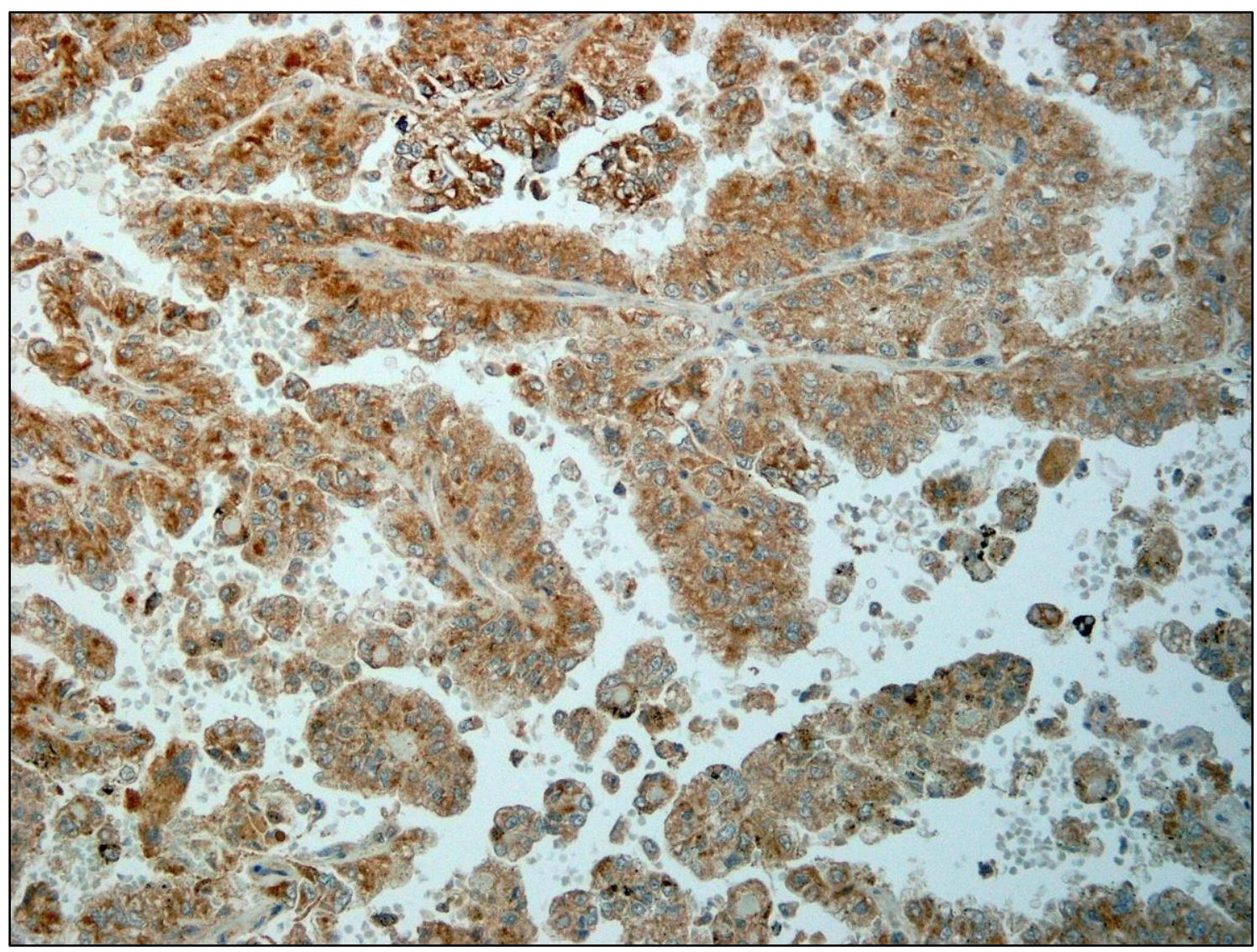




\subsection{4 p62}

Das Rezeptorprotein p62 tritt nukleär und zytoplasmatisch auf. Als ZellgerüstProtein (zytoplasmatisch) stellt es die Verbindung zwischen den abzubauenden Proteinen aus dem Zytosol und dem Autophagosom her. Nachdem es sich an LC3 der äußeren Membran des Autophagosoms gebunden hat, kommt es zu einem Verschmelzen mit der lysosomalen Membran. Nach Entkopplung steht p62 im Zytosol erneut zur Verfügung. Als Zellkern-Protein (nukleär) ermöglicht es den Transport von nukleären Proteinen zum zytoplasmatischen p62. Je mehr beschädigte Proteine abzubauen sind, desto mehr p62 kann nachgewiesen werden. Es kann somit als Marker für eine zytoprotektive Autophagie und deren Aktivität in Tumorzellen herangezogen werden. In unserer Arbeit haben wir in papillären Nierenzellkarzinomen sowohl eine nukleäre als auch zytoplasmatische Expression beobachtet und diese mittels IRS mikroskopisch beurteilt. Es zeigte sich für p62 sowohl zytoplasmatisch als auch nukleär ein medianer IRS von 7 . Abbildung 11 stellt die Häufigkeit in Abhängigkeit vom IRS dar.

Abbildung 11: Balkendiagramm: p62-Expression in papillären Nierenzellkarzinomen. Dargestellt ist die Proteinexpression nach dem IRS in Abhängigkeit von den beobachteten Fällen.

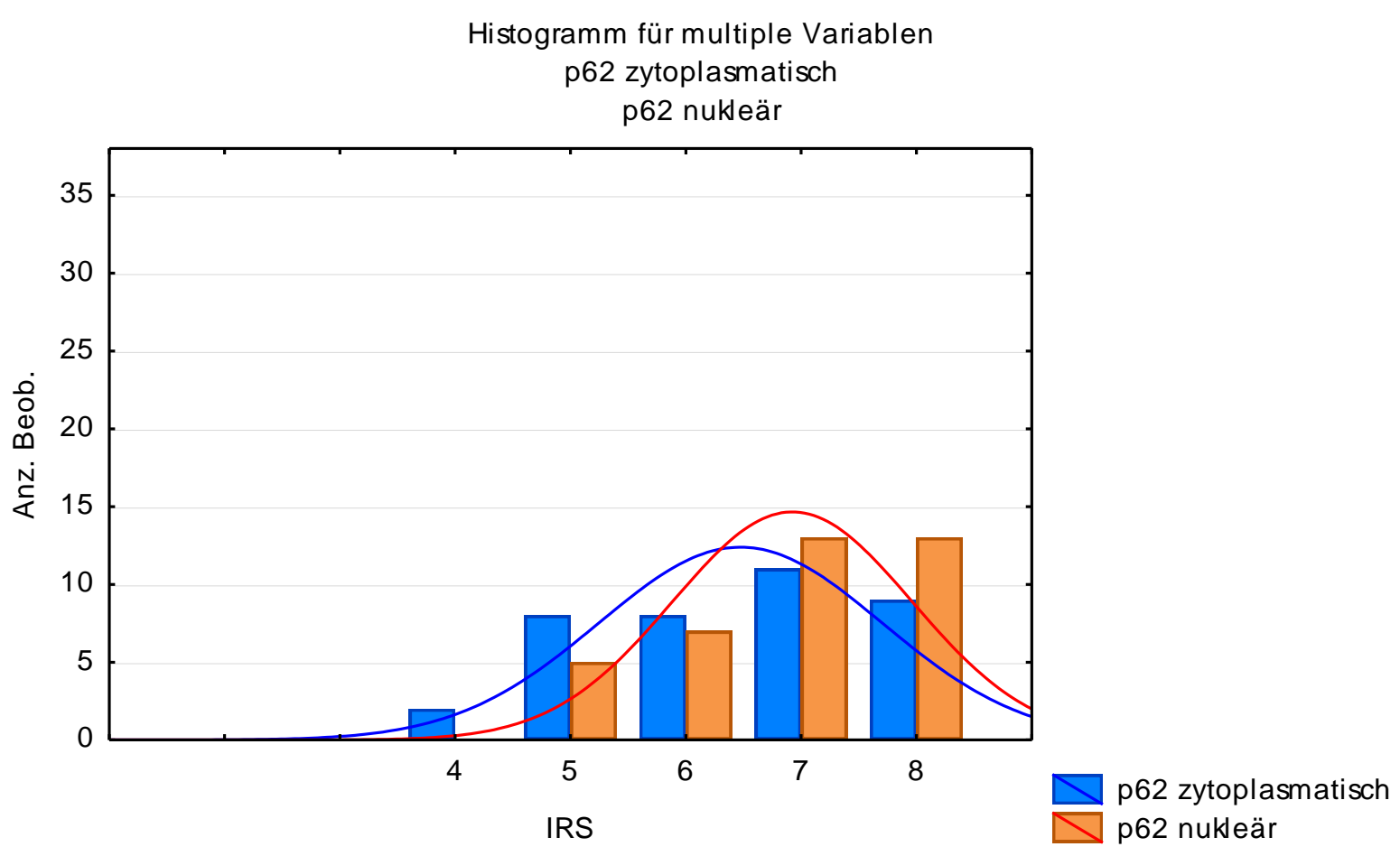


Abbildung 12 zeigt mittels Balkendiagramm sowie fotographisch den signifikanten Unterschied zwischen den Subtypen bei der zytoplasmatischen und der nukleären Expression von p62. Es konnte ein signifikanter Unterschied bei der zytoplasmatischen Expression zugunsten von Typ $2(p=0,048455)$ und bei der nukleären Expression zugunsten von Typ 1 festgestellt werden $(p=0,001358)$. Darüber hinaus zeigte sich eine signifikante negative Korrelation zwischen der Höhe des T-Stadiums und der nukleären p62 Expression $(p=0,003030$, Kendalls Tau= -0,335442), jedoch konnte keine ausreichende Evidenz in der positiven Korrelationsanalyse der zytoplasmatische Expression und der Tumorgröße festgestellt werden $(p=0,080300$, Kendalls Tau=0,197889). Das $p M-S t a d i u m$ wies ein signifikante positive Korrelation zur zytoplasmatischen Expression und eine negative Korrelation zur nukleären Expression von p62 auf (zytoplasmatisch: $p=$ 0,048127, Kendalls Tau= 0,223607, nukleär: $p=0,002167$, Kendalls Tau= 0,346944).

In Bezug auf das Grading stellte sich eine signifikant positive Korrelation zur zytoplasmatischen p62-Expression ( $p=0,000280$, Kendalls Tau= 0,411072) und eine signifikant negative Korrelation zur nukleären p62-Expression heraus $(p=$ 0,000165, Kendalls Tau= -0,426324, Abbildung 13).

Abbildung 12: 1) Balkendiagramm: niedrige $(=0)$ und hohe $(=1)$ zytoplasmatische (a) und nukleäre (b) p62Expression nach dem IRS in papillären Nierenzellkarzinomen Typ 1 und 2. 2) Ausschnitte aus den Schnittpräparaten: p62-Färbung, 20fache Vergrößerung, papilläres Nierenzellkarzinom Typ 1 und 2.

1a)

Histogramm

Variable: niedrige $(=0)$ und hohe $(=1)$ zytoplasmatische p62-Expression, Gruppen: Typ 1 und 2

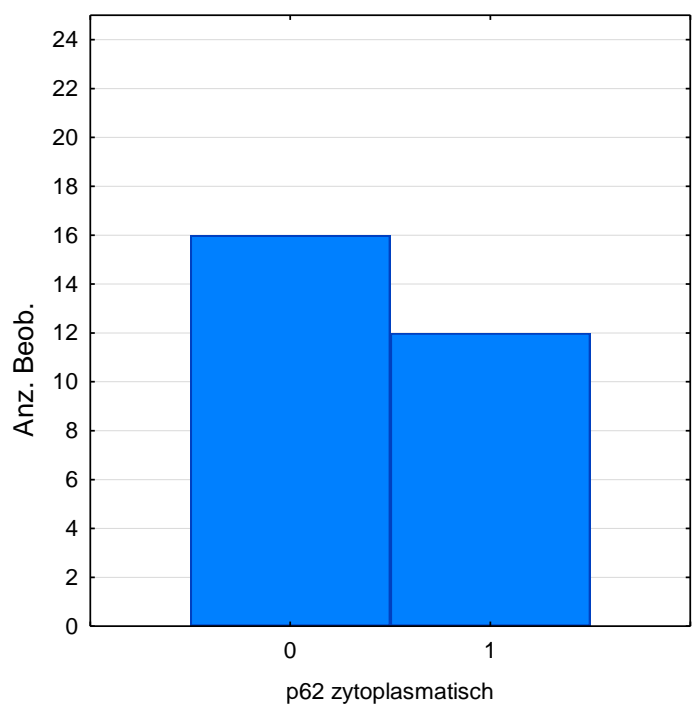

Typ: 1

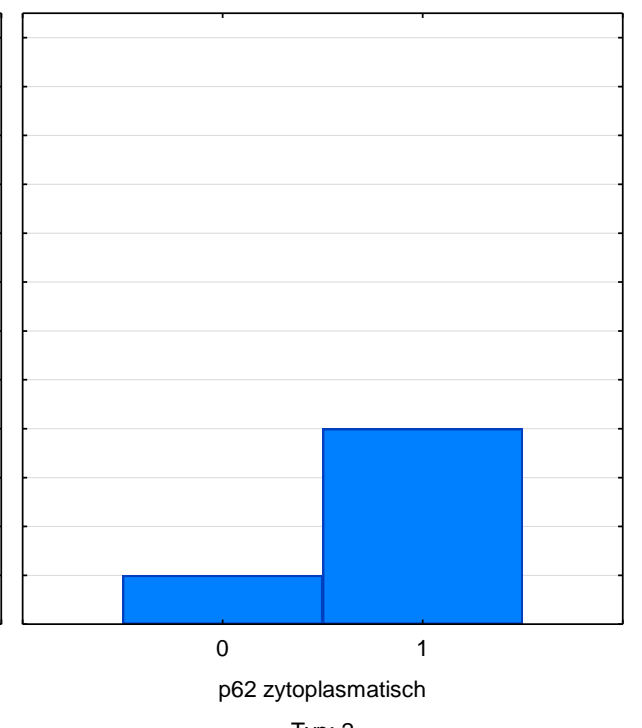

Typ: 2 
1b)

Histogramm

Variable: niedrige $(=0)$ und hohe $(=1)$ nukleäre p62-Expression, Gruppen: Typ 1 und 2

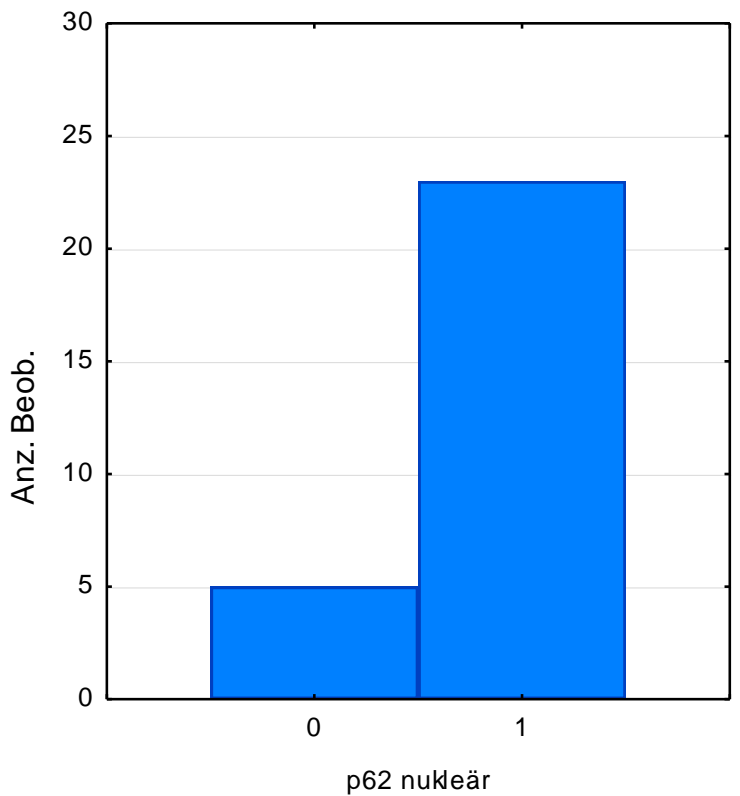

Typ: 1

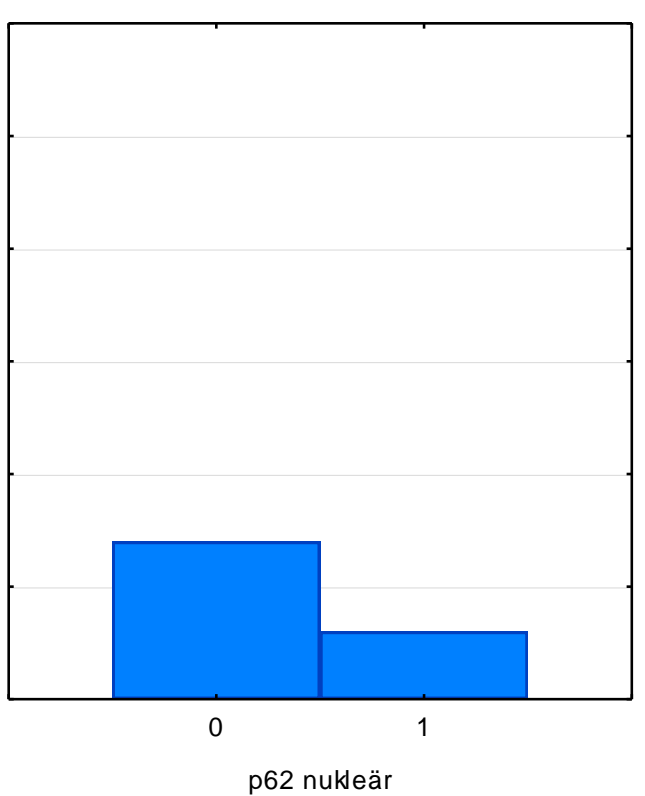

Typ: 2

2) Legende: $\quad \longrightarrow$ : zytoplasmatisch e Anfärbung $\quad \longrightarrow$ : nukleäre Anfärbung Typ 1

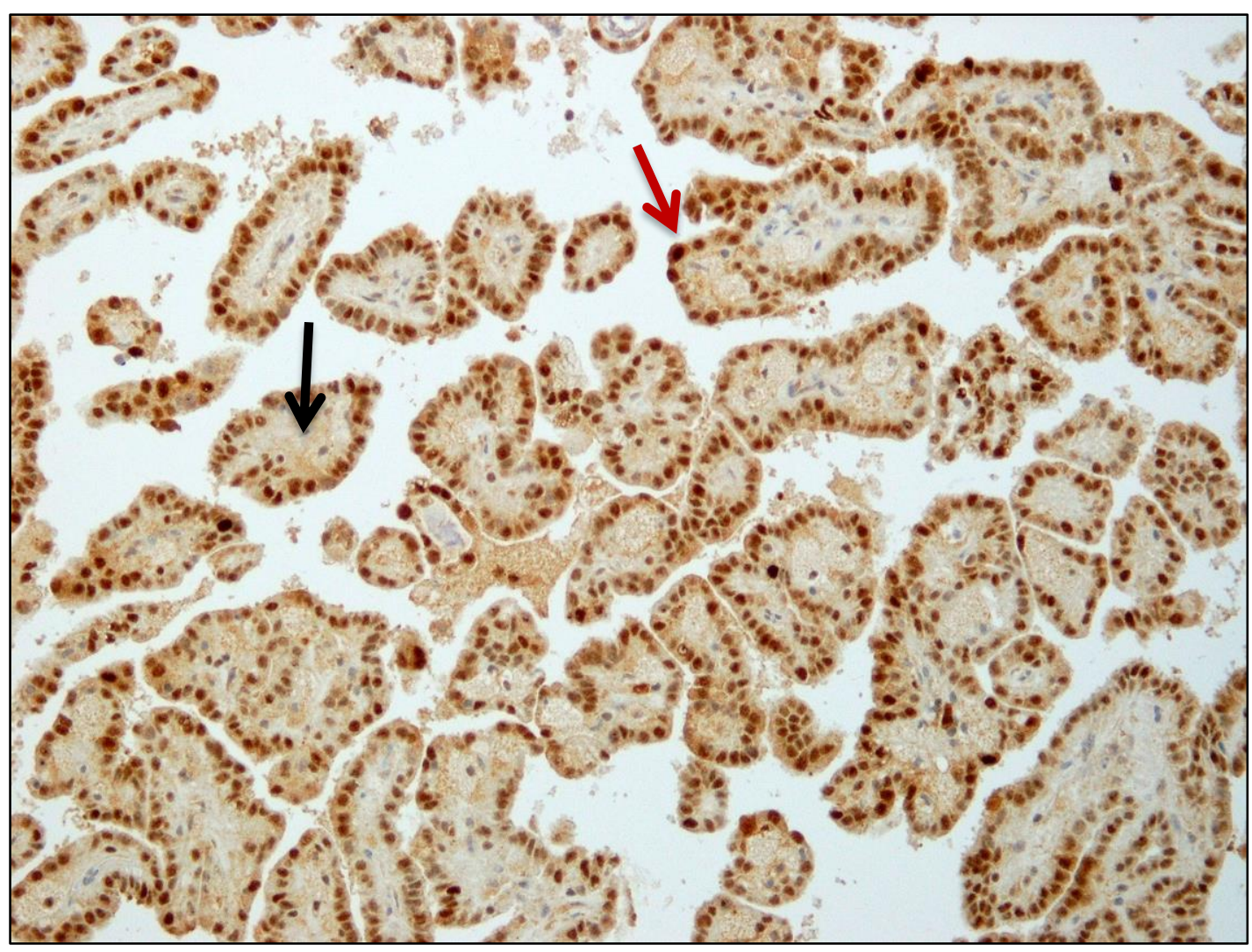


Typ 2

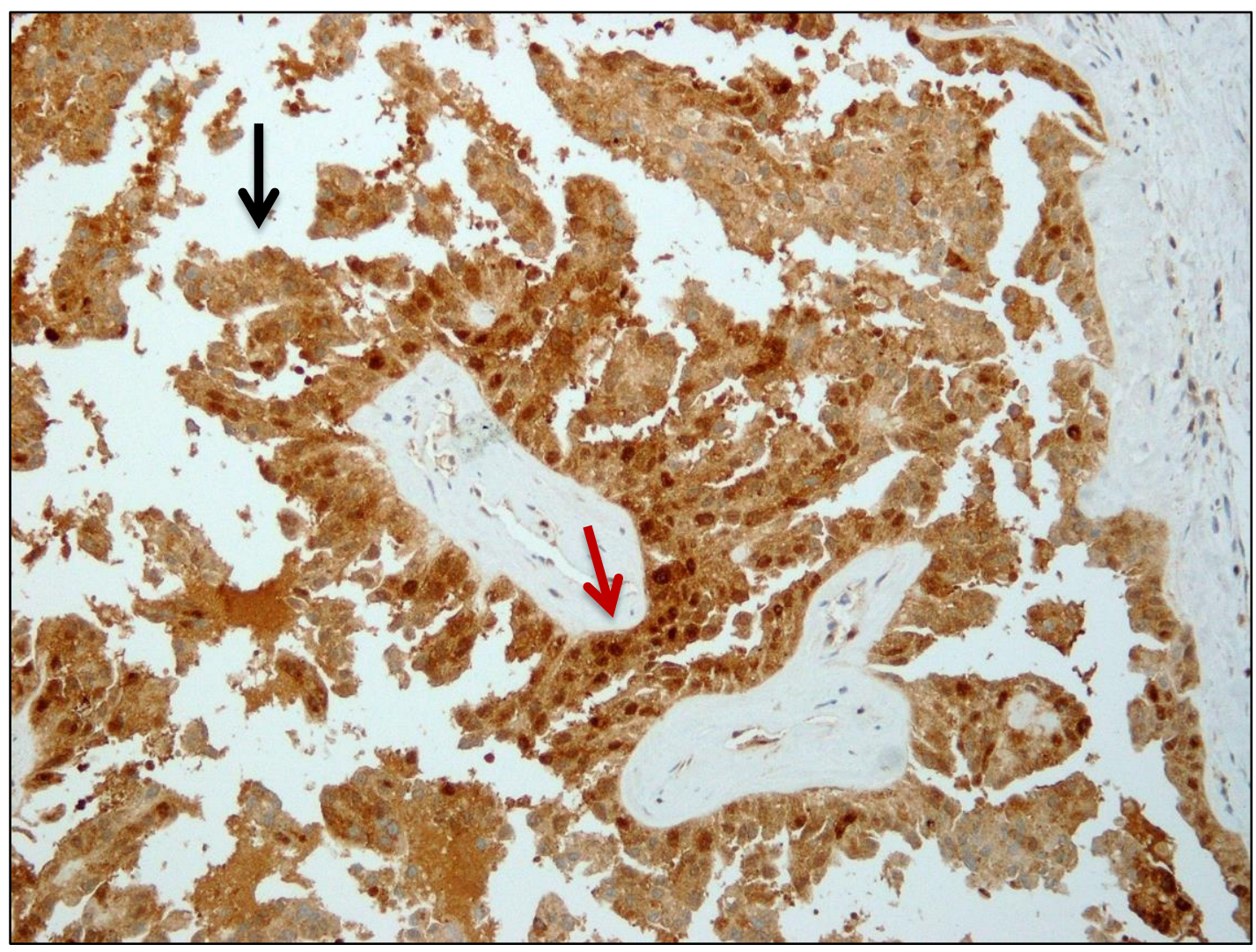

Abbildung 13: Scatterplot: Korrelationsanalyse der zytoplasmatischen und nukleären p62-Expression und Grading in papillären Nierenzellkarzinomen. Zytoplasmatisch: $p=0,000280$, Kendalls Tau=0,411072. Nukleär: $p=0,000165$, Kendalls Tau $=-0,426324$.

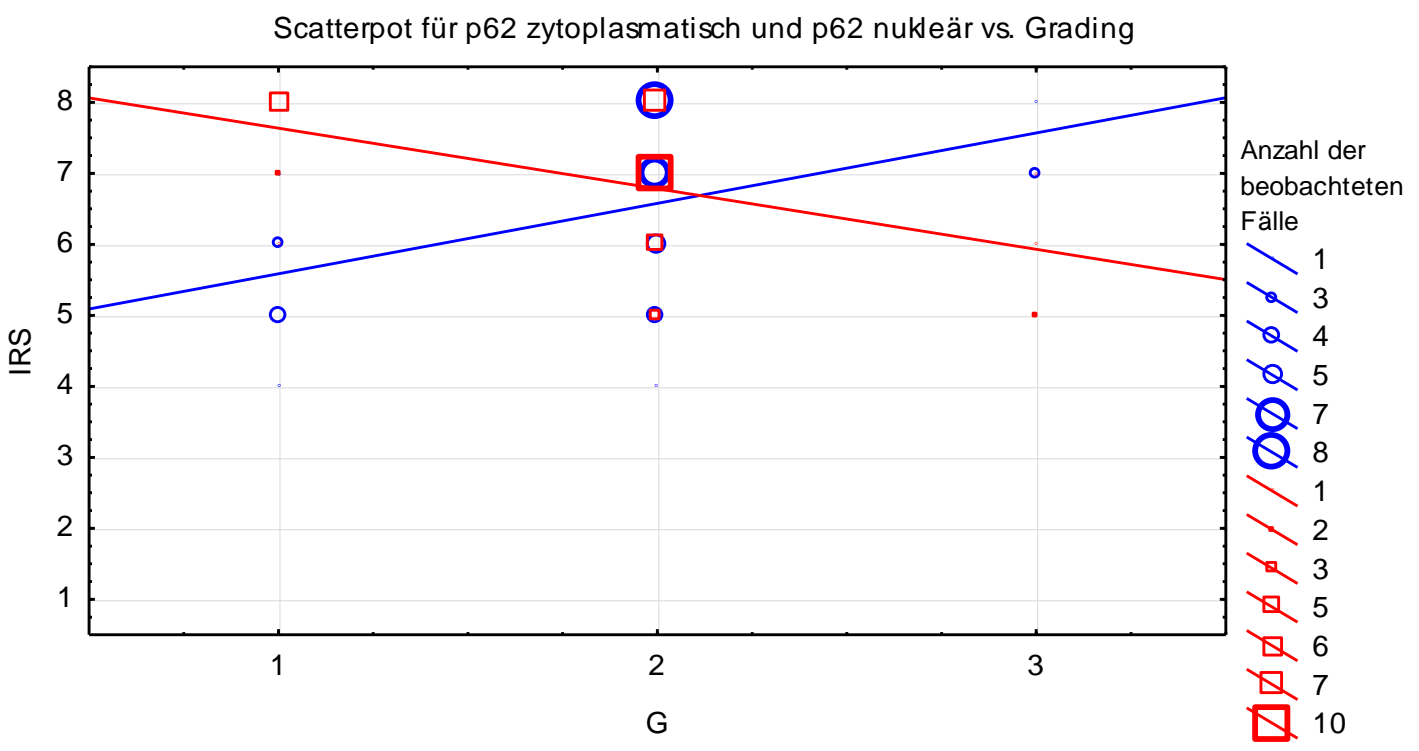




\subsection{Gesamtüberleben und remissionsfreies Überleben vom papillären Nierenzellkarzinom}

Anhand der folgenden Kaplan-Meier-Kurven wurden unter anderem die mediane Überlebenszeit sowie die 3-Jahres-Überlebensrate berechnet und abgelesen (Abbildung 14). In Tabelle 8 erkennt man den Anteil der vollständigen Fälle, bei denen der Tod oder ein Rezidiv eingetreten ist, und zensierten Fälle, bei denen der letzte Patientenkontakt festgehalten wurde, in den jeweiligen TNM-Stadien und Grading.

Tabelle 8: Anzahl und Prozentanteil der vollständigen (mit Eintritt des Todes oder eines Rezidivs) und zensierten (letzter Patientenkontakt) Überlebenszeiten in Bezug auf das TNM-Stadium und Grading im OS und DFS.

\begin{tabular}{l|l|l|l|l|l|l}
$\begin{array}{l}\text { TNM- } \\
\text { Stadium }\end{array}$ & $\begin{array}{l}\text { OS } \\
\text { vollständig }\end{array}$ & $\begin{array}{l}\text { OS } \\
\text { zensiert }\end{array}$ & $\begin{array}{l}\text { OS } \\
\text { Prozent \% } \\
\text { vollständig }\end{array}$ & $\begin{array}{l}\text { DFS } \\
\text { vollständig }\end{array}$ & $\begin{array}{l}\text { DFS } \\
\text { zensiert }\end{array}$ & $\begin{array}{l}\text { DFS } \\
\text { Prozent \% } \\
\text { vollständig }\end{array}$ \\
\hline pT1 & 19 & 8 & 70,4 & 2 & 25 & 7,4 \\
pT2 & 3 & 0 & 100 & 0 & 3 & 0 \\
pT3 & 7 & 0 & 100 & 3 & 4 & 42,9 \\
pT4 & 1 & 0 & 100 & 1 & 0 & 100 \\
pN0 & 24 & 8 & 75 & 2 & 30 & 6,3 \\
pN+ & 6 & 0 & 100 & 4 & 2 & 66,7 \\
pM 0 & 28 & 8 & 77,8 & 5 & 31 & 13,9 \\
pM 1 & 2 & 0 & 100 & 1 & 1 & 50 \\
G1 & 9 & 0 & 33 & 1 & 8 & 11,1 \\
G2 & 17 & 8 & 68 & 3 & 22 & 12 \\
G3 & 4 & 0 & 100 & 2 & 2 & 50
\end{tabular}

Wir konnten eine mediane Gesamtüberlebenszeit von 17,5 Monaten und eine 3Jahres-Überlebensrate von ca. $25 \%$ feststellen. Innerhalb von 24 Monaten war in ca. 30 \% der Fälle ein Rezidiv zu erwarten (Abbildung 14a).

Tabelle 9 und 10 geben die maximale sowie die mediane gesamte und remissionsfreie Überlebenszeit in Abhängigkeit von T-Stadium und Grading wieder. 
Tabelle 9: Maximales und medianes OS in Abhängigkeit von T-Stadium und Grading.

\begin{tabular}{l|l|l} 
T-Stadium und Grading & Maximales OS & Medianes OS \\
\hline pT1 & 62 Monate & 14 Monate \\
pT2 & 85 Monate & 39 Monate \\
pT3 & 41 Monate & 9,5 Monate \\
pT4 & 43 Monate & 4 Monate \\
\hline G1 & 47 Monate & 0,53 Monate \\
G2 & 85 Monate & 15 Monate \\
G3 & 38 Monate & 16 Monate
\end{tabular}

Tabelle 10: Maximales und medianes DFS in Abhängigkeit von T-Stadium und Grading.

\begin{tabular}{l|l|l} 
T-Stadium und Grading & Maximales DFS & Medianes DFS \\
\hline pT1 & 62 Monate & 13 Monate \\
pT2 & 85 Monate & 39 Monate \\
pT3 & 28 Monate & 9,5 Monate \\
pT4 & 27 Monate & 4 Monate \\
\hline G1 & 35 Monate & 0,53 Monate \\
G2 & 85 Monate & 14,5 Monate \\
G3 & 28 Monate & 16 Monate
\end{tabular}

Das Signifikanzniveau konnte in der Überlebensrate innerhalb der T-Stadien nicht erreicht werden. Wir konnten den größten Überlebensanteil im Stadium 1-3 feststellen. Stadium 2 hatte ein Gesamtüberleben von 7,07 Jahren (= circa 85 Monate) und eine 3-Jahres-Überlebensrate von ca. 68\%. Stadium 1, welches den größten Anteil unseres Patientenkollektives ausmachte, wies mit einem $70 \%$ igen unzensierten Anteil eine mediane Überlebenszeit von ca. 1,7 Jahren auf (Abbildung 14b, Tabelle 8-10). Tumoren im T-Stadium 2 und G2 zeigten das längste Gesamt- und remissionsfreie Überleben (Tabelle 9 und 10).

Die Patienten, bei denen bei Erstdiagnose Lymphknotenmetastasen auftraten (zusammengefasst als $\mathrm{pN}+$ ), hatten eine Gesamtüberlebenszeit von 5,07 Jahren und eine remissionsfreie Überlebenszeit von 3,1 Jahren. Innerhalb des Lymphknotenstadiums, pN0 und pN+ (pN1, pN2), war im Gesamtüberleben kein signifikanter Unterschied feststellbar $(p=0,59304)$. Die mediane Gesamtüberlebenszeit betrug bei pN0 19,5 Monate und bei pN+ 14,6 Monate. Im remissionsfreien Überleben konnte jedoch ein signifikanter Unterschied zwischen pN0 und $\mathrm{pN}+$ gesehen werden $(\mathrm{p}=0,00124)$. Das mediane remissionsfreie Überleben wies bei pN0 ca. 84,9 Monate und bei pN+ 15,1 Monate auf. 
Bei Auftreten von Organmetastasen stellte sich sowohl in der Gesamtüberlebenszeit $(p=0,30657)$ als auch im remissionsfreien Überleben ( $p=$ $0,44132)$ kein signifikanter Unterschied heraus. Bei Vorliegen von Metastasen betrug die vollständige Gesamtüberlebenszeit, innerhalb derer die Patienten verstorben waren, 41 Monate und die remissionsfreie Überlebenszeit, innerhalb derer ein Rezidiv aufgetreten war, 15 Monate (Abbildung 14d).

In Bezug auf das Grading des Tumors konnte ebenfalls kein signifikanter Unterschied in der Überlebenszeit festgestellt werden (OS: $p=0,08058$, DFS: $p=$ 0,29911, Abbildung 14e). Im Grading-Stadium 3 sahen wir eine maximale Gesamtund remissionsfreie Überlebenszeit von 2,3 Jahren $(=28,1$ Monate) und eine mediane Überlebenszeit von 15,7 Monaten.

Es stellte sich ein signifikanter Unterschied in der remissionsfreien Überlebenszeit zwischen hoher und niedriger Proliferationsrate heraus ( $p=0,00035)$. Im Gesamtüberleben konnte keine Signifikanz erreicht werden, es war jedoch eine kürzere Überlebenszeit in der Gruppe mit hoher Proliferation zu sehen ( $p=$ 0,95395).

Abbildung 14: Kaplan-Meier-Kurve für das OS und DFS in papillären Nierenzellkarzinomen (a), in Bezug auf das T-Stadium (b), auf Lymphknotenmetastasen (c), auf Metastasen (d) und auf das Grading (e). Vollständige Beobachtung: Eintritt des Todes oder des Rezidivs. Zensierte Beobachtung: letzter Patientenkontakt.

a)

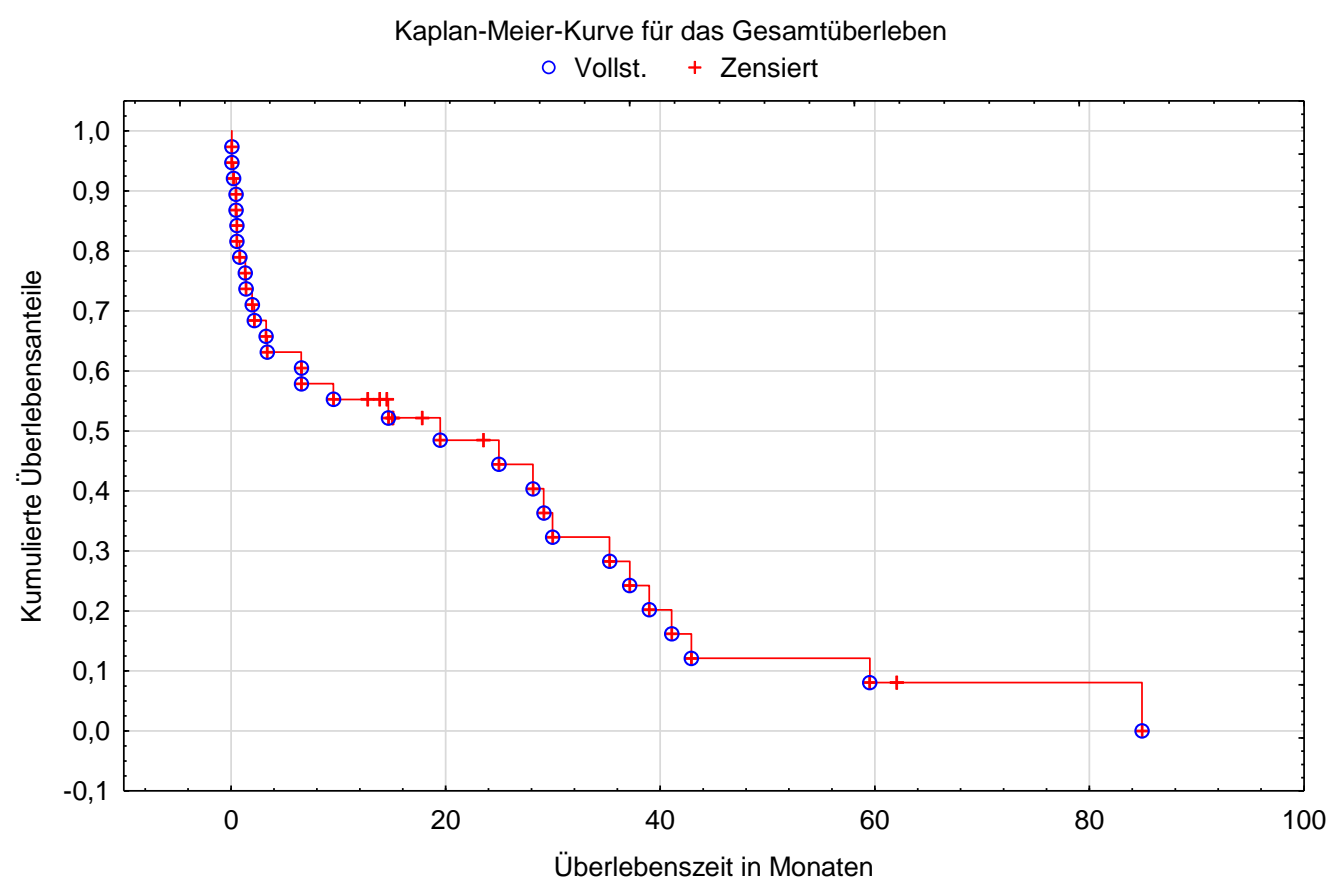


Kaplan-Meier-Kurve für das remissionsfreie Überleben

o Vollst. + Zensiert

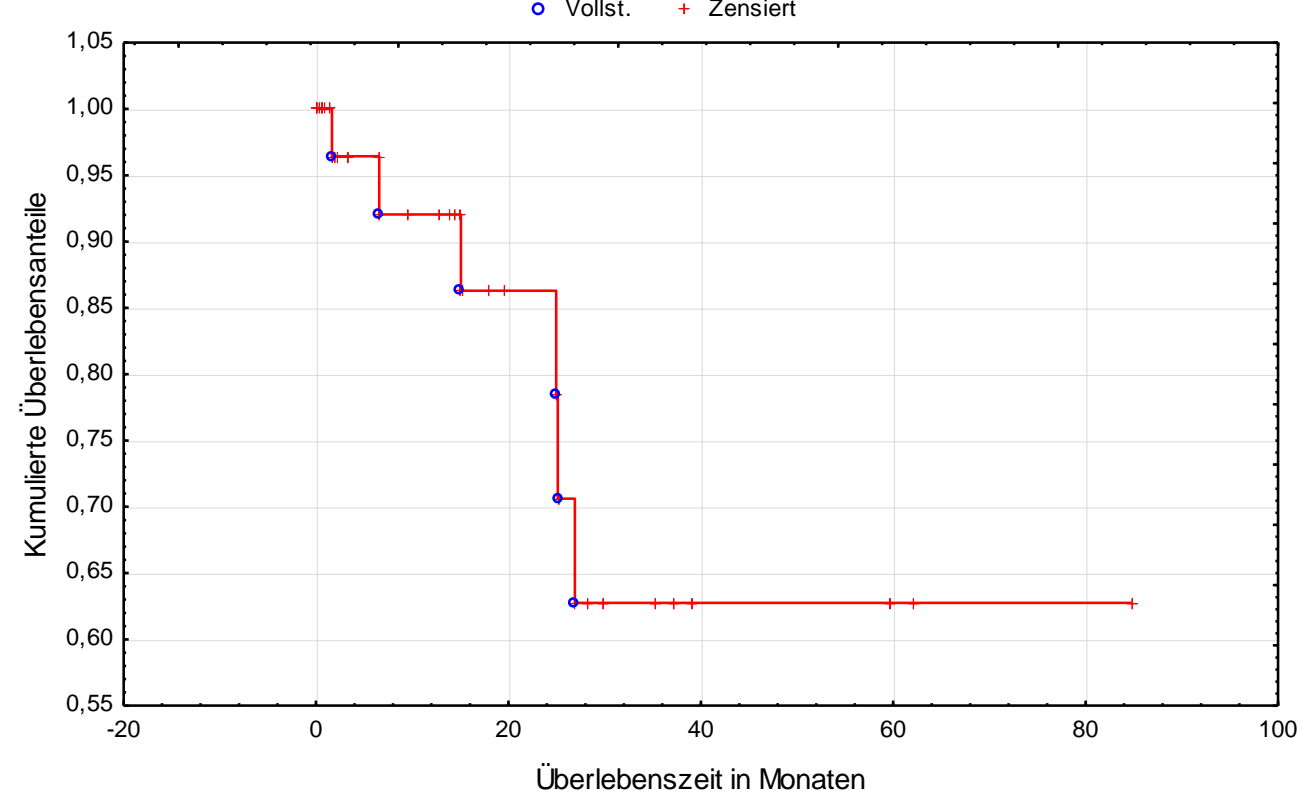

b)

Kumulierte Überlebensanteile (Kaplan-Meier) Gesamtüberlebensrate und $\mathrm{pT}^{*}$

o Vollst. + Zensiert

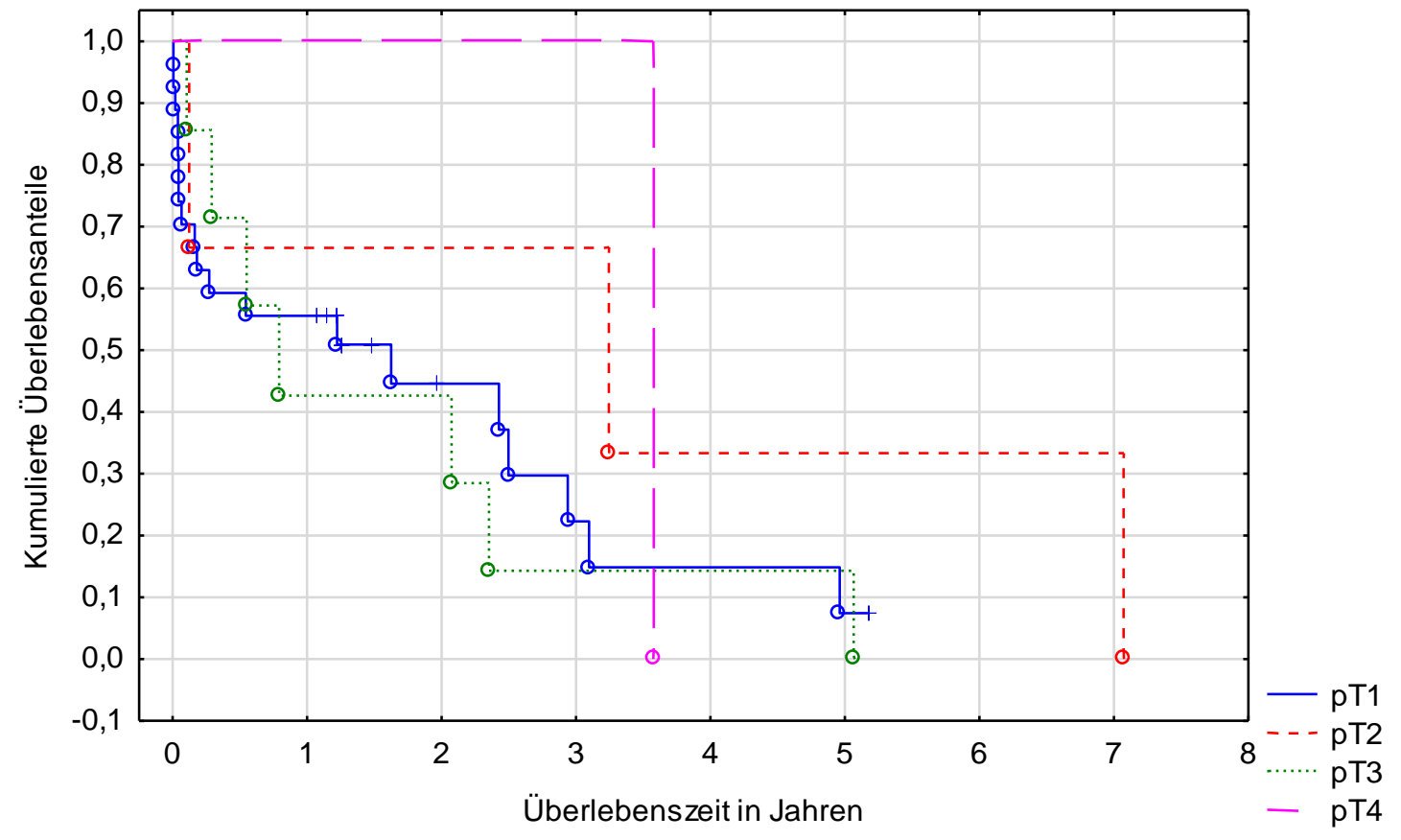




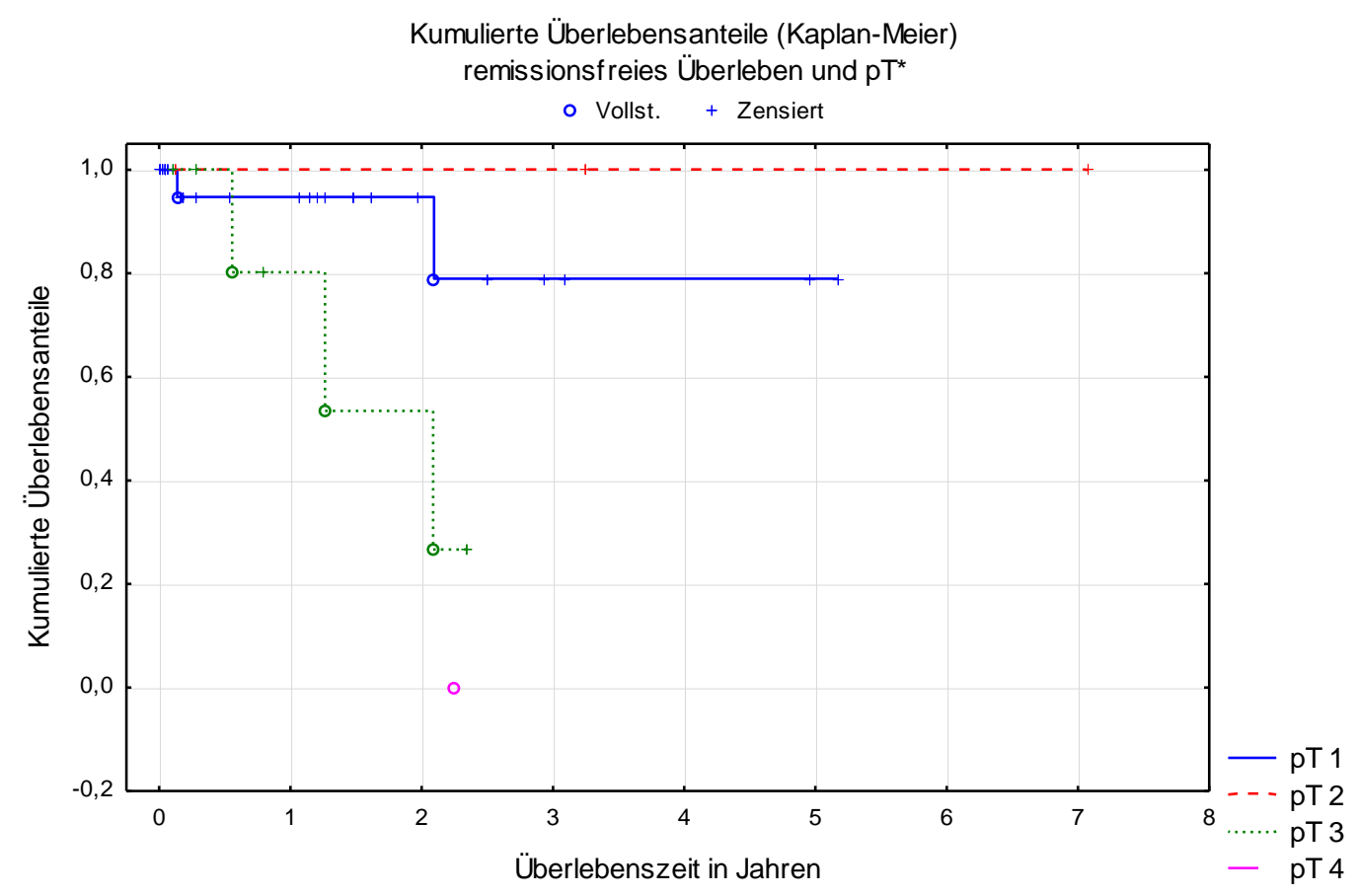

(c)

Kumulierte Überlebensanteile (Kaplan-Meier)

Gesamtüberleben und pN- Stadium ( $\mathrm{pN} 0$ und $\mathrm{pN}+(1-2)$ )

o Vollst. + Zensiert

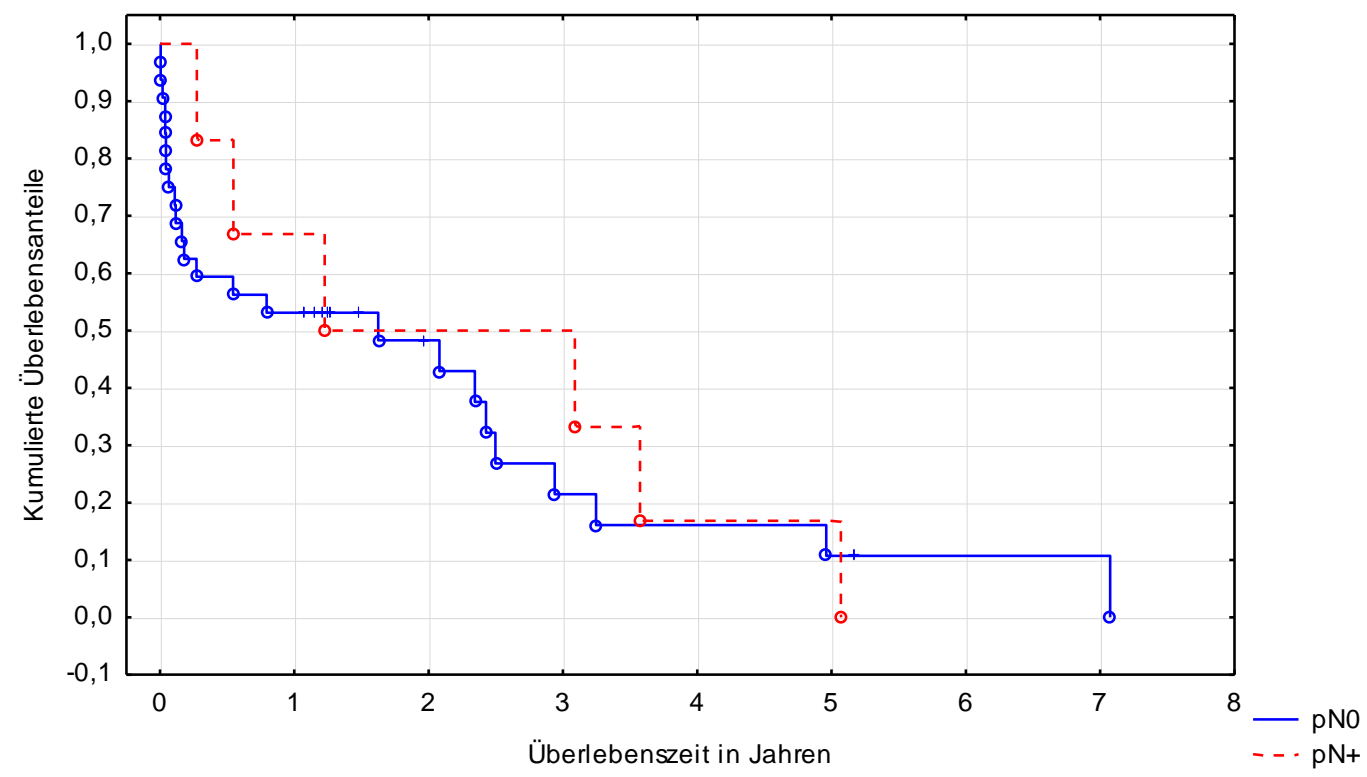


Kumulierte Überlebensanteile (Kaplan-Meier) remissionsfreies Überleben und pN-Stadium (pNO und pN+ (1-2)) o Vollst. + Zensiert

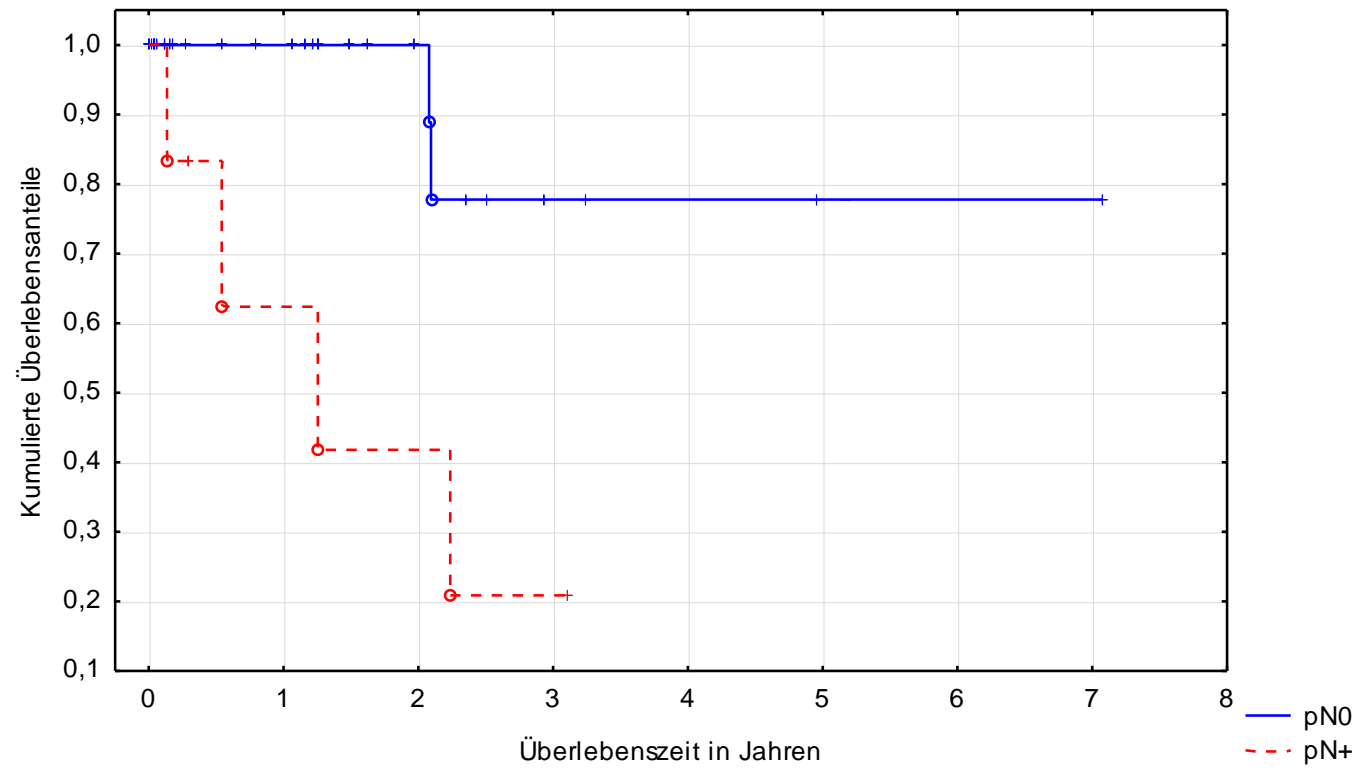

(d)

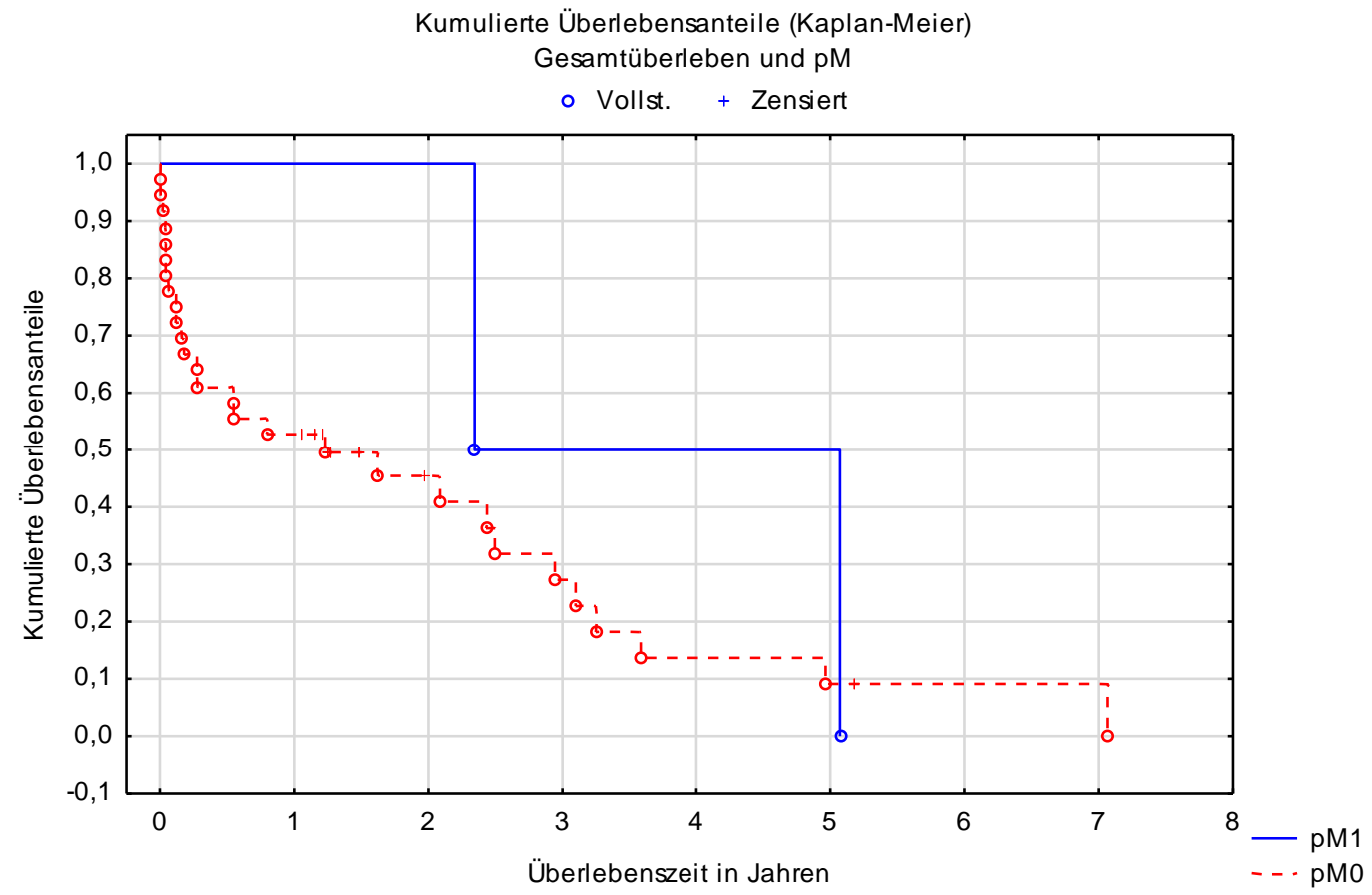


Kumulierte Überlebensanteile (Kaplan-Meier) Remissionsfreies Überleben und pM

o Vollst. + Zensiert

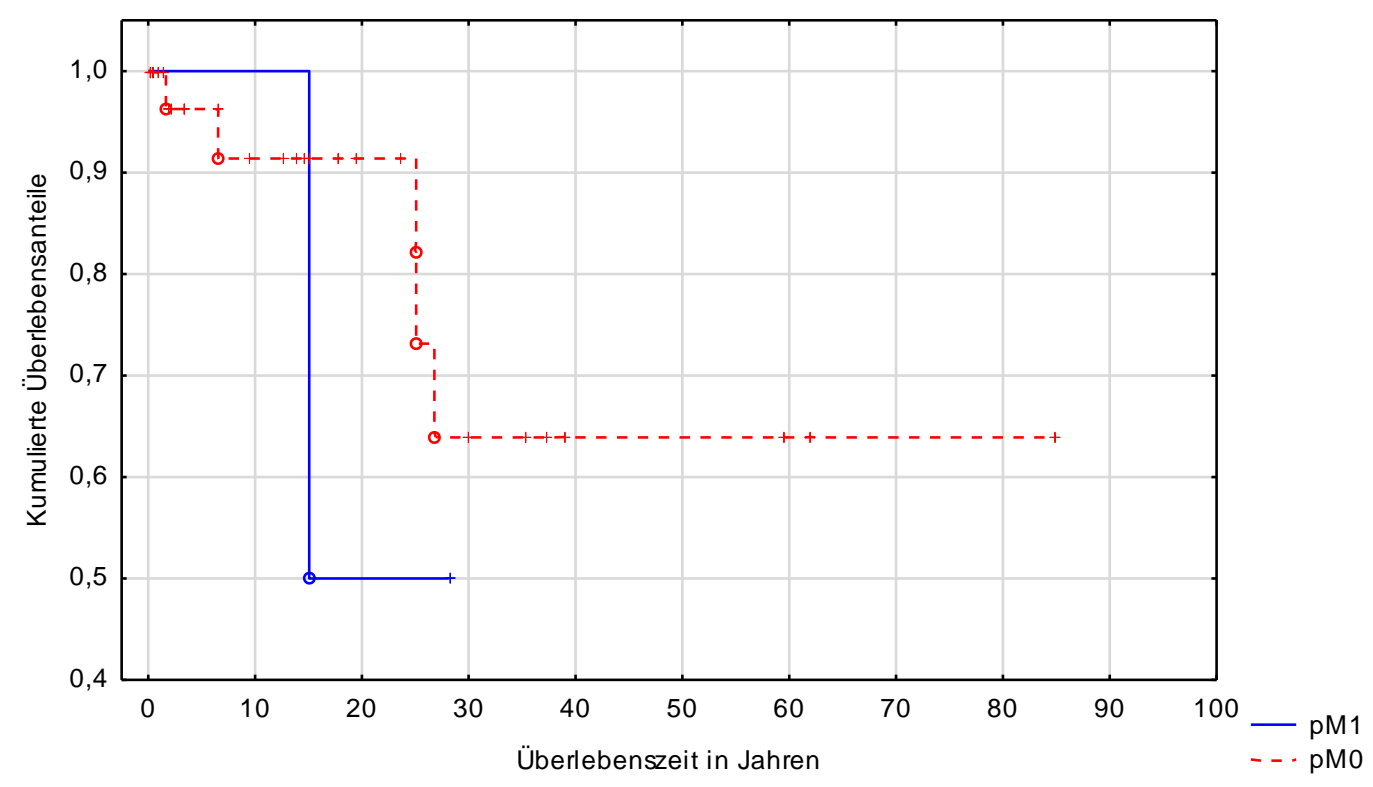

(e)

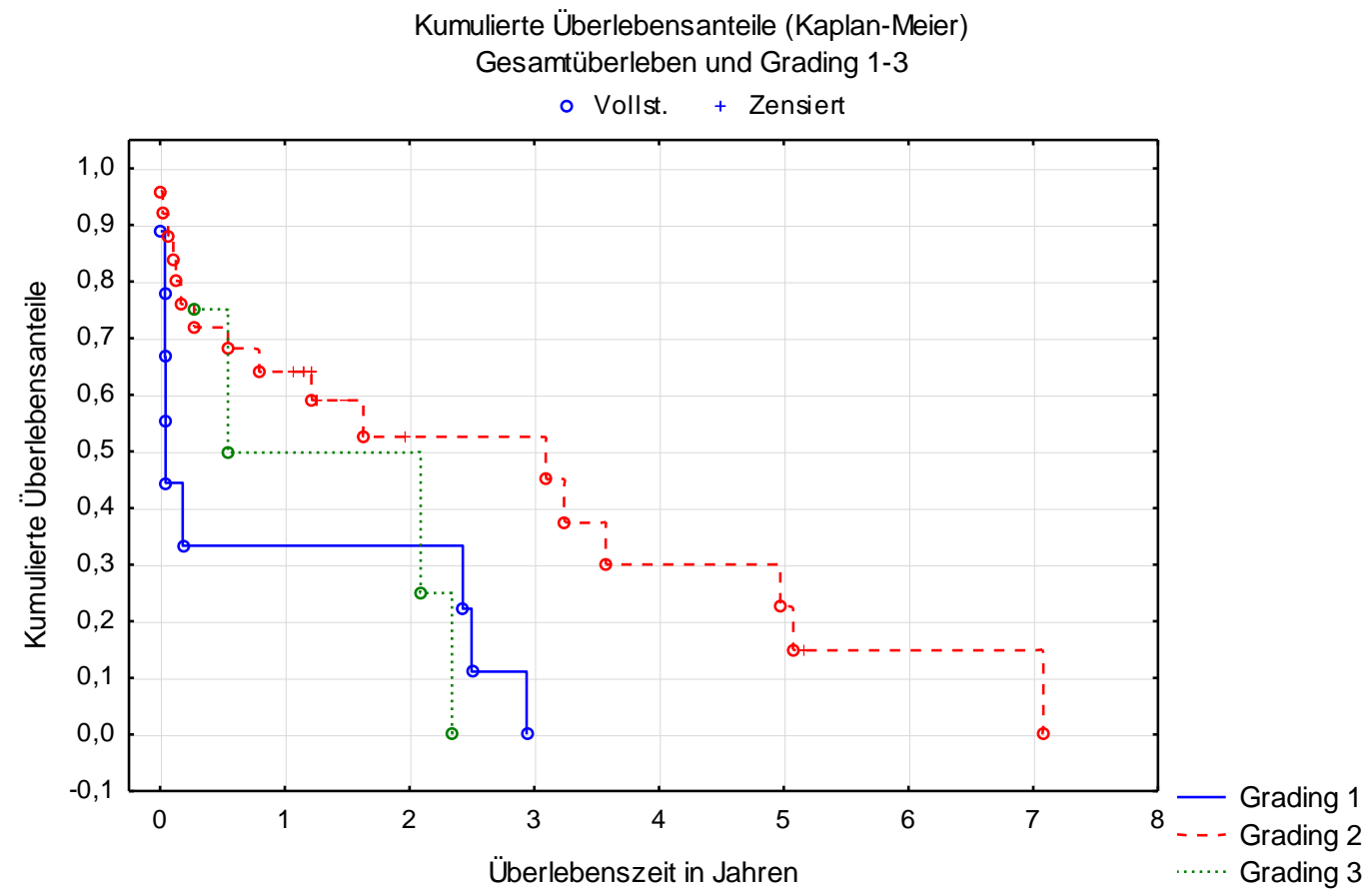


o Vollst. + Zensiert

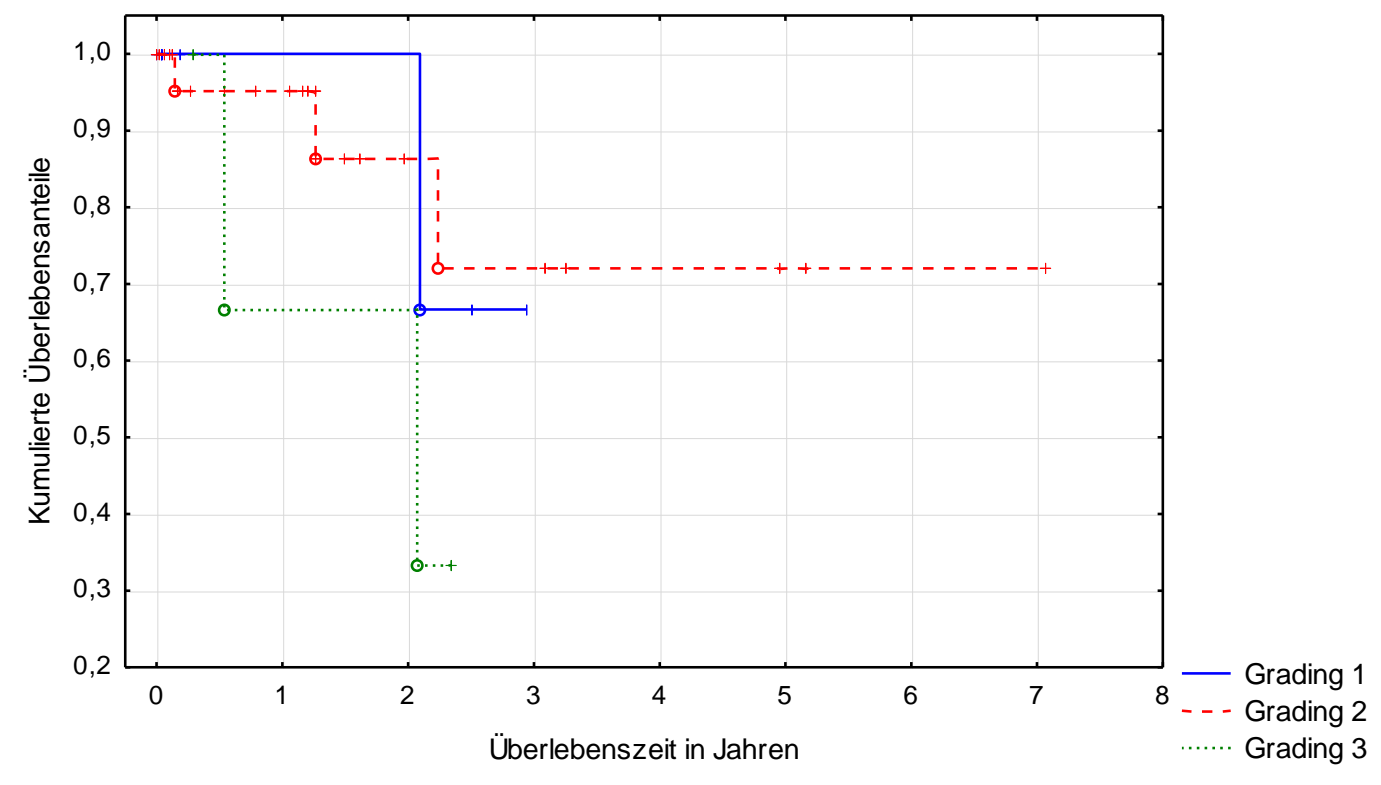

\subsection{Gesamtüberleben und remissionsfreies Überleben in Subtypen des papillären Nierenzellkarzinoms}

In Abbildung 15 wird das Gesamtüberleben und das remissionsfreie Überleben für papilläres Nierenzellkarzinom Typ 1 und 2 dargestellt. Hinsichtlich der Subtypen konnte bei Typ 1 nach 5 Jahren eine Gesamtüberlebensrate von ca. $14 \%$ und eine remissionsfreie Überlebensrate von ca. 89 \% festgestellt werden. Bei Typ 2 zeigte sich in $12 \%$ der Fälle ein Gesamt- und in $20 \%$ der Fälle ein remissionsfreies Überleben innerhalb von 5 Jahren. Ca. 89\% der Typ-1-Tumoren und ca. $20 \%$ der Typ-2-Tumoren waren über den maximalen Beobachtungszeitraum von 7,07 Jahren rezidivfrei.

In den Typ-1-Tumoren zeigte sich in unserem Patientenkollektiv eine 3-JahresGesamüberlebensrate von $30 \%$. Bei den Typ-2-Tumoren ergab die 3-JahresGesamtüberlebensrate nur ca. $26 \%$. Das mediane Gesamtüberleben betrug bei Typ 1 ca. 1,6 Jahre und bei Typ 2 ca. 1,2 Jahre. Hier konnte kein signifikanter Unterschied festgestellt werden $(p=0,90264)$. Das mediane remissionsfreie Überleben bei Typ 1 betrug ca. 7 Jahre und bei Typ 2 ca. 2 Jahre. In unserer Studienarbeit konnten wir bei Typ 2 signifikant häufiger ein Rezidiv feststellen als bei Typ $1(p=0,00123)$. 
Abbildung 15: Kaplan-Meier-Kurve: kumulierte Überlebensanteile in Abhängigkeit von der Zeit in Jahren, aufgeteilt in OS und DFS für Typ 1 und 2. Vollständige Beobachtung: Eintritt des Todes oder des Rezidivs. Zensierte Beobachtung: letzter Patientenkontakt.

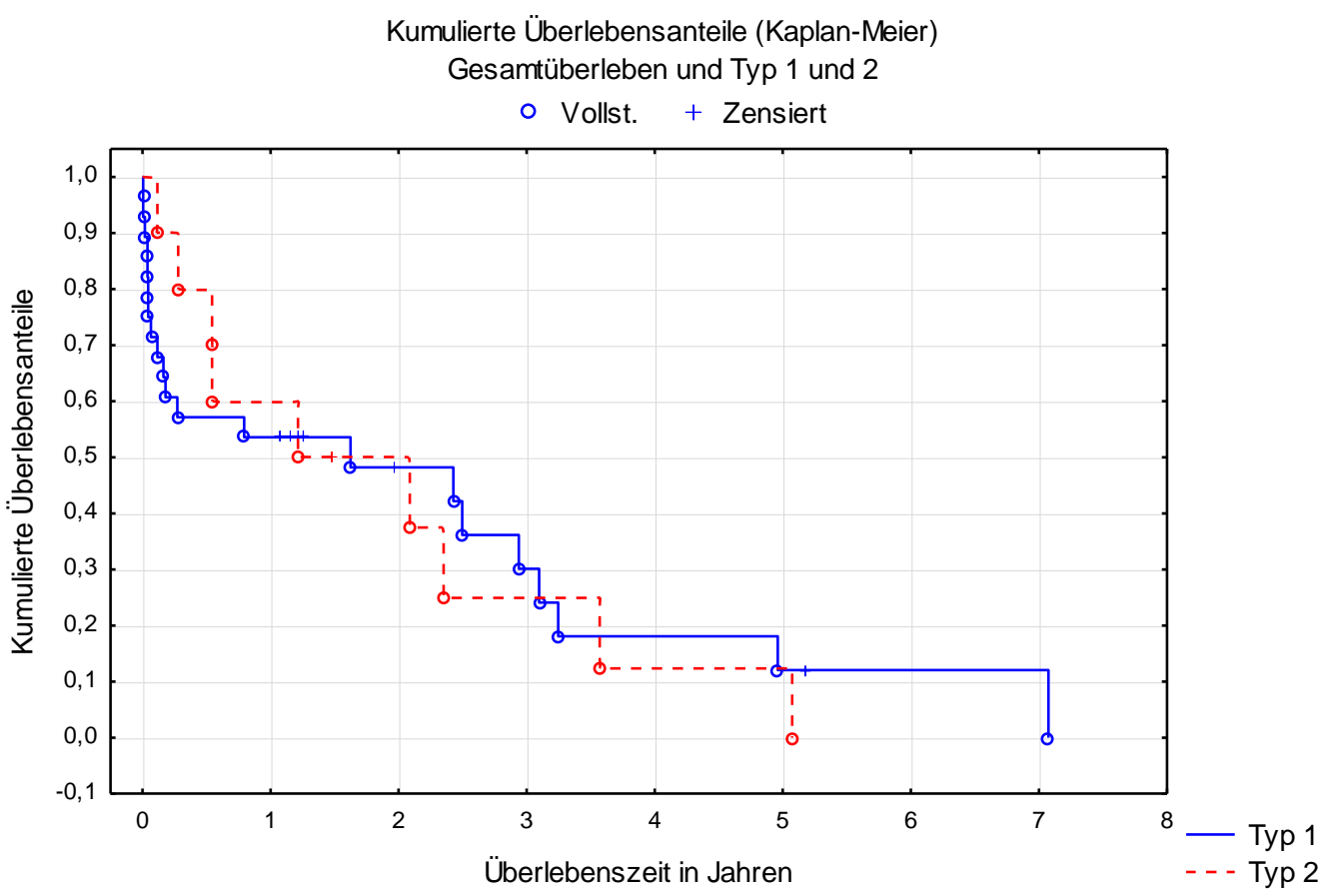

Kumulierte Überlebensanteile (Kaplan-Meier) remissionsfreie Überlebensrate und Typ 1 und 2

○ Vollst. + Zensiert

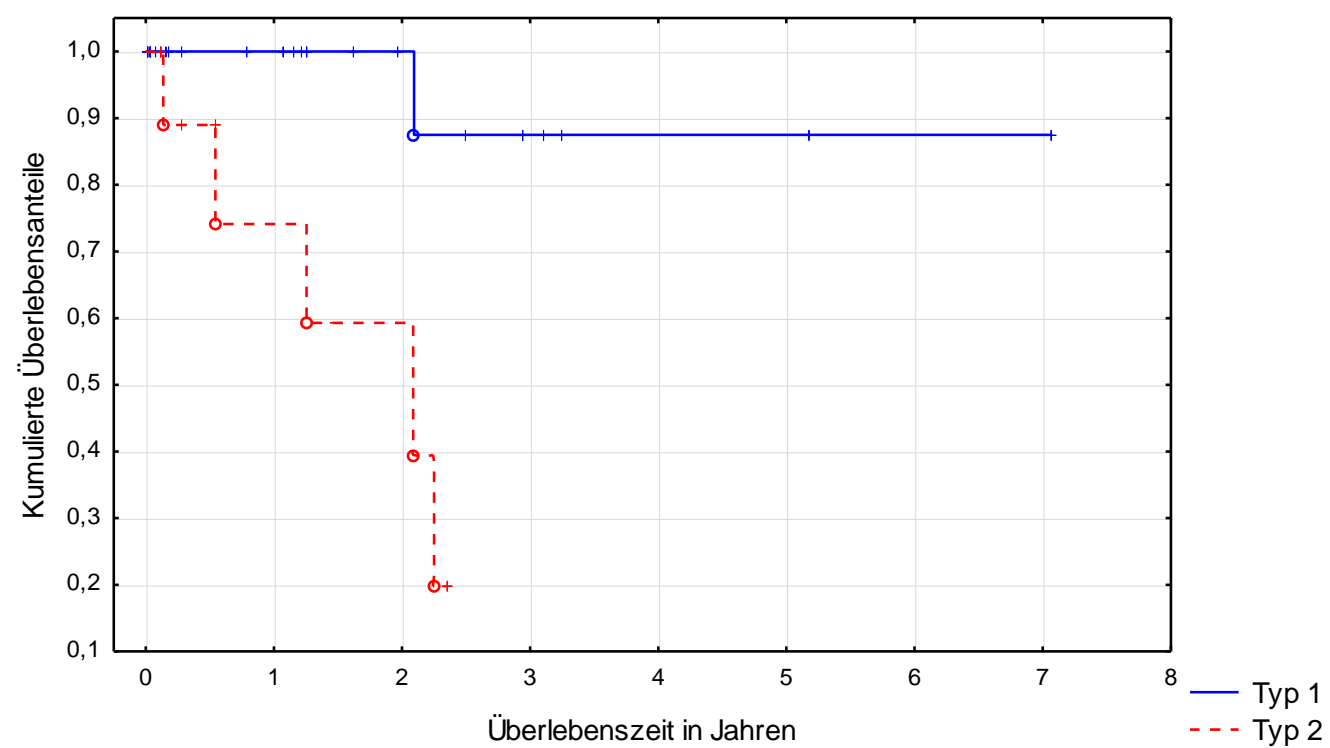




\subsection{Gesamtüberleben und remissionsfreies Überleben in Bezug zur Expression der Autophagie-Proteine}

Bei der Berechnung des Gesamtüberlebens und des remissionsfreien Überlebens in Abhängigkeit von der Expression der analysierten Autophagie-Proteine stellte sich kein signifikanter Unterschied heraus (Tabelle 11). Nachfolgend können die Überlebenszeiten in den jeweiligen Kaplan-Meier-Kurven abgelesen werden (Abbildung 14 und 15).

Tabelle 11: Log-Rank-Test: Auswirkungen der Expression der Autophagie-Marker auf das Gesamtüberleben und remissionsfreie Überleben. $p$-Wert mit Signifikanzniveau $<0,05$.

\begin{tabular}{l|l|l} 
Autophagie-Marker & Gesamtüberleben & $\begin{array}{l}\text { Remissionsfreies } \\
\text { Überleben }\end{array}$ \\
\hline Beclin-1 zytoplasmatisch* & $p=0,61930$ & $p=0,56228$ \\
Beclin-1 nukleär* & $p=0,45289$ & $p=0,80636$ \\
LC3* $^{*}$ & $p=0,45010$ & $p=0,67515$ \\
p62 zytoplasmatisch* & $p=0,70959$ & $p=0,08450$ \\
p62 nukleär* & $p=0,70959$ & $p=0,17745$
\end{tabular}




\subsubsection{Expression der Autophagie-Proteine und Gesamtüberleben}

Abbildung 16: Kaplan-Meier-Kurve für das Gesamtüberleben: Kumulierte Überlebensanteile in Abhängigkeit von der Zeit in Jahren in Bezug auf die kodierten Autophagie-Proteine (Beclin-1* (a), LC3* (b), p62* (c)). Gr. 0: niedrige Expression des Proteins. Gr. 1: hohe Expression. Vollständige Beobachtung: Eintritt des Todes oder eines Rezidivs. Zensierte Beobachtung: letzter Patientenkontakt.

(a)

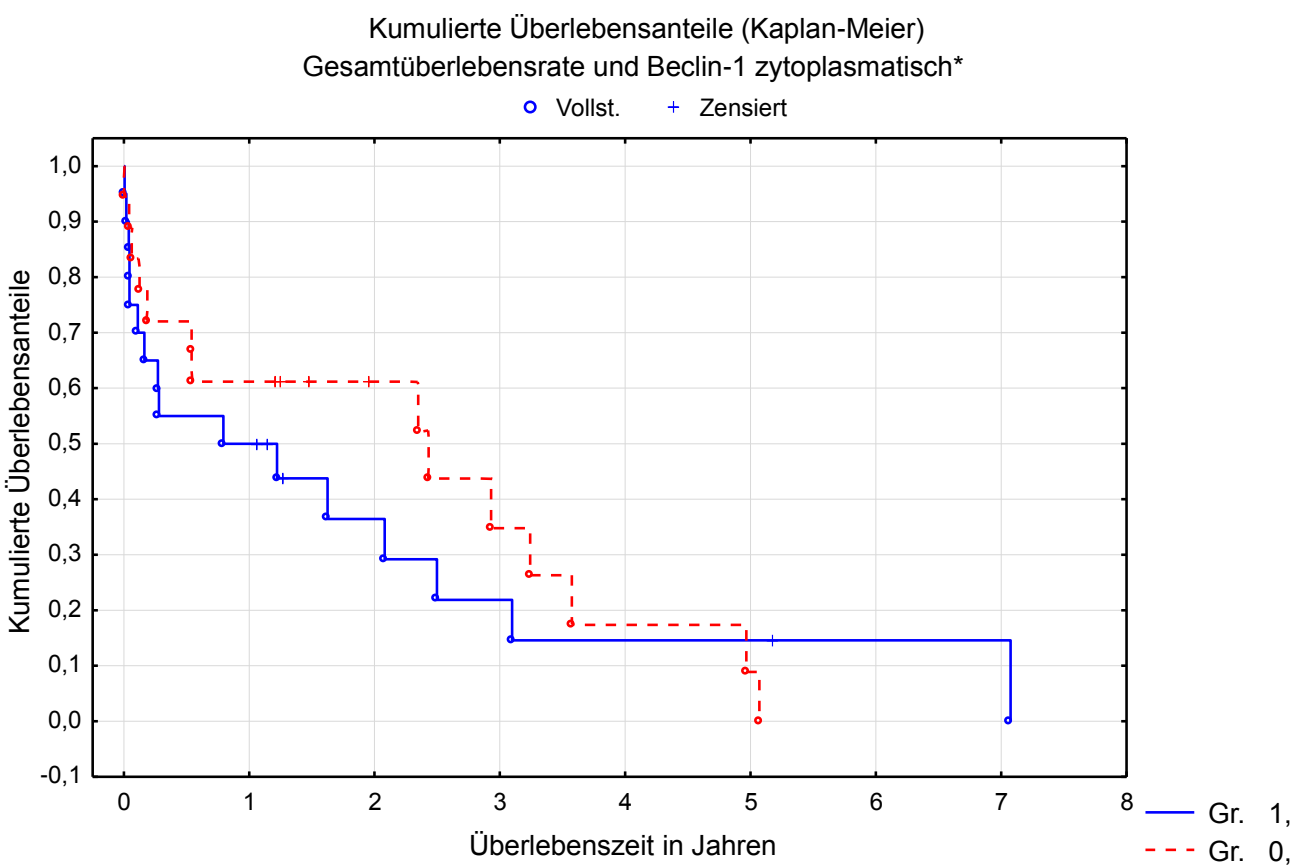

Kumulierte Überlebensanteile (Kaplan-Meier) Gesamtüberlebensrate und Beclin-1 nukleär* - Vollst. + Zensiert

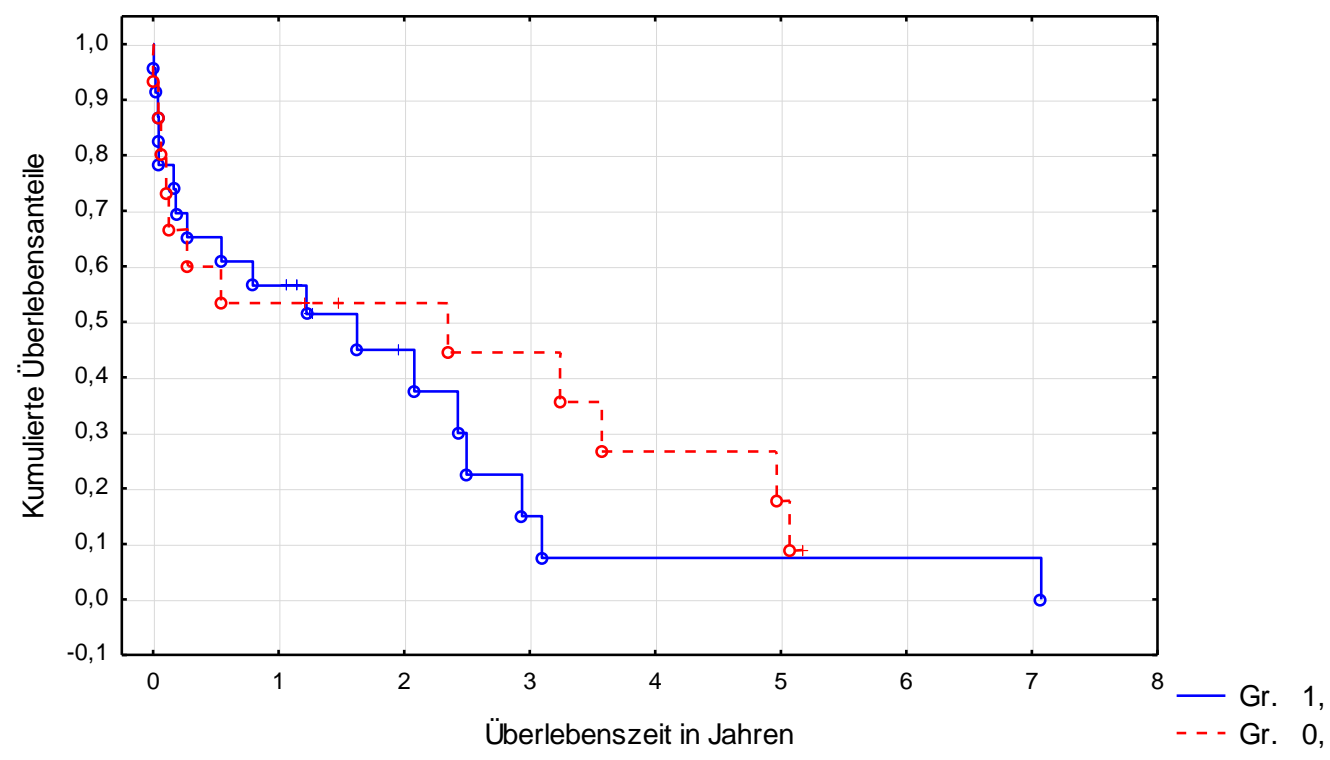


(b)

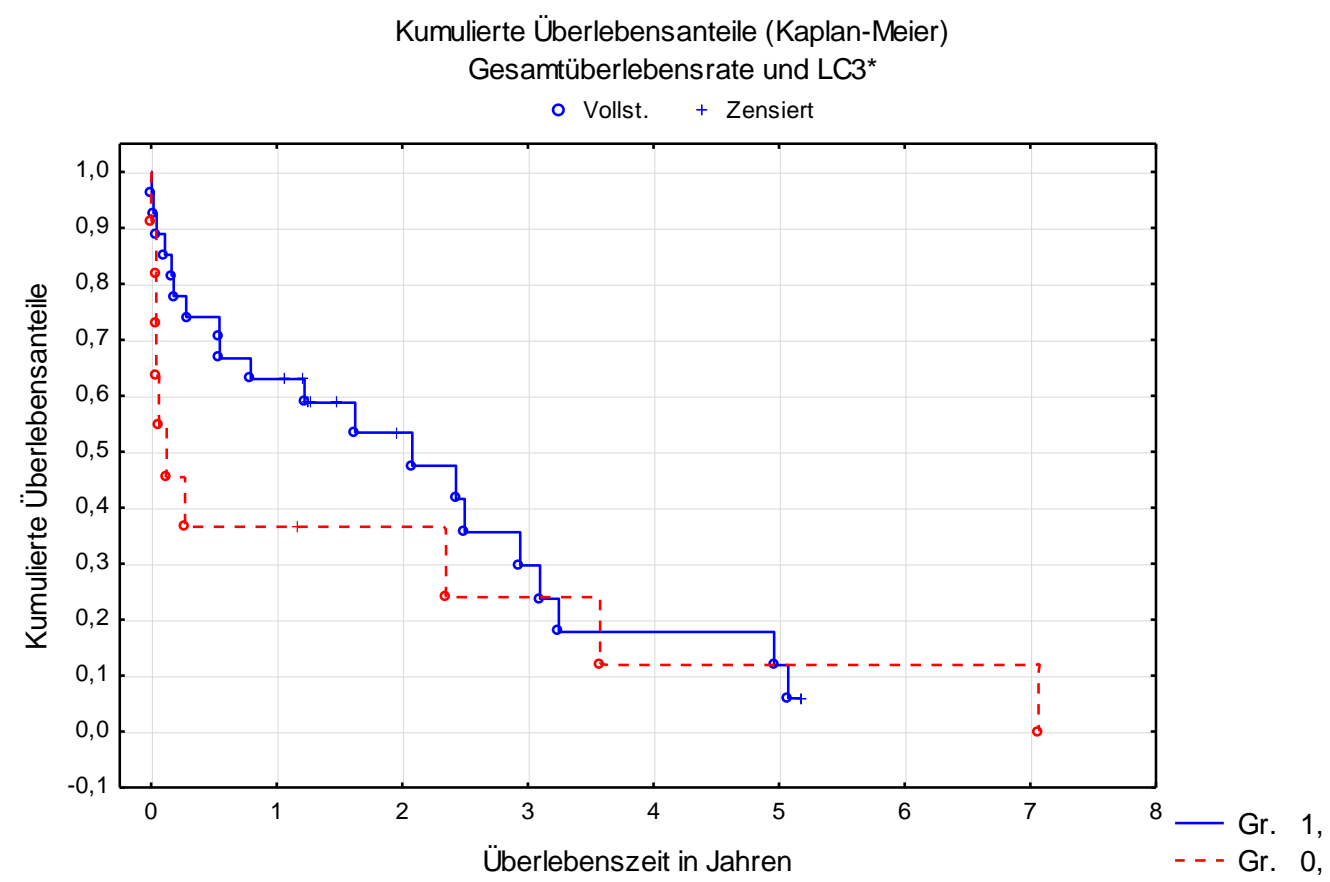

(c)

Kumulierte Überlebensanteile (Kaplan-Meier)

Gesamtüberlebensrate und p62 zytoplasmatisch*

o Vollst. + Zensiert

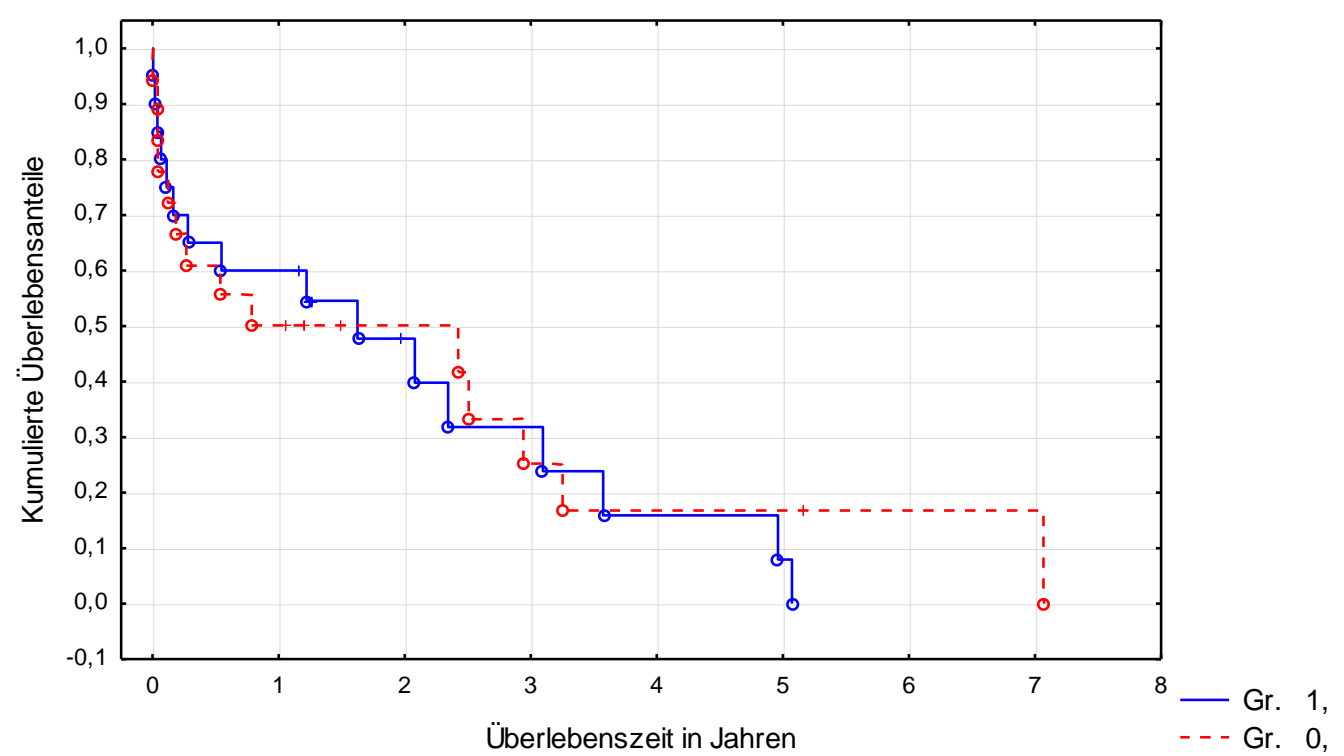




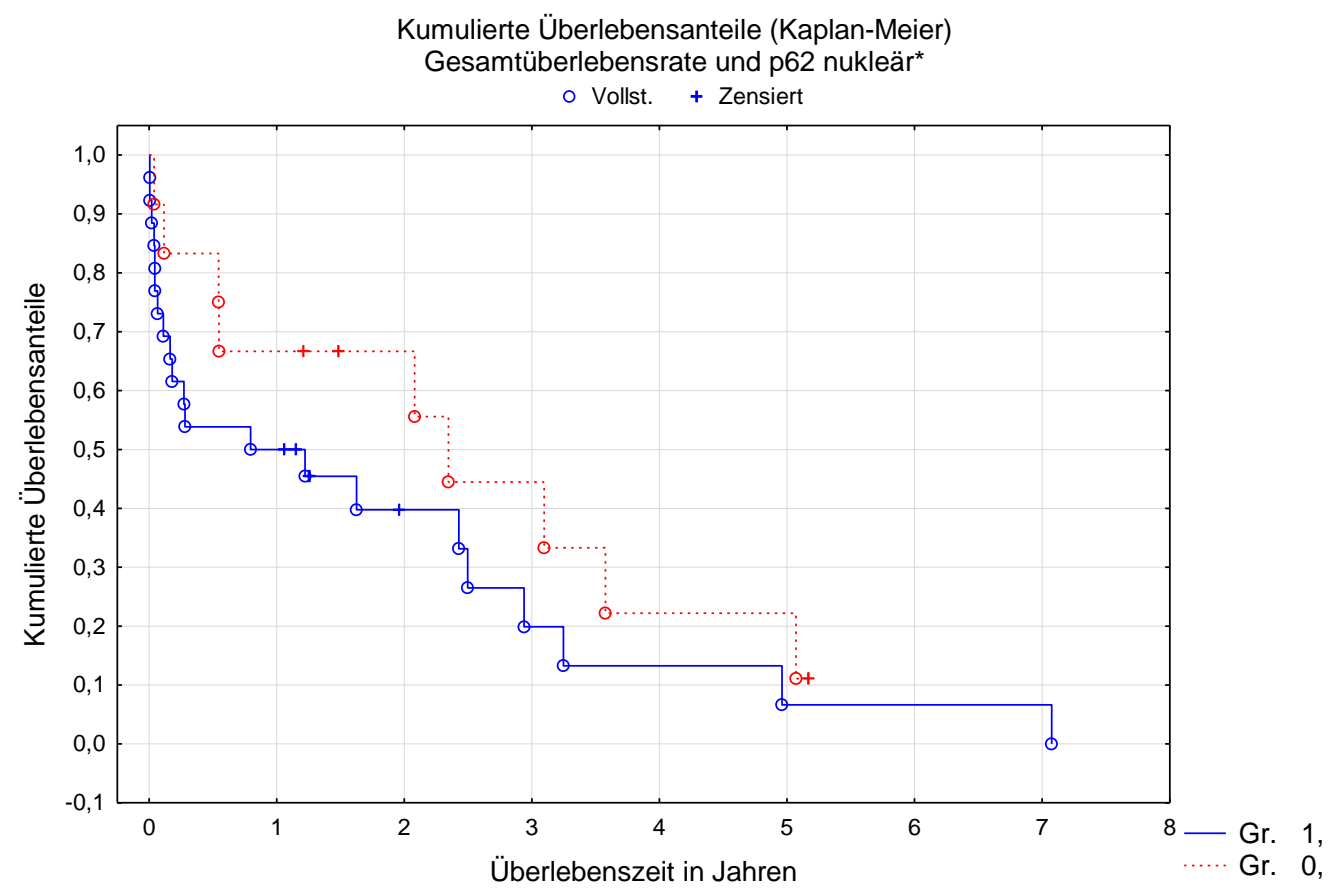

\subsubsection{Expression der Autophagie-Proteine und remissionsfreies Überleben}

Abbildung 17: Kaplan-Meier-Kurve für das rezidivfreie Überleben: Kumulierte Überlebensanteile in Abhängigkeit von der Zeit in Jahren in Bezug auf die kodierten Autophagie-Proteine (Beclin-1* (a), LC3* (b), p62* (c)). Gr. 0: niedrige Expression des Proteins. Gr. 1: hohe Expression. Vollständige Beobachtung: Eintritt des Todes oder eines Rezidivs. Zensierte Beobachtung: letzter Patientenkontakt.

(a)

Kumulierte Überlebensanteile (Kaplan-Meier)

remissionsfreies Überleben und Beclin-1 zytoplasmatisch*

○ Vollst. + Zensiert

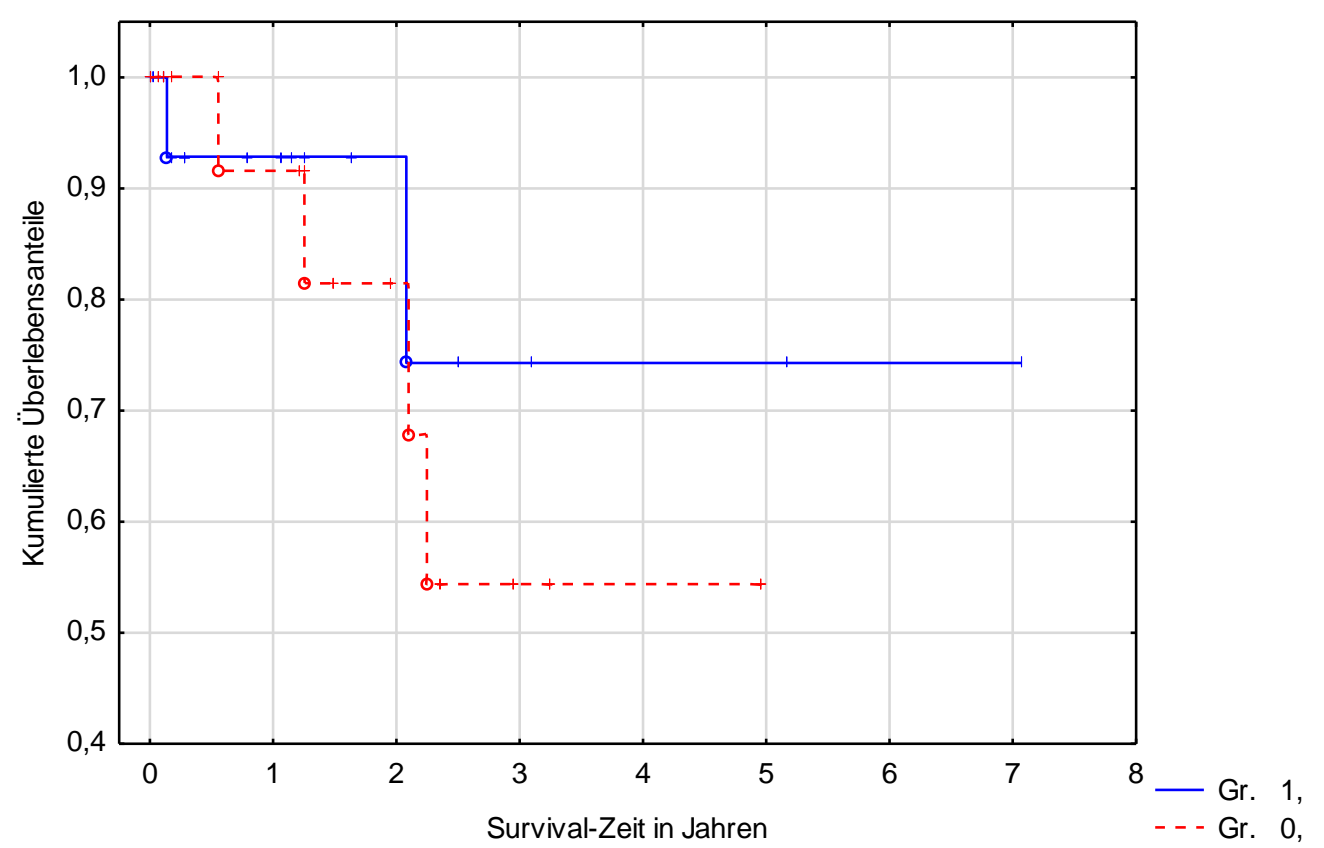


Kumulierte Überlebensanteile (Kaplan-Meier) remissionsfreies Überleben und Beclin-1 nukleär*

- Vollst. I Zensiert

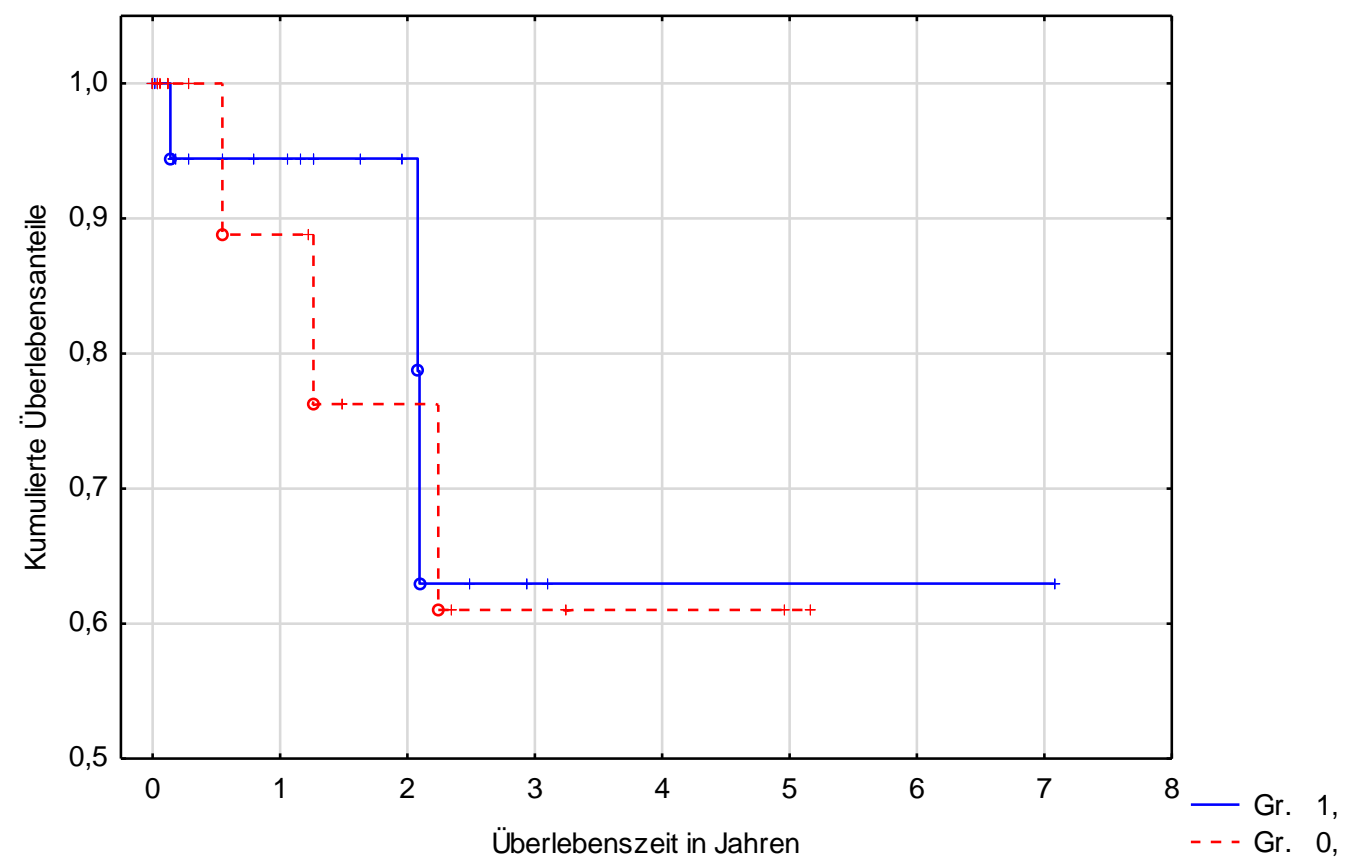

(b)

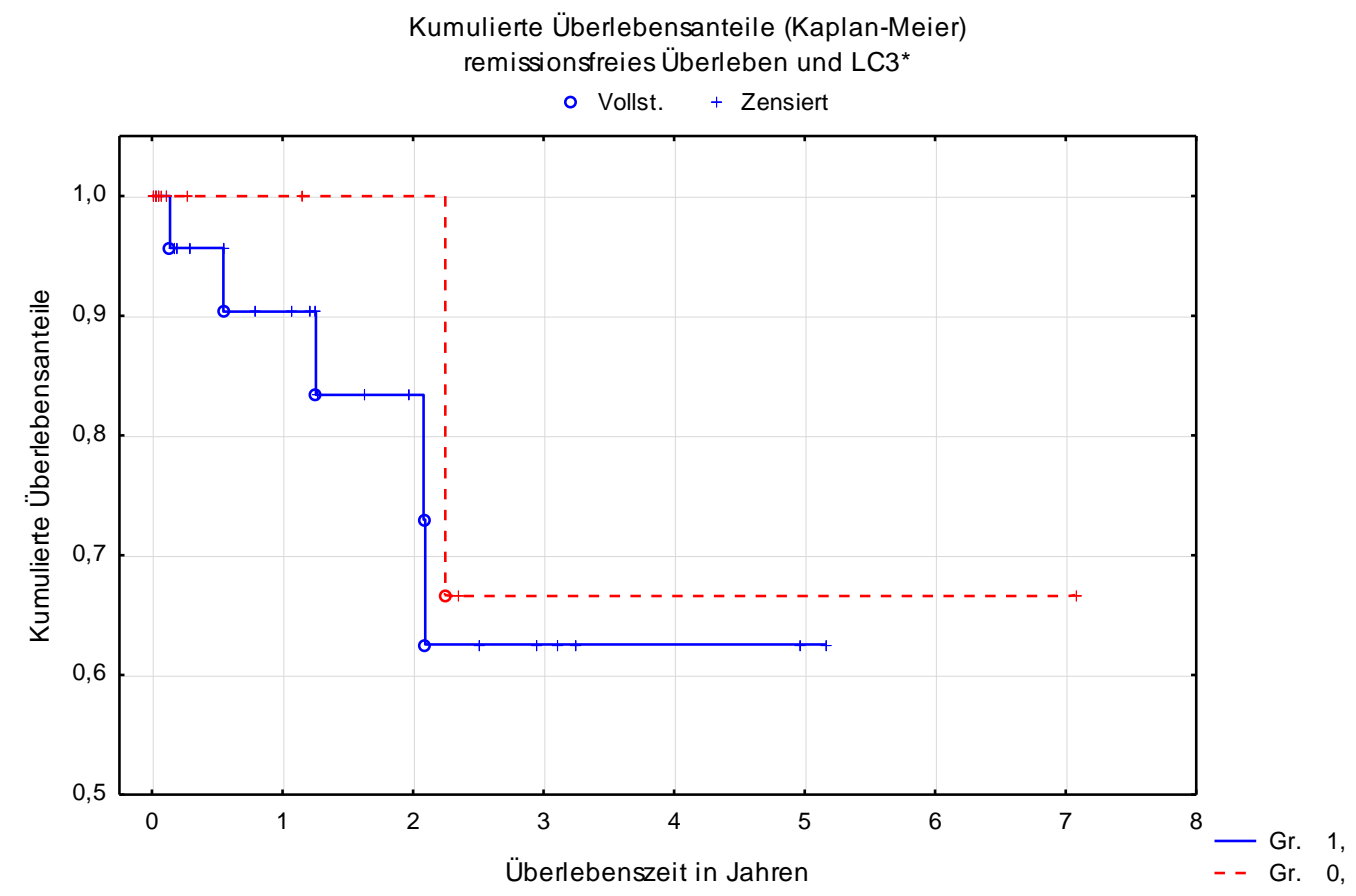


(c)

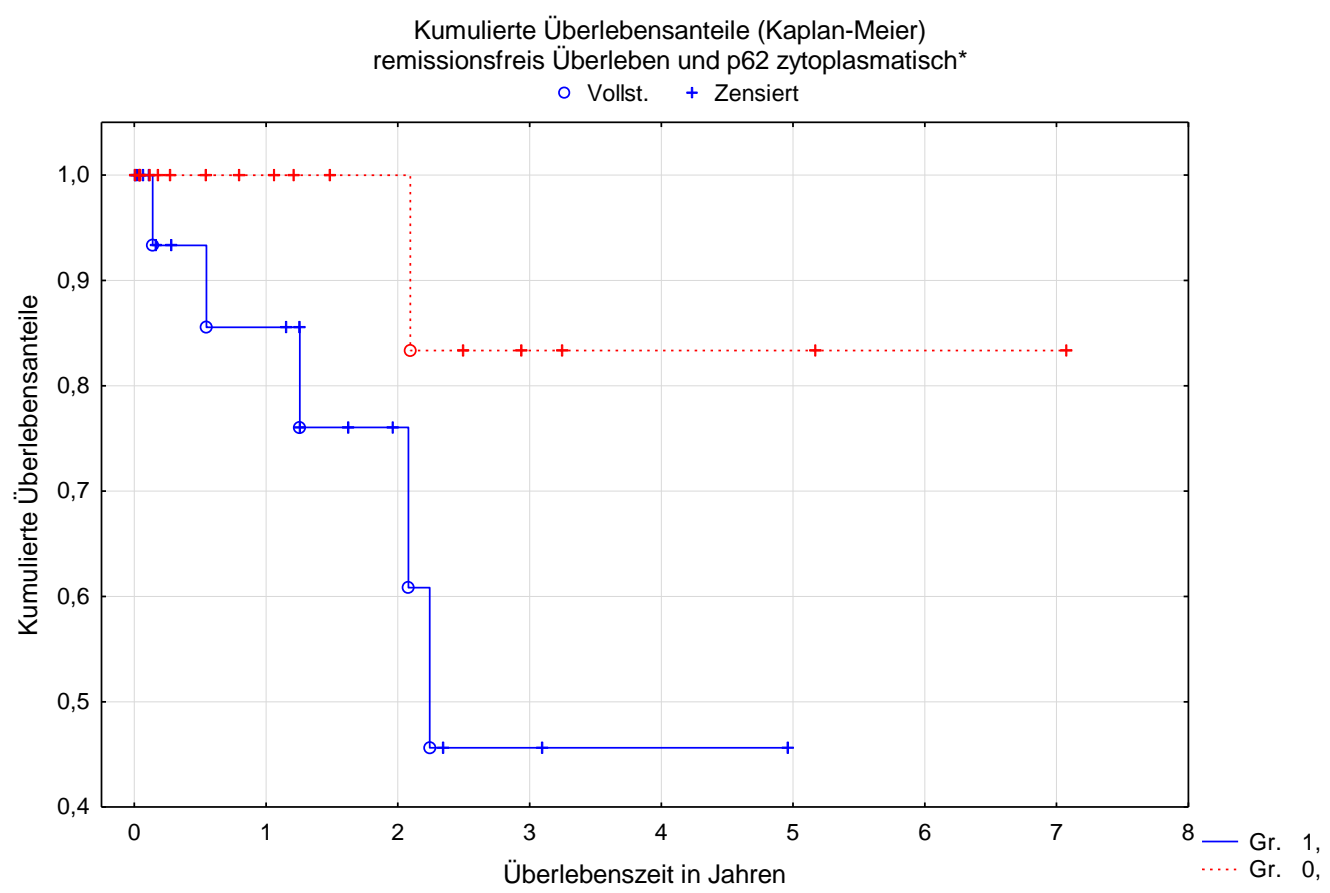

Kumulierte Überlebensanteile (Kaplan-Meier) remissionsfreies Überleben und p62 nukleär*

○ Vollst. + Zensiert

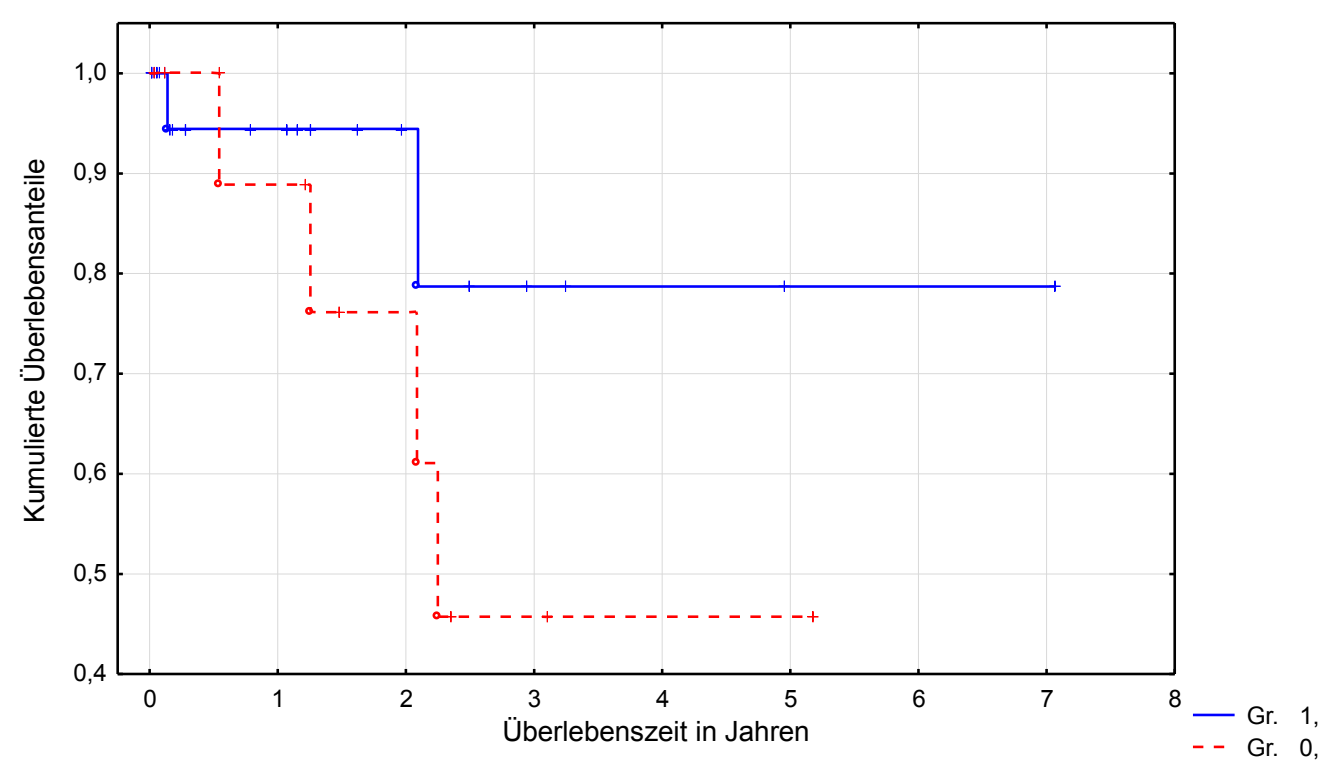




\section{Diskussion}

\subsection{Papilläre Nierenzellkarzinome}

Das papilläre Nierenzellkarzinom ist ein seltener Tumor des proximalen Nierentubulus und umfasst ein breites morphologisches Spektrum (Cairns 2010). Die Unterteilung in Typ 1 und 2, welche insbesondere durch Delahunt und Eble beschrieben wurde, hat eine prognostische Bedeutung (Delahunt und Eble 1997). Bereits in vorangegangenen Studien konnte zwischen papillärem Nierenzellkarzinom Typ 1 und 2 ein signifikanter Unterschied in der Höhe des T-Stadiums bei Erstdiagnose der Erkrankung festgehalten werden. Typ-1-Karzinome wurden eher in niedrigeren Stadien (pT1-2) und Typ 2 eher in höheren Stadien (pT3-4) diagnostiziert (Delahunt und Eble 1997; Allory et al. 2003).

In unserer Arbeit wurden insgesamt 28 Fälle von papillären Nierenzellkarzinomen Typ 1 und 10 Fälle von papillären Nierenzellkarzinomen Typ 2 beobachtet (Tabelle 6) und aufgrund ihrer typischen Morphologie teilweise reklassifiziert und an die neue UICC-Klassifikation angepasst. Unsere Ergebnisse zeigten ebenfalls in Typ 1 vorwiegend niedrige T-Stadien und in Typ 2 eher höhere T-Stadien (Abbildung 4). Zudem waren in unserem Patientenkollektiv Metastasen und eine geringere Differenzierung der Zellen eher bei Typ-2-Tumoren feststellbar, was mit einer erhöhten Mortalitätsrate einherging.

Bei der Berechnung der Überlebenszeitrate konnte eine geringere Überlebenszeit in Typ-2- gegenüber Typ-1-Tumoren festgestellt werden (Abbildung 15). Auch in vorangegangenen Studien wies Typ 1 eine bessere Prognose als Typ 2 auf, welches unter anderem durch den früheren Diagnosezeitpunkt und durch die geringere Expression des Proliferationsmarkers Ki-67 in Typ 1 untermauert wurde (Allory et al. 2003; Pignot et al. 2007).

Auch wir konnten eine signifikant höhere Ki-67-Expression in papillären Nierenzellkarzinomen Typ 2 als in Typ 1 zeigen ( $p=0,004868$, Abbildung 5). Zudem korrelierte der Anteil Ki-67-exprimierender Zellen mit einem höheren TStadium ( $p=0,004263$, Kendalls Tau $=0,323378$ ). Es stellte sich ebenfalls eine positive Korrelation zwischen der Ki-67-Expression und dem Grading heraus ( $p=$ 0,000140, Kendall Tau= 0,430911). 
In der vorliegenden Arbeit war eine erhöhte Ki-67-Expression mit einem kürzerem Gesamt- und remissionsfreien Überleben assoziiert, wobei die remissionsfreie Überlebenszeit das Signifikanzniveau erreichte $(p=0,00035)$. Die Ergebnisse des von uns untersuchten Kollektivs bestätigen somit die zu erwartende schlechte Prognose für das papilläre Nierenzellkarzinom Typ 2 mit einer erhöhten Ki-67Expression (Delahunt et al. 2001).

\subsection{Autophagie in papillären Nierenzellkarzinomen}

Der Zusammenhang zwischen Makroautophagie und Tumorentstehung wurde in einigen Studien erforscht, jedoch ist er noch nicht vollständig geklärt. Insgesamt wächst das Interesse an dem Mechanismus und der Bedeutung von Autophagie sowie deren Einfluss auf Tumorzellen. Initial vermutete man, dass Autophagie eine zytoprotektive Funktion ausfüllt, indem sie die Tumorzellen vor ungünstigen Umweltbelastungen schützt und ihnen so das Überleben ermöglicht (Klionsky 2007; Dalby et al. 2010; Choi et al. 2013; Gutierrez et al. 2014; Brech et al. 2009). Heute ist darüber hinaus bekannt, dass Autophagie sowohl den Tumorprogress als auch den Tumorzerfall begünstigen kann. Denn eine ungehemmte und dann zytoreduktiv-wirkende Autophagie, bei der alle Zellbestandteile verbraucht werden, kann den programmierten Zelltod Typ II, welcher aufgrund intrinsischer Aktivierung entsteht, auslösen (Shintani und Klionsky 2004; Yu et al. 2004; Choi et al. 2013). Jedoch muss betont werden, dass nicht immer eindeutig ist, in welche Richtung Autophagie in Tumorzellen gelenkt wird (zytoreduktiv oder zytoprotektiv).

In unserer Studienarbeit bestimmten wir die Aktivität der Autophagie anhand der Expression der Autophagie-assoziierten Proteine Beclin-1, LC3 und p62 (Autophagiemarker) sowie deren Korrelation mit Subtypisierung, TNM-Stadium und Grading von papillären Nierenzellkarzinomen.

Bei der Unterteilung in reduzierte und erhöhte Expression der Autophagiemarker wurde in unserer Arbeit zur Vereinfachung der Median des IRS angewendet. Wir legten einen IRS unterhalb des jeweiligen Medians als geringere Expression und einen IRS gleich oder oberhalb des jeweiligen Medians als erhöhte Expression der Autophagie-assoziierten Proteine fest.

Abbildung 18 zeigt, dass in den meisten untersuchten Fällen der in unserer Studie berücksichtigten papillären Nierenzellkarzinome ein insgesamt erhöhter Nachweis 
der Autophagiemarker beobachtet werden konnte. Insbesondere LC3 sowie p62 stachen mit einem IRS von 7-8 und damit hoher Expression hervor.

Abbildung 18: Histogramm: Autophagiemarker nach dem IRS in den in dieser Studie untersuchten Fällen von papillären Nierenzellkarzinomen.

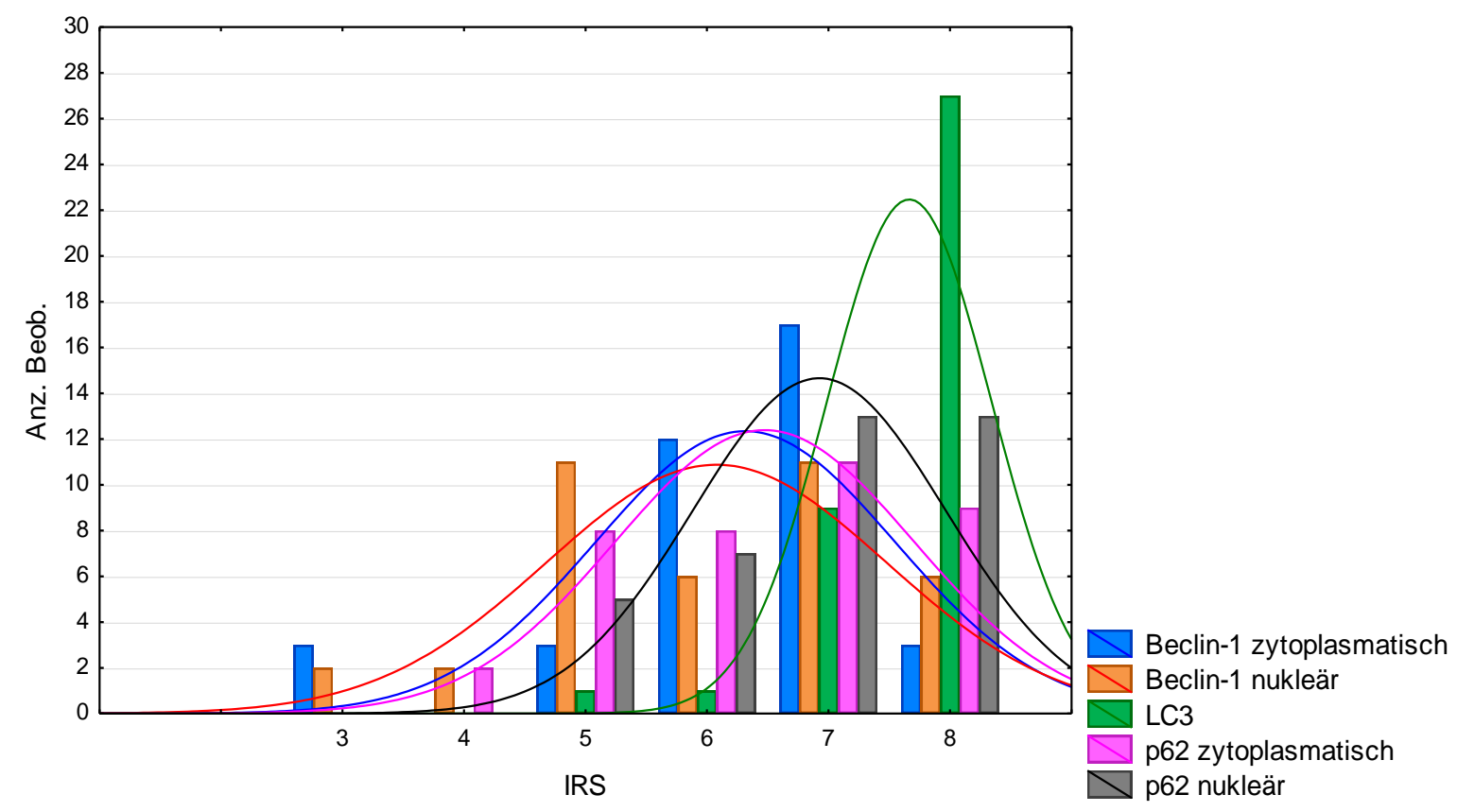

Beclin-1 ist das erste Protein, welches in den Zusammenhang mit Autophagie gebracht wurde. Es ist ein Tumorsuppressor und stellt ein Bindeglied zwischen autophagischen und apoptotischen Prozessen dar. Jedoch ist die Datenlage paradox, denn es kann zum einen vermehrt und zum anderen vermindert nachgewiesen werden (Funderburk et al. 2010). 1999 wurde erstmals eine Deletion im Beclin-1-Gen auf Chromosom 17q21 gefunden, welches zur Tumorentstehung beitragen soll.

In unserer Ausarbeitung der papillären Nierenzellkarzinome wurde eine insgesamt erhöhte zytoplasmatische sowie nukleäre Expression von Beclin-1 beschrieben (Abbildung 6). Im Vergleich zu anderen Tumoren wurde in Zervix- und Lungenkarzinomen sowie in Melanomen eine Hochregulation und in einigen anderen wie Brust-, Ovarial-, Prostata- und Hirntumoren eine Herunterregulation beschrieben, letztere durch eine Mutation von Beclin-1 bedingt (Ogier-Denis und Codogno 2003; Shintani und Klionsky 2004; Oh et al. 2011; Liang et al. 1999; Aita et al. 1999; Miracco et al. 2007). Es wird in diversen Studien angenommen, dass Beclin-1 bei Hochregulation als Bestandteil der zytoreduktiven Autophagie das Zellwachstum hemmt und somit zu einem längerem Überleben der Patienten führt 
(Hao et al. 2014). Eine Herunterregulation von Beclin-1 in Tumoren bedeutet somit, dass Beclin-1 als Tumorsuppressor wegfällt und der Tumor ungehindert wachsen kann (Shintani und Klionsky 2004). Zusätzlich fand man in Beclin-1Knockout-Mäusen ein vermehrtes Auftreten von einigen epithelialen sowie hämatopoetischen Malignomen wie beispielsweise Lungen-, Leber- und Brustkrebs sowie Lymphomen (Yu et al. 2004; Zarzynska 2014).

Im Vergleich beider Subtypen war hinsichtlich der zytoplasmatischen Beclin-1Expression kein signifikanter Unterschied zu sehen. Dagegen konnten wir bei der Unterscheidung zwischen Typ 1 und 2 einen signifikanten Unterschied in der nukleären Beclin-1-Expression feststellen, wobei in Typ-1- eine höhere Aktivität als in Typ-2-Tumoren dokumentiert wurde (Abbildung 7). Die zytoplasmatische Expression war ohne ausreichender Evidenz in hohen T-Stadien reduziert und in niedrigen T-Stadien erhöht. Die nukleäre Beclin-1-Expression dagegen war in niedrigen T-Stadien signifikant höher nachweisbar als in fortgeschrittenen Stadien (Abbildung 8). Insbesondere in geringer Beclin-1-Expression (zytoplasmatisch sowie nukleär) waren in unserem Patientenkollektiv Metastasen signifikant nachweisbar (Tabelle 7).

Im Grading konnte eine nicht signifikante positive Korrelation zum zytoplasmatischen Beclin-1 und eine signifikante negative Korrelation zum nukleären Beclin-1 gezeigt werden. Basierend auf diesen Ergebnissen, scheint das nukleäre Beclin-1 im papillären Nierenzellkarzinom eine zytoreduktive und apoptotische Wirkung zu haben, da bekanntermaßen Typ-1-Tumoren und Tumoren mit niedrigem T-Stadium prognostisch günstigeren Verlauf als Typ-2-Tumoren und Tumoren mit hohen T-Stadien haben.

Für diese Vermutung kann die signifikant negative Korrelation zwischen nukleärem Beclin-1 und Grading als Argument hinzugenommen werden, die in differenzierten Tumoren eine erhöhte Expression von nukleärem Beclin-1 zeigte. Dieses Ergebnis lässt vermuten, dass die zytoreduktive Funktion von Beclin-1 als Tumorsuppressor in wenig differenzierten Tumoren mit hohem Grading eine untergeordnete Rolle zu spielen scheint. Eine erhöhte Aktivität von Beclin-1 als Tumorsuppressor bei Patienten mit niedrigem Grading scheint sich dagegen bei noch niedrigem TStadium prognostisch günstig auszuwirken. 
Diese prognostische Relevanz für Beclin-1 konnte jedoch in gastrointestinalen Tumoren und Melanomen nicht bestätigt werden (Han et al. 2011; Choi et al. 2014).

Unsere Ergebnisse sprechen somit für eine zytoreduktive Funktion von Beclin-1 und damit für eine prognoseverbessernde Eigenschaft. Auch wenn bei der zytoplasmatischen Beclin-1-Expression keine signifikanten Unterschiede zu sehen waren, zeigten die Ergebnisse zumindest einen Trend, welcher der signifikanten nukleären Expression ähnelt. Es liegt nahe, dass die nukleäre Expression von Beclin-1 in den von uns untersuchten Tumoren die größere Rolle spielt.

Die LC3 kommt zytoplasmatisch (-I) und membranständig (-II) vor (Kabeya et al. 2000). Als Membranprotein (LC3-II) der äußeren und inneren Membran des Autophagosoms spiegelt es die Aktivität der Autophagie einer Zelle wider (Kabeya et al. 2004). Es hat die Funktion der Elongation und Phagosombildung (Deng et al. 2013). Eine erhöhte Expression von LC3 wurde in Situationen der Hypoxie, Infektion, in Hungerzuständen und Tumorgenese beobachtet (Choi et al. 2014).

In unserer Arbeit war LC3 in den meisten Fällen $(n=27)$ mit einem IRS von 8 in einem erhöhten Level nachweisbar. Dieses Ergebnis ließ uns schlussfolgern, dass LC3 einen großen Einfluss auf das Tumorwachstum in papillären Nierenzellkarzinomen hat. Diese Hypothese wird durch experimentelle Arbeiten gestützt, in denen LC3 mit einer zytoprotektiven Autophagie in Zusammenhang gebracht wurde. Genannt wurden diesbezüglich LC3-überexprimierende Melanome und Kolorektalkarzinome (Han et al. 2011; Choi et al. 2014). Auch in Ösophaguskarzinomen ohne Lymphknotenmetastasen war eine erhöhte Expression von LC3 mit kürzerem Überleben assoziiert (Hao et al. 2014). Zwischen den Subtypen konnte kein signifikanter Unterschied der Expression festgestellt werden. Jedoch zeigte sich der IRS von 8 mit einem prozentual höheren Anteil in Typ-2- (80 \%) als in Typ-1-Tumoren (67,8 \%). Es wurde ein nicht signifikanter negativer Zusammenhang zwischen der Expression von LC3 und dem T-Stadium sowie bei Nachweis von Metastasen gesehen. Ein nicht signifikanter positiver Zusammenhang konnte hingegen in der Korrelationsanalyse zwischen LC3-Expression und Grading festgestellt werden. Auch wenn bei diesen Korrelationen das Signifikanzniveau nicht erreicht werden konnte, geben sie jedoch einen Hinweis darauf, dass eine erhöhte Expression von LC3 in papillären 
Nierenzellkarzinomen zytoprotektiv wirkt, da papilläre Nierenzellkarzinome Typ 2 und Tumoren mit hohem Grading eine schlechtere Prognose aufweisen.

Der Mechanismus der Überexpression von LC3 und der damit verbundenen schlechteren Prognose ist jedoch unklar. Diskutiert werden hierzu in der Literatur Hypoxie, metabolischer Stress und ein Einfluss auf das anti-apoptotischen Protein Bcl-2 (B-Zell Lymphom 2), welches unter anderem in Lymphomen vorkommt (Hao et al. 2014). Eine vergleichende Studie über Sorafenib-sensible und -resistente hepatozelluläre Karzinome veröffentlichte Daten über die Aktivität von Autophagie mittels Messung der Expression von LC3. In Tumorzellen, die auf Sorafenib sensibel reagierten, zeigte sich eine induzierte Erhöhung von LC3 als Überlebensstrategie, wohingegen in der resistenten Gruppe diese fehlte (Fischer et al. 2014).

Zusammen mit den genannten Studien lässt sich schlussfolgern, dass die LC3 Überexpression in den hier untersuchten fortgeschrittenen papillären Nierenzellkarzinomen einen zytoprotektiven Mechanismus darstellt und somit das Tumorwachstum fördert.

p62 ist ein Rezeptor- und Bindeprotein zwischen den abzubauenden Proteinen und dem Autophagosom. Zum Schutz der Zelle führt p62 zu einer Aggregation dieser Proteine. Anschließend werden die Aggregate über Bindung von p62 an LC3 in das Autophagosom geschleust. Wenn der Mechanismus der Autophagie in Zellen von Tumoren beschädigt ist, kommt es zu einer Anhäufung der p62Aggregate, die das Tumorwachstum begünstigen (Mathew et al. 2009). Die Akkumulation von p62 in der Zelle bewirkt eine übermäßige Aktivierung eines Transkriptionsfaktors, wie Nrf2, welcher eine Überexpression von onkogenen Proteinen verursacht (Puissant et al. 2012). Basierend auf diesem Mechanismus gilt p62 auch als Indikator einer gestörten Autophagie, welche das Tumorwachstum fördert (Mathew et al. 2009).

In unserer Untersuchung wurde p62 insgesamt vermehrt nachgewiesen, sodass von einer gesteigerten Aktivität der Autophagie in papillären Nierenzellkarzinomen auszugehen ist. Eine vermehrte Expression von p62 wurde in vielen anderen Tumoren beschrieben. Genannt wurden Fälle mit hepatozellulären Karzinomen, nicht-kleinzelligen Lungenkarzinomen und Brusttumoren (Puissant et al. 2012; Mizushima und Levine 2010). 
Bei der Unterscheidung der Subtypen waren ein signifikant höherer Nachweis von zytoplasmatischem p62 und ein signifikant geringerer Nachweis von nukleärem p62 in Typ-2-Tumoren feststellbar. In Typ-1-Tumoren dagegen konnte eine signifikant geringere Expression von zytoplasmatischem p62 und eine signifikant höhere Expression von nukleärem p62 nachgewiesen werden. Das zytoplasmatische Vorkommen war insbesondere in hohen T-Stadien mit positiver Korrelation ohne ausreichende Evidenz erhöht. Das nukleäre p62 war mit einer signifikant negativen Korrelation insbesondere in niedrigen T-Stadien nachweisbar. Metastasen waren mit ausreichender Evidenz mit hoher zytoplasmatischer p62-Expression assoziiert, dagegen waren keine Metastasen bei niedriger nukleären p62-Expression feststellbar.

Ein höheres Grading war mit einem erhöhten Nachweis von zytoplasmatischem p62 assoziiert. Im Gegensatz dazu konnte eine signifikant erhöhte nukleäre p62Expression in differenzierten Tumorzellen mit niedrigem Grading nachgewiesen werden. Der Grund für diese diskrepanten Ergebnisse zwischen zytoplasmatischem und nukleärem p62 ist nicht eindeutig belegbar.

Die Ergebnisse geben Rückschlüsse darauf, dass die nukleäre p62-Form eher in niedrigen Stadien und das zytoplasmatische Vorkommen eher in hohen Stadien der Tumorentwicklung mit Auftreten von Metastasen einen Einfluss haben.

Die Unterschiede des Vorkommens von p62 lassen schlussfolgern, dass das zytoplasmatisch akkumulierte p62 einen protektiven Einfluss auf das Tumorwachstum hat und damit prognostisch ungünstig ist. Die zytoprotektive Wirkung von p62 konnte ebenfalls in vorangegangenen Studien anhand einer positiven Korrelation zwischen erhöhtem p62-Level und schlechterer Prognose in Bronchialkarzinomen gezeigt werden (Inoue et al. 2012). Zudem wurde in Glioblastomen mit vermehrtem Nachweis von p62 eine erhöhte Mortalität nachgewiesen (Galavotti et al. 2013). Auch experimentelle Studien über kolorektale Karzinome, die auf den Mechanismus der Autophagie abzielten, zeigten einen positiven Zusammenhang zwischen Autophagie und Tumorstadium, Grading, Invasivität sowie Rezidivneigung. Dementsprechend war eine erhöhte Rate der Autophagie eher in fortgeschrittenen und rezidivierenden Kolorektalkarzinomen zu verzeichnen (Kim et al. 2014).

Es wird jedoch vermutet dass die zytoplasmatische Form von p62 gegenüber dem nukleären Vorkommen die aktivere Form darstellt und so den direkten Kontakt zu 
weiteren Autophagie-assoziierten Proteinen herstellen kann. Die nukleäre Form von p62 transportiert unter hypoxischen Zuständen beschädigte Proteine aus dem Zellkern ins Zytosol (Pankiv et al. 2010). Somit vermuten wir, dass ein erhöhtes Vorkommen von p62 im Zellkern in noch niedrigen Stadien der Tumorentwicklung in papillären Nierenzellkarzinomen auf eine noch nicht aktive oder eine vorbereitende Autophagie hinweist, da die Bindung an LC3 als nächster Schritt im Autophagie-Prozess nur im Zytosol stattfinden kann.

Es ist seit einigen Jahren bekannt, dass zytoprotektive Autophagie in verschiedenen Tumoren hochreguliert wird, sodass ihr Überleben bei geringerer Nährstoff-versorgung, Hypoxie, ebenso unter Chemo- und Radiotherapie gewährleistet werden kann (Klionsky 2007; Dalby et al. 2010; Choi et al. 2013; Gutierrez et al. 2014; Brech et al. 2009). Dies zeigt, dass Autophagie einen Mechanismus darstellt, der es Tumorzellen ermöglicht, unter erschwerten Bedingungen zu überleben.

Demgegenüber existieren Tumoren, in denen eine herunterregulierte und damit am ehesten zytoreduktive Autophagie beschrieben wurde. Häufig genannte Tumoren in diesem Zusammenhang sind Brust-, Eierstock- und Prostata-Krebs, bei denen zu 40-75\% eine Mutation im Beclin-1-Gen und damit verbundene verminderte Aktivität der zytoreduktiven Autophagie gefunden wurde (Ávalos et al. 2014). Ein verminderter Nachweis von autophagischen Proteinen wurde ebenfalls in Studien über Autophagie und hepatozelluläre Karzinome festgestellt (Kisen et al. 1993; Ding et al. 2008; Liang et al. 1999).

In einem kürzlich veröffentlichten Experiment von Deng et al. zeigte sich in fortgeschrittenen klarzelligen Nierenzellkarzinomen eine Herunterregulation der Autophagie mit einer geringen Expression von LC3 und Beclin-1. Autophagie kann im Beispiel des klarzelligen Nierenzellkarzinoms folglich eine nicht-protektive oder zytoreduktive Wirkung zeigen (Deng et al. 2013; Liu et al. 2015).

Eine Tumorsuppression, die durch aktive Autophagie bewirkt werden kann, entsteht durch den autophagischen Abbau von defekten Mitochondrien und die Reduktion von oxidativem Stress, welcher potentiell eine Genom-Instabilität und möglicherweise Mutationen zur Tumorentstehung verursachen kann (Ávalos et al. 2014). Des Weiteren verhindert eine intakte Autophagie den Zelltod und damit verbunden eine lokale Entzündungsreaktion sowie Nekrose. Die Sekretion 
proinflammatorischer Zytokine, die bei Ausschüttung einen positiven Einfluss auf Tumorwachstum, Angiogenese, Metastasierung und Resistenz gegenüber antineoplastischen Medikamente hätten, wird unterdrückt. Als weiterer Tumorsuppressor-Mechanismus kann eine übermäßig autophagisch tätige Zelle, bei der die Autophagie-assoziierten Proteine überexprimiert sein sollen, durch zum Beispiel Hemmung von anti-apoptotischen Proteinen wie Bcl-2 ihren eigenen programmierten Zelltod initiieren (Brech et al. 2009; Dalby et al. 2010; Ávalos et al. 2014).

Zusammenfassend betrachtet, zeigen die Ergebnisse unserer Expressionsanalysen von LC3 und p62, dass die Autophagie in papillären Nierenzellkarzinomen zytoprotektiv oder nicht-tumorsuppressiv ist. Bei der Unterscheidung zwischen Typ 1 und 2 stellte sich eine höhere Expression von LC3 und zytoplasmatischem p62 zugunsten der Typ-2-Tumoren dar. LC3 und zytoplasmatisches p62 korrelierten in unserer Studie mit hohem Grading, weshalb diese Autophagie-Marker mit einer tumorprotektiven Autophagie in Zusammenhang gebracht wurden. Die Funktion von Beclin-1 in Tumoren ist noch nicht vollständig geklärt. In unserer Arbeit belegt der Nachweis einer geringeren Expression von Beclin-1 in Typ-2-Tumoren, hohen T-Stadien mit Nachweis von Metastasen und hohem Grading eine zytoreduktive Funktion von Beclin-1 als Tumorsuppressor. Jedoch war eine insgesamt erhöhte Expression von Beclin-1 mit einem medianen IRS von 7 (zytoplasmatisch) und 6 (nukleär) in papillären Nierenzellkarzinomen nachweisbar. Die Ergebnisse deuten darauf hin, dass Beclin-1 trotz entarteter Zellen in papillären Nierenzellkarzinomen als Schutzfunktion des Körpers erhalten geblieben ist. Darüber hinaus gibt es bisher keinen Beweis dafür, dass Beclin-1 ebenfalls an einer zytoprotektiven Autophagie beteiligt ist.

Die Korrelation zwischen Autophagie und TNM-Stadium des Tumors wird kontrovers diskutiert und führt bis heute zu keiner eindeutigen Datenlage. Allgemein wird vermutet, dass Autophagie in beginnenden Stadien der Tumorausbreitung unter sauerstoffarmen Bedingungen, wenn es noch nicht zu einer ausreichenden Vaskularisierung gekommen ist, das Überleben der Zellen sichert. In späteren Stadien soll es zu Mutationen der Autophagie-beteiligten Proteine LC3, p62 und Beclin-1 kommen, sodass eine unzureichende Autophagie 
das Tumorwachstum nicht mehr aufhalten kann oder die hochregulierten Autophagie-assoziierten Proteine das Tumorwachstum begünstigen (Mathew et al. 2009; Choi et al. 2014; Zarzynska 2014)

Die Ergebnisse unserer Arbeit sowie der angeführten Studien weisen darauf hin, dass bei der Diagnose eines Tumors die Bestimmung der Aktivität der Autophagie im Zusammenhang mit dem Staging und Grading zur Prognoseeinschätzung des Tumors beitragen kann.

\subsection{Autophagie und Überleben in papillären Nierenzellkarzinomen}

Papilläre Nierenzellkarzinome sind nach dem klarzelligem Nierenzellkarzinom die zweithäufigsten bösartigen Nierentumoren. Sie machen jedoch nur $10 \%$ von allen Nierenzellkarzinomen aus. Die wichtigsten Faktoren, die Einfluss auf die Prognose in nicht metastasierten Nierenzellkarzinomen haben, sind TNM-Stadium und Grading. Eine frühere Ansicht, dass unterschiedliche Genmutationen oder morphologische Subtypen sich ebenfalls prognostisch auf das Überleben auswirken, ist heute umstritten (Lee et al. 2014). Aus diesem Grund wurde in der vorliegenden Arbeit kein Schwerpunkt auf die Beschreibung einzelner Charakteristika der Morphologie, sondern auf den Vergleich zwischen Typ 1 und 2 hinsichtlich TNM-Stadium, Grading und Überleben der papillären Nierenzellkarzinome gelegt.

In unserer Studie zeigte sich eine maximale Gesamt- und rezidivfreie Überlebenszeit von ca. 7 Jahren (= circa 85 Monate). Vorangegangene Analysen konnten zeigen, dass papilläre Nierenzellkarzinome insgesamt bessere Überlebensraten aufwiesen als klarzellige Nierenzellkarzinome (Delahunt et al. 2007). Dies war unter anderem darauf zurückzuführen, dass diese Tumoren meist in niedrigeren T-Stadien detektiert und operativ behandelt wurden (Warrick et al. 2014). Hinsichtlich der TNM-Stadien bestätigten unsere Ergebnisse die vorherigen Studien, bei denen ebenfalls eine längere Überlebenszeit in niedrigen T-Stadien (pT1-3) beschrieben wurde.

Auch im Vergleich der Subtypen des papillären Nierenzellkarzinoms wurden die zu erwartenden Überlebenszeiten vorangegangenen Studienergebnissen gerecht. Insbesondere im remissionsfreien Überleben stellten wir einen signifikanten 
Unterschied zugunsten von Typ-1-Tumoren fest (Abbildung 15), welche bekanntermaßen die günstigere Prognose aufweisen (Allory et al. 2003; Pignot et al. 2007). Einige Studien berichteten in lokalen Stadien von papillären Nierenzellkarzinomen Typ 1 von einer 95 \%igen und in Typ 2 von einer 74 \%igen 10-Jahres-Überlebensrate, wobei bei Typ 1 in weiter fortgeschrittenen Stadien wiederum eine schlechtere Prognose als bei Typ 2 nachweisbar war (Klatte et al. 2009; Farber et al. 2012). Nach Delahunt et al. betrug die 5-Jahres-Sterberate bei Typ 1 circa $40 \%$ und bei Typ 2 circa 50 \% (Delahunt et al. 2001). Des Weiteren zeigte sich in unserer Untersuchung wie in einigen anderen Studien bei Typ-1Tumoren eine signifikant niedrigeres Grading als in Typ-2-Tumoren (Tabelle 9 und 10) (Cheville et al. 2003; Pignot et al. 2007; Warrick et al. 2014).

Die Gründe für die günstigere Überlebensrate in Typ-1-Tumoren sind neben dem geringerem Tumorprogress die Differenzierung des Tumors (Grading) sowie der frühere Zeitpunkt der Diagnose (Delahunt und Eble 1997). Insgesamt jedoch wird den Nierenzellkarzinomen durch das Fehlen von Frühsymptomen eine schlechtere Prognose zugesprochen. Durch den Fortschritt in der Diagnostik und im Rahmen anderer Früherkennungsmaßnahmen werden in Deutschland die Nierenzellkarzinome jedoch zunehmend in frühen Stadien erkannt, sodass in den letzten Jahren eine bessere Prognose zu beobachten war.

Durch unsere Ergebnisse können wir unter Berücksichtigung der Autophagie einen weiteren Prognosefaktor für das papilläre Nierenzellkarzinom hinzuziehen.

Insgesamt stellten wir eine erhöhte Expression der Autophagiemarker fest. Die nukleäre Beclin-1-Expression als zytoreduktiv-apoptotisch wirkende Autophagie war in prognostisch günstigeren Typ-1- signifikant höher als in prognostisch ungünstigeren Typ-2-Karzinomen nachweisbar.

Im Zusammenhang mit der Expression von Autophagiemarkern und Überleben konnten wir eine tendenziell längeres Gesamtüberleben und remissionsfreies Überleben bei niedriger exprimiertem LC3 und zytoplasmatischen p62 feststellen (Abbildung 16b und c). Eine erhöhte Expression von Beclin-1 sowie vom nukleären p62 war ebenfalls mit einem längeren Gesamt- und remissionsfreien Überleben assoziiert (Abbildungen 16a und c, 17a und c). Unsere Ergebnisse bestätigten die Daten aus vorangegangenen Studien, in denen bei erhöhter Autophagieaktivität ein kürzeres Gesamt- und remissionsfreies Überleben beschrieben wurde. Zu berichten ist hier von einer Studie über Melanome, in der eine erhöhte Expression 
von LC3 mit einer kürzeren Überlebensrate und eine erhöhte Expression von Beclin-1 ohne Auswirkung auf das Gesamtüberleben einhergingen (Han et al. 2011). Eine kürzlich veröffentlichte Studie über nicht metastasierte Ösophaguskarzinome brachte ebenfalls einen erhöhten LC3-Nachweis mit einer kürzeren und eine vermehrte Beclin-1-Expression mit einer längeren Überlebenszeit in Zusammenhang (Hao et al. 2014).

Unter Berücksichtigung unserer und schon bekannter Erkenntnisse anderer Studien ist die Mitbestimmung der Autophagiemarker im papillären Nierenzellkarzinom durchaus von prognostischer Bedeutung.

\subsection{Autophagie und Therapie in papillären Nierenzellkarzinomen}

In den letzten Jahren gewann die Autophagie bei der Suche nach prognostischen Biomarkern in verschiedenen Tumoren zunehmend an Interesse. Es wurden Tumorsuppressoren sowie Tumorprogressoren detektiert, die in den Mechanismus der Autophagie eingriffen. Die Art der Regulation sowie die Auswirkungen der Autophagie auf das Tumorwachstum sind bis heute nur ansatzweise geklärt. Zu betonen ist, dass die Hemmung eines einzigen ATG's die Blockierung des gesamten Autophagie-Mechanismus bewirken kann (Ávalos et al. 2014). Auch bestimmte äußere Faktoren und Medikamente können einen hemmenden, aber auch einen aktivierenden Einfluss auf die Autophagie in Zellen haben und werden zur Therapie in bestimmten Tumoren eingesetzt. Bekannt sind induzierende Faktoren wie zum Beispiel Hypoxie, oxidativer Stress sowie niedriger Wachstumsfaktorenspiegel (Levine und Klionsky 2004). Ferner wurden einige Hormone beschrieben, die den Mechanismus der Autophagie beeinflussen. Das in kataboler Stoffwechsellage vermehrt vorkommende Hormon Glukagon soll Autophagie induzieren, wohingegen Insulin eine inhibierende Wirkung haben soll (de Duve et al. 1955; Deter et al. 1967). Einer der wichtigsten Modulatoren ist die mTOR-Kinase, die einen hemmenden Einfluss auf die Autophagie und das Zellwachstum haben soll. Im Falle eines Defektes dieses Enzyms soll es vermehrt zur Entwicklung von Krankheiten und Tumoren kommen (Ávalos et al. 2014; Funderburk et al. 2010). 
Bekannt ist, dass eine erhöhte Aktivität der Autophagie ein Fortschreiten der Tumorzellproliferation begünstigt und sogar eine Resistenz gegen Chemotherapeutika bewirken kann (Hao et al. 2014). Eine Studie über Bcl-2exprimierenden Tumoren, wie zum Beispiel Mammakarzinome, brachte Erkenntnisse über eine hochregulierte zytoprotektive Autophagie als Schutz vor Radio- und Chemotherapie (Dalby et al. 2010). Bei ausreichender Nährstofflage hat das anti-apoptotische Protein $\mathrm{Bcl}-2$ unter physiologischen Bedingungen durch Bindung an Beclin-1 eine hemmende Wirkung auf die Autophagie. Unter nährstoffarmen Bedingungen, wie sie insbesondere bei Malignomen vorkommen, dissoziiert Bcl-2 von der Bindungsstelle, und die Autophagie wird aktiviert (Wei et al. 2008). Es ist jedoch noch nicht vollständig klar, wie der Beclin-1/Bcl-2-Komplex eine Blockierung der autophagischen Funktion verursacht, weshalb hier noch weitere Forschungen erforderlich sind.

Neben Bcl-2 können Radio- und Chemotherapeutika selbst eine Autophagiebedingte Resistenzentwicklung in einigen Tumoren verursachen. So bewirkt zum Beispiel das Chemotherapeutikum Doxorubicin eine vermehrte Bildung von autophagalen Proteinen, sodass es zu einer Hochregulation der zytoprotektiven Autophagie kommt (Shintani und Klionsky 2004; Zarzynska 2014).

Wenn eine erhöhte Rate der zytoprotektiven Autophagie in Tumoren das Fortschreiten der Erkrankung trotz Therapie begünstigt, so kann eine Hemmung der Autophagie das Tumorwachstum reduzieren (Dalby et al. 2010; Gutierrez et al. 2014; Funderburk et al. 2010). Substanzen wie Hydroxychloroquin sind bekannt dafür, dass sie Autophagie hemmen können. Einige aktuelle Studien bestätigen, dass Hydroxychloroquin bei Malignomen, in denen die Autophagie als Resistenzmechanismus gegen Chemotherapie hochreguliert ist, die Tumorzellen wieder für die Chemo - und Radiotherapie sensibilisieren kann (Lotze et al. 2013; Zarzynska 2014).

Auf der anderen Seite gibt es Medikamente, die zu einer Verstärkung der apoptotisch wirkenden Autophagie führen. In einer Studie über die Therapie von nicht-kleinzelligen Lungenkarzinomen mit einem epithelialen WachstumsfaktorRezeptor-Inhibitor wurde eine reduzierte Hemmung von Beclin-1 beschrieben, wodurch es zu einer erhöhten Aktivität der zytoreduktiven Autophagie kam (Wei et al. 2013). Weitere klinische Arbeiten in den letzten Jahren haben gezeigt, dass Vitamin D3 in Kombination mit einer Radiotherapie bei Brusttumoren die 
zytoreduktive Autophagie verstärken kann (Bristol et al. 2012). Insbesondere beim Pankreaskarzinom könnte die Induzierung der zytoreduktiven Autophagie eine interessante Therapiemöglichkeit darstellen, da dieser Tumor aufgrund seiner schlechten Ansprechbarkeit auf Radio- und Chemotherapie eine infauste Prognose aufweist (Dalby et al. 2010).

Neben diesen neuen Erkenntnissen berichten weitere Studien über die Option der therapeutischen Aktivierung der zytoreduktiven Autophagie in Prostata-, Mammakarzinomen und Hirntumoren (Brech et al. 2009; Peng et al. 2008; Kim et al. 2007; Cao et al. 2006; Shintani und Klionsky 2004).

Erwähnenswert ist ebenfalls, dass es bisher erst wenige Studien über Therapieansätze in der Autophagiekaskade in Nierenzellkarzinomen gibt. Bei der Therapie mit einem spezifischen Molekül namens STF-62247 in Nierenzellkarzinomen mit Von-Hippel-Lindau-Defekt wurden ein induziertes erhöhtes LC3Aufkommen und ein damit verbundener vermehrter Zelltod nachgewiesen. Bei Hemmung der Autophagie unter diesen Bedingungen, zeigte sich ein geringeres Ansprechen des Tumors auf das STF-62247-Molekül (Turcotte et al. 2008). Diese Wirkung korreliert nicht mit den aus anderen Studien bekannten Ergebnissen, dass LC3 mit einer schlechteren Überlebensrate assoziiert ist. Dies zeigt wiederum, dass der Mechanismus der Autophagie in Tumoren, insbesondere in Nierenzellkarzinomen immer noch nicht gänzlich verstanden ist.

Die Erforschung Autophagie-assoziierter Therapiemöglichkeiten steckt noch in den Anfängen, sodass nicht klar ist, welche Auswirkungen solche Therapien auf normale Zellen und den Stoffwechsel haben könnten. Die medikamentöse Beeinflussung der Autophagie sollte natürlich möglichst selektiv sein, sodass nur Tumorzellen und nicht physiologisch vorkommende Zellen darauf ansprechen (Brech et al. 2009). Außerdem ist noch nicht geklärt, wie es in verschiedenen Stadien der Tumorentwicklung zu einer Aktivierung oder Hemmung von Autophagie kommt, sodass wahrscheinlich eine stadiengerechte Therapie je nach TNM-Stadium nötig wäre.

Da Nierenzellkarzinome auf Strahlen- und Chemotherapie nicht ansprechen, könnte hier der Autophagie als therapeutische Option eine relevante Rolle zukommen. Um diese Theorie zu bestätigen, sind jedoch weiterführende Studien zur Wirkung (zytoprotektiv versus zytoreduktiv) der Autophagie und zu deren medikamentöser Regulation in Nierenzellkarzinomen unumgänglich. 


\section{$5 \quad$ Zusammenfassung}

Die Rolle der Makroautophagie in malignen Prozessen des menschlichen Körpers ist Gegenstand aktueller Forschung. In einigen Tumoren wie Brust- und Pankreaskrebs wurde eine Herunterregulation der Autophagieaktivität und in anderen Krebsarten wie Lebertumoren eine Hochregulation festgestellt. Die Auswirkungen der Autophagie sind, abhängig vom Aktivitätsgrad, unterschiedlich und bis heute noch nicht vollends verstanden. Auch unter Berücksichtigung der bisherigen Literatur bleiben die Daten widersprüchlich: Auf der einen Seite berichten Studien über einen fördernden Einfluss der Autophagie auf den Krankheitsprozess insbesondere bei Krebserkrankungen. Zum anderen kann Autophagie bei zu hoher Aktivierung den programmierten Zelltod herbeiführen, was zu einer Hemmung des Tumorwachstums führt.

Ziel unserer Arbeit war es, die Expression der an der Autophagie beteiligten Proteine (Beclin-1, LC3 und p62) in papillären Nierenzellkarzinomen zu untersuchen und so den prognostischen Zusammenhang zwischen Autophagieaktivität und Überleben aufzuzeigen.

Wir konnten in unserer Arbeit eine erhöhte Expression von Beclin-1, LC3 und p62 in papillären Nierenzellkarzinomen nachweisen. Bei der Unterteilung in Typ 1 und 2 konnten wir für LC3 einen nicht signifikanten und für zytoplasmatisches p62 einen signifikanten Unterschied zugunsten von Typ-2-Tumoren feststellen. Nukleäres Beclin-1 sowie nukleäres p62 waren dagegen insbesondere in Typ-1Tumoren sowie in lokal begrenzten Tumoren signifikant nachweisbar. In fortgeschrittenen, metastasierten Stadien sowie in wenig differenzierten papillären Nierenzellkarzinomen waren dagegen ein vermehrter Nachweis von LC3, ein signifikant vermehrter Nachweis von zytoplasmatischem p62 und eine signifikant geringere Beclin-1-Expression zu sehen.

Darüber hinaus konnten wir ein nicht signifikant längeres Gesamtüberleben sowie rezidivfreies Überleben bei erhöhter Expression von Beclin-1 und nukleärem p62 sowie bei niedriger exprimiertem LC3 und zytoplasmatischem p62 feststellen.

Aufgrund unserer Daten ist somit trotz der signifikanten Unterschiede der Expression der Autophagie-assoziierten Proteine in den Subtypen der papillären Nierenzellkarzinome eine Prognoseeinschätzung aufgrund der Autophagieaktivität für papilläre Nierenzellkarzinome nur bedingt vorzunehmen. 
Die erhöhte Expression der Autophagie-assoziierten Proteine in unserer Untersuchung weist auf eine zytoprotektive und somit keine zytoreduktive Funktion in papillären Nierenzellkarzinomen hin. Insbesondere die erhöhte Aktivität der Autophagie in Typ 2-Tumoren unterstützt diese Hypothese, da papilläre Nierenzellkarzinome Typ 2 mit einem höheren T-Stadium und einem kürzeren Überleben einhergehen.

Hinsichtlich neuer Therapiemöglichkeiten könnte die Autophagie eine Rolle bei der Resistenzentwicklung gegenüber Chemo- und Radiotherapie spielen und somit ihre Hemmung eine zusätzliche therapeutische Option darstellen. 


\section{$6 \quad$ Literaturverzeichnis}

Aita VM, Liang XH, Murty VV, Pincus DL, Yu W, Cayanis E, Kalachikov S, Gilliam TC, Levine B (1999): Cloning and genomic organization of beclin 1, a candidate tumor suppressor gene on chromosome 17q21. Genomics $\underline{59}, 59-65$

Allory Y, Ouazana D, Boucher E, Thiounn N, Vieillefond A (2003): Papillary renal cell carcinoma. Prognostic value of morphological subtypes in a clinicopathologic study of 43 cases. Virchows Arch 442, 336-342

Amin MB, Amin MB, Tamboli P, Javidan J, Stricker H, de-Peralta Venturina M, Deshpande A, Menon M (2002): Prognostic impact of histologic subtyping of adult renal epithelial neoplasms: an experience of 405 cases. Am J Surg Pathol $\underline{26}$, 281-291

Ávalos Y, Canales J, Bravo-Sagua R, Criollo A, Lavandero S, Quest, Andrew FG (2014): Tumor suppression and promotion by autophagy. Biomed Res Int 2014, 603980

AWMF-Leitlinie 2017 zum Nierenzellkarzinom, Diagnostik, Therapie und Nachsorge. O. Verf., o. O. 2017. http://www.awmf.org/leitlinien/detail/II/043017OL.html, Zugriff am 02.03.2018

Axe EL, Walker SA, Manifava M, Chandra P, Roderick HL, Habermann A, Griffiths G, Ktistakis NT (2008): Autophagosome formation from membrane compartments enriched in phosphatidylinositol 3-phosphate and dynamically connected to the endoplasmic reticulum. J Cell Biol $\underline{182}, 685-701$

Baba M, Takeshige K, Baba N, Ohsumi Y (1994): Ultrastructural analysis of the autophagic process in yeast: detection of autophagosomes and their characterization. J Cell Biol 124, 903-913

Behnes CL, Hemmerlein B, Strauss A, Radzun HJ, Bremmer F (2012): N-cadherin is differentially expressed in histological subtypes of papillary renal cell carcinoma. Diagn Pathol $\underline{7}, 95$ 
Behnes CL, Schlegel C, Shoukier M, Magiera I, Henschke F, Schwarz A, Bremmer F, Loertzer H (2013): Hereditary papillary renal cell carcinoma primarily diagnosed in a cervical lymph node: a case report of a 30 -year-old woman with multiple metastases. BMC Urol $\underline{13}, 3$

Bonsib SM, Bhalodia A (2010): Renal Neoplasms: An Update on Immunohistochemical and Histochemical Features. Connection 2010, 178-186 [s. http://patologi.com/renal\%20neoplasms.pdf]

Boya P, González-Polo RA, Casares N, Perfettini JL, Dessen P, Larochette N, Métivier D, Meley D, Souquere S, Yoshimori T (2005): Inhibition of macroautophagy triggers apoptosis. Mol Cell Biol 25, 1025-1040

Brech A, Ahlquist T, Lothe RA, Stenmark H (2009): Autophagy in tumour suppression and promotion. Mol Oncol $\underline{3}, 366-375$

Bristol ML, Di X, Beckman MJ, Wilson EN, Henderson SC, Maiti A, Fan Z, Gewirtz DA (2012): Dual functions of autophagy in the response of breast tumor cells to radiation: cytoprotective autophagy with radiation alone and cytotoxic autophagy in radiosensitization by vitamin $\mathrm{D} 3$. Autophagy $\underline{8}, 739-753$

Cairns P (2010): Renal cell carcinoma. Cancer Biomark $\underline{9}$, 461-473

Cao C, Subhawong T, Albert JM, Kim KW, Geng L, Sekhar KR, Gi YJ, Lu B (2006): Inhibition of mammalian target of rapamycin or apoptotic pathway induces autophagy and radiosensitizes PTEN null prostate cancer cells. Cancer Res $\underline{66}$, 10040-10047

Cheville JC, Lohse CM, Zincke H, Weaver AL, Blute ML (2003): Comparisons of outcome and prognostic features among histologic subtypes of renal cell carcinoma. Am J Surg Pathol 27, 612-624

Choi J, Jung W, Koo JS (2013): Expression of autophagy-related markers beclin-1, light chain $3 \mathrm{~A}$, light chain $3 \mathrm{~B}$ and p62 according to the molecular subtype of breast cancer. Histopathology $\underline{62}, 275-286$

Choi JH, Cho Y-S, Ko YH, Hong SU, Park JH, Lee MA (2014): Absence of autophagy-related proteins expression is associated with poor prognosis in patients with colorectal adenocarcinoma. Gastroenterol Res Pract 2014, 179586 
Chow WH, Dong LM, Devesa SS (2010): Epidemiology and risk factors for kidney cancer. Nat Rev Urol $\underline{7}, 245-257$

Cohen HT, McGovern FJ (2005): Renal-cell carcinoma. N Engl J Med 353, 24772490

Dalby K, Tekedereli I, Lopez-Berestein G, Ozpolat B (2010): Targeting the prodeath and pro-survival functions of autophagy as novel therapeutic strategies in cancer. Autophagy $\underline{6}, 322-329$

De Duve C, Pressman BC, Gianetto R, Wattiaux R, Appelmans F (1955): Tissue fractionation studies. 6. Intracellular distribution patterns of enzymes in rat-liver tissue. Biochem J $\underline{60}, 604-617$

Delahunt B, Eble JN (1997): Papillary renal cell carcinoma: a clinicopathologic and immunohistochemical study of 105 tumors. Mod Pathol 10, 537-544

Delahunt B, Eble JN, McCredie MR, Bethwaite PB, Stewart JH, Bilous AM (2001): Morphologic typing of papillary renal cell carcinoma: comparison of growth kinetics and patient survival in 66 cases. Hum Pathol $\underline{32}, 590-595$

Delahunt B, Bethwaite PB, Nacey JN (2007): Outcome prediction for renal cell carcinoma: evaluation of prognostic factors for tumours divided according to histological subtype. Pathology $\underline{39}$, 459-465

Deng Q, Wang Z, Wang L, Zhang L, Xiang X, Wang Z, Chong T (2013): Lower mRNA and protein expression levels of LC3 and Beclin1, markers of autophagy, were correlated with progression of renal clear cell carcinoma. Jpn J Clin Oncol $\underline{43}, 1261-1268$

Deter R, Baudhuin P, de Duve C (1967): Participation of lysosomes in cellular autophagy induced in rat liver by glucagon. J Cell Biol $\underline{35}$, C11-16

Dice JF (2014): Chaperone-Mediated Autophagy. Autophagy $\underline{3}$, 295-299

Dimarco DS, Lohse CM, Zincke H, Cheville JC, Blute ML (2004): Long-term survival of patients with unilateral sporadic multifocal renal cell carcinoma according to histologic subtype compared with patients with solitary tumors after radical nephrectomy. Urology $\underline{64}$, 462-467 
Ding ZB, Shi YH, Zhou J, Quu SJ, Xu Y, Dai Z, Shi GM, Wang XY, Ke AW, Wu B (2008): Association of autophagy defect with a malignant phenotype and poor prognosis of hepatocellular carcinoma. Cancer Res $\underline{68}, 9167-9175$

Dunn WA (1994): Autophagy and related mechanisms of lysosome-mediated protein degradation. Trends Cell Biol $\underline{4}, 139-143$

Eble JN, Sauter G, Epstein I, Sesterhenn I (Hrsg.): Pathology and genetics of tumours of the urinary system and male genital organs: Tumours of the kidney (World Health Organization classification of tumours 6); IARC Press, Lyon 2004 [s. https://www.iarc.fr/en/publications/pdfs-online/pat-gen/bb7/BB7.pdf] Eskelinen E (2008): To be or not to be? Examples of incorrect identification of autophagic compartments in conventional transmission electron microscopy of mammalian cells. Autophagy $\underline{4}, 257-260$

Farber LJ, Furge K, Teh BT (2012): Renal cell carcinoma deep sequencing: recent developments. Curr Oncol Rep 14, 240-248

Ferlay J, Parkin DM, Steliarova-Foucher E (2010): Estimates of cancer incidence and mortality in Europe in 2008. Eur J Cancer $\underline{46}$, 765-781

Fischer TD, Wang JH, Vlada A, Kim JS, Behrns KE (2014): Role of autophagy in differential sensitivity of hepatocarcinoma cells to sorafenib. World J Hepatol $\underline{6}$, $752-758$

Funderburk SF, Wang QJ, Yue Z (2010): The Beclin 1-VPS34 complex--at the crossroads of autophagy and beyond. Trends Cell Biol 20, 355-362

Galavotti S, Bartesaghi S, Faccenda D, Shaked-Rabi M, Sanzone S, McEvoy A, Dinsdale D, Condorelli F, Brandner S, Campanella M (2013): The autophagyassociated factors DRAM1 and p62 regulate cell migration and invasion in glioblastoma stem cells. Oncogene $\underline{32}, 699-712$

Gutierrez E, Des Richardson R, Jansson PJ (2014): The Anticancer Agent Di-2pyridylketone 4,4-Dimethyl-3-thiosemicarbazone (Dp44mT) Overcomes Prosurvival Autophagy by Two Mechanisms: Persistent Induction of Autophagosome Synthesis and Impairment of Lysosomal Integrity. J Biol Chem 289, 33568-33589 
Gutierrez MG, Master SS, Singh SB, Taylor GA, Colombo MI, Deretic V (2004): Autophagy is a defense mechanism inhibiting BCG and Mycobacterium tuberculosis survival in infected macrophages. Cell 119, 753-766 Han C, Sun B, Wang W, Cai W, Lou D, Sun Y, Zhao X (2011): Overexpression of Microtubule-Associated Protein-1 Light Chain 3 Is Associated with Melanoma Metastasis and Vasculogenic Mimicry. Tohoku J Exp Med 223, 243-251 Hao CJ, Li Y, Yang HX, Luo RZ, Zhang Y, Zhang MF, Cheng YF, Wang X (2014): High level of microtubule-associated protein light chain 3 predicts poor prognosis in resectable esophageal squamous cell carcinoma. Int J Clin Exp Pathol 7, 42134221

Hartmann A, Stöhr CG, Junker K (2010) Hereditäre Nierenzellkarzinome. Pathologe 31, 455-463

Hunt JD, van der Hel, Olga L, McMillan GP, Boffetta P, Brennan P (2005): Renal cell carcinoma in relation to cigarette smoking: meta-analysis of 24 studies. Int $\mathrm{J}$ Cancer $\underline{114}, 101-108$

Ichimura Y, Kirisako T, Takao T, Satomi Y, Shimonishi Y, Ishihara N, Mizushima N, Tanida I, Kominami E, Ohsumi M (2000): A ubiquitin-like system mediates protein lipidation. Nature $\underline{408}, 488-492$

Inoue D, Suzuki T, Mitsuishi Y, Miki Y, Suzuki S, Sugawara S, Watanabe M, Sakurada A, Endo C, Uruno A (2012): Accumulation of p62/SQSTM1 is associated with poor prognosis in patients with lung adenocarcinoma. Cancer Sci 103, 760766

Kaatsch P, Spix C, Katalinic A, Hentschel S, Luttmann S, Stegmaier C, Caspritz S, Christ M, Ernst A, Folkerts J: Krebs in Deutschland 2011/2012. Beiträge zur Gesundheitsberichterstattung des Bundes. 10. Ausgabe, Robert-Koch-Institut, Berlin 2015

Kabeya Y, Mizushima N, Ueno T, Yamamoto A, Kirisako T, Noda T, Kominami E, Ohsumi Y, Yoshimori T (2000): LC3, a mammalian homologue of yeast Apg8p, is localized in autophagosome membranes after processing. EMBO J 19, 5720-5728 
Kabeya Y, Mizushima N, Yamamoto A, Oshitani-Okamoto S, Ohsumi Y, Yoshimori T (2004): LC3, GABARAP and GATE16 localize to autophagosomal membrane depending on form-II formation. J Cell Sci 117, 2805-2812

Kim EH, Sohn S, Kwon HJ, Kim SU, Kim MJ, Lee SJ, Choi KS (2007): Sodium selenite induces superoxide-mediated mitochondrial damage and subsequent autophagic cell death in malignant glioma cells. Cancer Res $\underline{67}, 6314-6324$ Kim YS, Shin JH, Bae MK, Lee CY, Kim DJ, Chung KY, Lee JG (2014): Autophagy activity in pulmonary metastatic tumor tissues from colorectal cancer: a pilot study. Yonsei Med J $\underline{55}, 1484-1488$

Kirisako T, Ichimura Y, Okada H, Kabeya Y, Mizushima N, Yoshimori T, Ohsumi M, Takao T, Noda T, Ohsumi Y (2000): The reversible modification regulates the membrane-binding state of Apg8/Aut7 essential for autophagy and the cytoplasm to vacuole targeting pathway. J Cell Biol 151, 263-276

Kisen G $\varnothing$, Tessitore L, Costelli P, Gordon PB, Schwarze PE, Baccino FM, Seglen PO (1993): Reduced autophagic activity in primary rat hepatocellular carcinoma and ascites hepatoma cells. Carcinogenesis 14, 2501-2505

Klatte T, Pantuck AJ, Said JW, Seligson DB, Rao NP, LaRochelle JC, Shuch B, Zisman A, Kabbinavar FF, Belldegrun AS (2009): Cytogenetic and molecular tumor profiling for type 1 and type 2 papillary renal cell carcinoma. Clin Cancer Res $\underline{15}$, 1162-1169

Klionsky DJ (2007): Autophagy: from phenomenology to molecular understanding in less than a decade. Nat Rev Mol Cell Biol $\underline{8}, 931-937$

Klionsky DJ, Ohsumi Y (1999): Vacuolar import of proteins and organelles from the cytoplasm. Annu Rev Cell Dev Biol 15, 1-32

Kovacs G (1993): Molecular differential pathology of renal cell tumours. Histopathology $\underline{22}, 1-8$

Laplante M, Sabatini DM (2012): mTOR signaling in growth control and disease. Cell $\underline{149}, 274-293$ 
Lee WK, Lee SE, Hong SK, Jeong CW, Park YH, Kang SH, Kim YJ, Hong SH, Choi WS, Byun S-S (2014): Characteristics and prognostic value of papillary histologic subtype in nonmetastatic renal cell carcinoma in Korea: a multicenter study. Urol J $\underline{11}, 1884-1890$

Leitlinie Nierenzellkarzinom, Diagnostik, Therapie und Nachsorge s. AWMFLeitlinie 2017

Levine B (2005): Eating oneself and uninvited guests: autophagy-related pathways in cellular defense. Cell $120,159-162$

Levine B, Klionsky DJ (2004): Development by Self-DigestionMolecular Mechanisms and Biological Functions of Autophagy. Dev Cell $\underline{6}, 463-477$ Liang X, Kleeman L, Jiang H, Gordon G, Goldman J, Berry G, Herman B, Levine B (1998): Protection against fatal Sindbis virus encephalitis by beclin, a novel Bcl-2interacting protein. J Virol $\underline{72}, 8586-8596$

Liang X, Jackson S, Seaman M, Brown K, Kempkes B, Hibshoosh H, Levine B (1999): Induction of autophagy and inhibition of tumorigenesis by beclin 1. Nature $\underline{402}, 672-676$

Liu XD, Yao J, Tripathi DN, Ding Z, Xu Y, Sun M, Zhang J, Bai S, German P, Hoang A (2015): Autophagy mediates HIF2alpha degradation and suppresses renal tumorigenesis. Oncogene $\underline{34}$, 2450-2460

Ljungberg B, Alamdari FI, Stenling R, Roos G (1999): Prognostic Significance of the Heidelberg Classification of Renal Cell Carcinoma. Eur Urol 36, 565-569 Lonser RR, Glenn GM, Walther M, Chew EY, Libutti SK, Linehan, W. Marston, Oldfield EH (2003): von Hippel-Lindau disease. Lancet 361, 2059-2067 Loos B, Engelbrecht AM, Lockshin RA, Klionsky DJ, Zakeri Z (2013): The variability of autophagy and cell death susceptibility: Unanswered questions. Autophagy $\underline{9}, 1270-1285$

Lopez-Beltran A, Scarpelli M, Montironi R, Kirkali Z (2006): 2004 WHO classification of the renal tumors of the adults. Eur Urol $\underline{49}, 798-805$ Lotze MT, Maranchie J, Appleman L (2013): Inhibiting autophagy: a novel approach for the treatment of renal cell carcinoma. Cancer J $\underline{19}$, 341-347 
Mathew R, Karp CM, Beaudoin B, Vuong N, Chen G, Chen HY, Bray K, Reddy A, Bhanot G, Gelinas C (2009): Autophagy suppresses tumorigenesis through elimination of p62. Cell $\underline{137}, 1062-1075$

McGuire BB, Fitzpatrick JM (2011): BMI and the risk of renal cell carcinoma. Curr Opin Urol 21, 356-361

Mehrpour M, Esclatine A, Beau I, Codogno P (2010): Autophagy in health and disease. 1. Regulation and significance of autophagy: an overview. Am J Physiol Cell Physiol 298, C776-785

Mejean A, Hopirtean V, Bazin JP, Larousserie F, Benoit H, Chrétien Y, Thiounn N, Dufour B (2003): Prognostic factors for the survival of patients with papillary renal cell carcinoma: meaning of histological typing and multifocality. J Urol $\underline{170}, 764-$ 767

Miracco C, Cosci E, Oliveri G, Luzi P, Pacenti L, Monciatti I, Mannucci S, de Nisi MC, Toscano M, Malagnino V (2007): Protein and mRNA expression of autophagy gene Beclin 1 in human brain tumours. Int J Oncol 30, 429-436

Mizushima N, Levine B (2010): Autophagy in mammalian development and differentiation. Nat Cell Biol 12, 823-830

Mortimore G, Lardeux B, Adams C (1988): Regulation of microautophagy and basal protein turnover in rat liver. Effects of short-term starvation. J Biol Chem $\underline{263}$, 2506-2512

Murai M, Oya M (2004): Renal cell carcinoma: etiology, incidence and epidemiology. Curr Opin Urol 14, 229-233

Ogier-Denis E, Codogno P (2003): Autophagy: a barrier or an adaptive response to cancer. Biochim Biophys Acta $\underline{1603}, 113-128$

Oh S, Xiaofei E, Ni D, Pirooz SD, Lee JY, Lee D, Zhao Z, Lee S, Lee H, Ku B (2011): Downregulation of autophagy by Bcl-2 promotes MCF7 breast cancer cell growth independent of its inhibition of apoptosis. Cell Death Differ $\underline{18}, 452-464$ Ohsumi Y (2001): Molecular dissection of autophagy: two ubiquitin-like systems. Nat Rev Mol Cell Biol 2, 211-216 
Pankiv S, Lamark T, Bruun JA, Øvervatn A, Bjørkøy G, Johansen T (2010): Nucleocytoplasmic shuttling of p62/SQSTM1 and its role in recruitment of nuclear polyubiquitinated proteins to promyelocytic leukemia bodies. J Biol Chem $\underline{285}$, $5941-5953$

Patard JJ, Leray E, Rioux-Leclercq N, Cindolo L, Ficarra V, Zisman A, de la Taille A, Tostain J, Artibani W, Abbou CC (2005): Prognostic value of histologic subtypes in renal cell carcinoma: a multicenter experience. J Clin Oncol 23, 2763-2771

Pattingre S, Tassa A, Qu X, Garuti R, Liang XH, Mizushima N, Packer M, Schneider MD, Levine B (2005): Bcl-2 antiapoptotic proteins inhibit Beclin 1dependent autophagy. Cell 122, 927-939

Peng PL, Kuo WH, Tseng HC, Chou FP (2008): Synergistic tumor-killing effect of radiation and berberine combined treatment in lung cancer: the contribution of autophagic cell death. Int J Radiat Oncol Biol Phys $\underline{70}$, 529-542

Perret AG, Clemencon A, Li G, Tostain J, Peoc'h M (2008): Differential expression of prognostic markers in histological subtypes of papillary renal cell carcinoma.

BJU Int 102, 183-187

Pignot G, Elie C, Conquy S, Vieillefond A, Flam T, Zerbib M, Debré B, AmsellemOuazana D (2007): Survival analysis of 130 patients with papillary renal cell carcinoma: prognostic utility of type 1 and type 2 subclassification. Urology $\underline{69}$, 230-235

Puissant A, Fenouille N, Auberger P (2012): When autophagy meets cancer through p62/SQSTM1. Am J Cancer Res 2 , 397-413

Reggiori F, Klionsky DJ (2002): Autophagy in the Eukaryotic Cell. Eukaryot Cell 1, $11-21$

Reggiori F, Klionsky DJ (2005): Autophagosomes: biogenesis from scratch? Curr Opin Cell Biol 17, 415-422

Ross H, Martignoni G, Argani P (2012): Renal cell carcinoma with clear cell and papillary features. Arch Pathol Lab Med 136, 391-399 
Schmidt L, Duh FM, Chen F, Kishida T, Glenn G, Choyke P, Scherer SW, Zhuang Z, Lubensky I, Dean M (1997): Germline and somatic mutations in the tyrosine kinase domain of the MET proto-oncogene in papillary renal carcinomas. Nat Genet $\underline{16}, 68-73$

Shintani T, Klionsky DJ (2004): Autophagy in health and disease: a double-edged sword. Science 306, 990-995

Srigley JR, Delahunt B, Eble JN, Egevad L, Epstein JI, Grignon D, Hes O, Moch H, Montironi R, Tickoo SK (2013): The International Society of Urological Pathology (ISUP) Vancouver Classification of Renal Neoplasia. Am J Surg Pathol 37, 1469-1489

Sudarshan S, Linehan WM, Neckers L (2007): HIF and fumarate hydratase in renal cancer. Br J Cancer $\underline{96}$, 403-407

Sugawara K, Suzuki NN, Fujioka Y, Mizushima N, Ohsumi Y, Inagaki F (2004): The crystal structure of microtubule-associated protein light chain 3 , a mammalian homologue of Saccharomyces cerevisiae Atg8. Genes Cells $\underline{9}, 611-618$

Tallóczy Z, Virgin HW, Levine B (2006): PKR-dependent autophagic degradation of herpes simplex virus type 1 . Autophagy $\underline{2}, 24-29$

Thumm M, Egner R, Koch B, Schlumpberger M, Straub M, Veenhuis M, Wolf DH (1994): Isolation of autophagocytosis mutants of Saccharomyces cerevisiae. FEBS Lett $\underline{349}$, 275-280

Toro JR, Nickerson ML, Wei MH, Warren MB, Glenn GM, Turner ML, Stewart L, Duray P, Tourre O, Sharma N (2003): Mutations in the fumarate hydratase gene cause hereditary leiomyomatosis and renal cell cancer in families in North America. Am J Hum Genet $\underline{73}$, 95-106

Tsukada M, Ohsumi Y (1993): Isolation and characterization of autophagydefective mutants of Saccharomyces cerevisiae. FEBS Lett $\underline{33}, 169-174$ Turcotte S, Chan DA, Sutphin PD, Hay MP, Denny WA, Giaccia AJ (2008): A molecule targeting $\mathrm{VHL}$-deficient renal cell carcinoma that induces autophagy. Cancer Cell $\underline{14}, 90-102$ 
Waldert M, Haitel A, Marberger M, Katzenbeisser D, Ozsoy M, Stadler E, Remzi M (2008): Comparison of type I and II papillary renal cell carcinoma (RCC) and clear cell RCC. BJU Int 102, 1381-1384

Warrick JI, Tsodikov A, Kunju LP, Chinnaiyan AM, Palapattu GS, Morgan TM, Alva A, Tomlins S, Wu A, Montgomery JS (2014): Papillary renal cell carcinoma revisited: a comprehensive histomorphologic study with outcome correlations. Hum. Pathol. $\underline{45}, 1139-1146$

Wei Y, Pattingre S, Sinha S, Bassik M, Levine B (2008): JNK1-mediated phosphorylation of $\mathrm{Bcl}-2$ regulates starvation-induced autophagy. Mol. Cell $\underline{30}$, 678-688

Wei Y, Zou Z, Becker N, Anderson M, Sumpter R, Xiao G, Kinch L, Koduru P, Christudass CS, Veltri RW (2013): EGFR-mediated Beclin 1 phosphorylation in autophagy suppression, tumor progression, and tumor chemoresistance. Cell $\underline{154}$, 1269-1284

Wittekind C, Meyer HJ: TNM-Klassifikation maligner Tumoren, 7. Auflage; Springer, Berlin 2010

Yu L, Alva A, Su H, Dutt P, Freundt E, Welsh S, Baehrecke EH, Lenardo MJ (2004): Regulation of an ATG7-beclin 1 program of autophagic cell death by caspase-8. Science $\underline{304}, 1500-1502$

Yue Z, Jin S, Yang C, Levine AJ, Heintz N (2003): Beclin 1, an autophagy gene essential for early embryonic development, is a haploinsufficient tumor suppressor. Proc Natl Acad Sci U S A $100,15077-15082$

Zarzynska JM (2014): The Importance of Autophagy Regulation in Breast Cancer Development and Treatment. Biomed Res Int 2014, 710345

Zbar B, Alvord WG, Glenn G, Turner M, Pavlovich CP, Schmidt L, Walther M, Choyke P, Weirich G, Hewitt SM (2002): Risk of renal and colonic neoplasms and spontaneous pneumothorax in the Birt-Hogg-Dubé syndrome. Cancer Epidem Biomar 11, 393-400 


\section{Danksagung}

Ich bedanke mich bei allen Personen, die mich bei meiner Doktorarbeit unterstützt haben. Insbesondere gilt mein Dank:

Meinem Doktorvater Herrn Prof. Dr. med. H.-J. Radzun für die Unterstützung und kritische Durchsicht der Arbeit;

Meinem Doktorbetreuer Herrn Dr. med C.-L. Behnes für die Unterstützung, gute Zusammenarbeit und konstruktive Kritik;

Dem Team der medizin-technischen Laboratoriumsassitenten/-innen der Pathologie der Uniklinik Göttingen für die freundliche und zuverlässige Unterstützung bei der Anfertigung und Färbung der histologischen Schnitte im Labor;

Dem Team der Medizinischen Statistik der Universität Göttingen für die Hilfe bei der statistischen Auswertung. 